Portland State University

PDXScholar

Fall 12-2-2015

\title{
Insights into the Mental Imagery and Gestural Awareness of Representational Gestures Produced in Everyday Talk: An Exploratory Study of Using Participants' Comments as Data
}

Sue M. Wendel

Portland State University

Follow this and additional works at: https://pdxscholar.library.pdx.edu/open_access_etds

Part of the Communication Commons

Let us know how access to this document benefits you.

\section{Recommended Citation}

Wendel, Sue M., "Insights into the Mental Imagery and Gestural Awareness of Representational Gestures Produced in Everyday Talk: An Exploratory Study of Using Participants' Comments as Data" (2015). Dissertations and Theses. Paper 2646.

https://doi.org/10.15760/etd.2642

This Thesis is brought to you for free and open access. It has been accepted for inclusion in Dissertations and Theses by an authorized administrator of PDXScholar. Please contact us if we can make this document more accessible: pdxscholar@pdx.edu. 


\author{
Insights into the Mental Imagery and Gestural Awareness of \\ Representational Gestures Produced in Everyday Talk: \\ An Exploratory Study of Using Participants' Comments as Data
}

by

Sue M. Wendel

A thesis submitted in partial fulfillment of the

requirements for the degree of

\author{
Master of Science \\ in \\ Communication
}

Thesis Committee:

L. David Ritchie, Chair

Jeffrey Robinson

Tanya Romaniuk

Portland State University

2015 
(C) 2015 Sue M. Wendel 


\begin{abstract}
To better understand representational gestures used in everyday talk, this study explores the ways participants talk about their own mental imagery and gestural awareness, and how their comments affect analysis. Literature pertaining to representational gestures, mental imagery, gestural awareness, and self-report data provide the theoretical framework for the study's design and implementation. Data is drawn from observations of two video recorded dyads engaged in everyday conversation, and four audio recorded interviews with each participant individually as they viewed and commented on selected video segments in which they had produced a representational gesture. Findings indicate that participants talked about mental imagery and gestural awareness in ways that were descriptive, explanatory, and self-reflective. They described their mental imagery in i) visual and motor terms, ii) as mental simulations, iii) as textural sensations, and iv) in linguistic metaphors. Participants talked about gestural awareness in terms of i) spontaneity, ii) intentionality, and iii) affective states. Taken altogether, participant comments suggest embodied cognition as a useful framework for analyzing and understanding representational gestures. Further, findings indicate that participant comments served to i) confirm, ii) clarify, and/or iii) expand my analysis, suggesting that participant comments can enhance understanding of mental imagery and gestural awareness in ways that could not be achieved by a researcher's observations and analysis alone.
\end{abstract}




\section{Dedication}

To every speaker's expressive hands.

“These gestures are a person's memories and thoughts rendered visible." McNeill, 1992, p. 12 


\section{Acknowledgements}

I want to express my gratitude and appreciation to my thesis committee members: Dr. Ritchie, Dr. Robinson, and Dr. Romaniuk; and to all my professors who were part of the process that made the completion of this thesis possible. Special thanks to Dr. Ritchie for inspiring me, for his guidance, and for our lengthy discussions about the ubiquitous yet elusive representational gesture; to Dr. Robinson, for his valuable guidance, advice, and feedback, especially the technical aspects related to video recording and data collection processes; and to Dr. Romaniuk for the invaluable edits and guidance she provided after my defense. Thanks to the study participants, who gave of their time and provided the insightful data; to fellow Communication cohorts Molly Major, Lana Buckholz, and Sarah Martin, who offered their support and advice along the way; and to many friends and family members who cheered me on and kept me going, especially my sister Dr. Geralyn Crain who had gone through this challenging process herself. Finally, a special thanks goes to my husband Peter, for his never-ending inspiration, support, and his excellent set of editing eyes; and to my son and daughter, Max and JoAnna for, well, just for being everything. 


\section{Table of Contents}

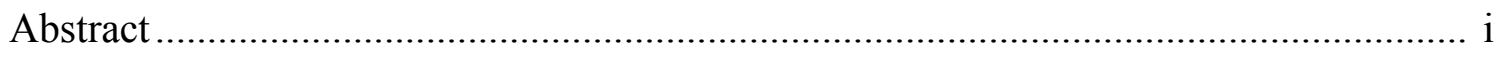

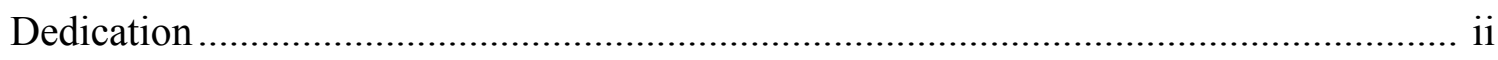

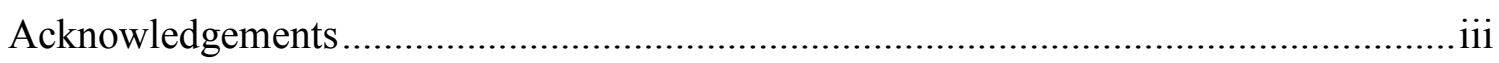

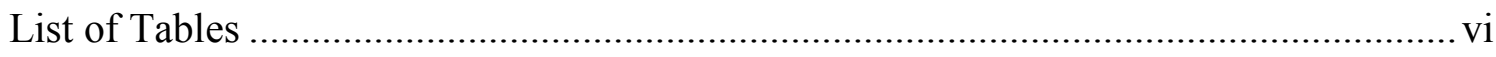

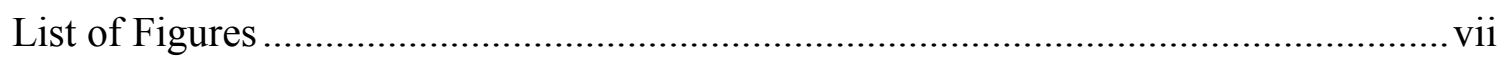

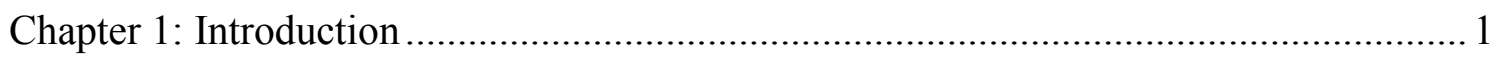

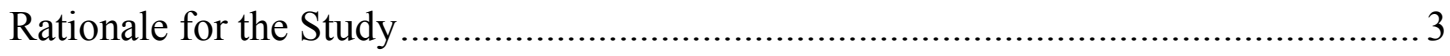

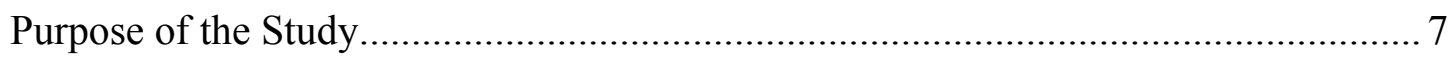

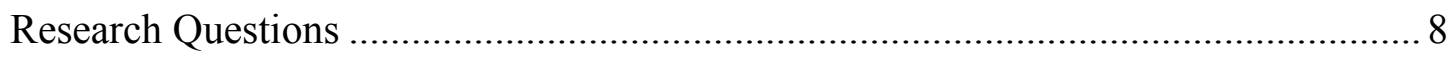

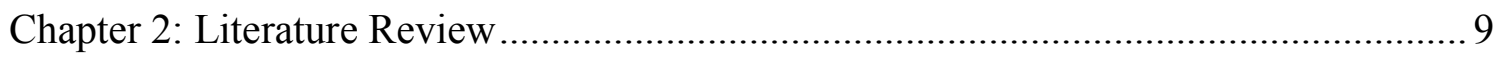

Representational Gestures ........................................................................... 9

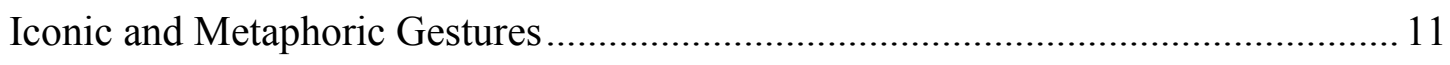

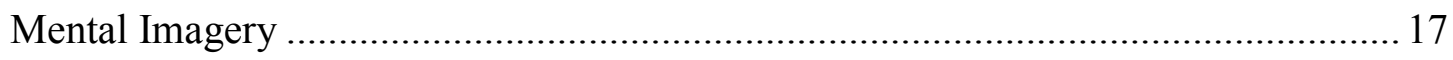

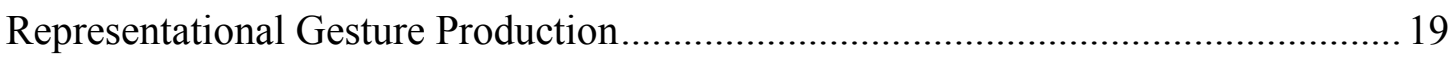

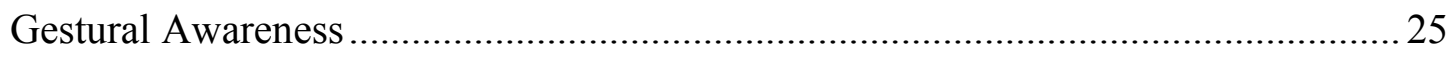

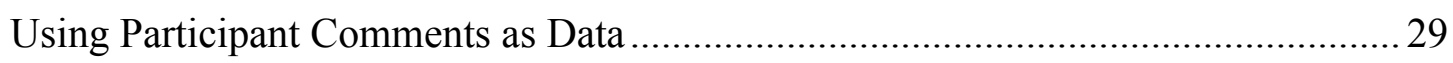

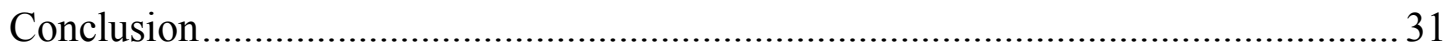

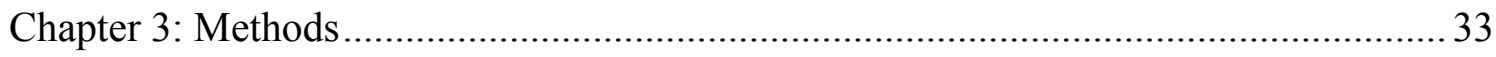

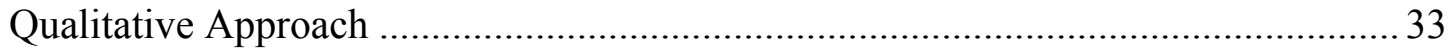

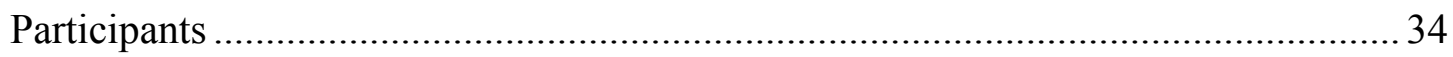

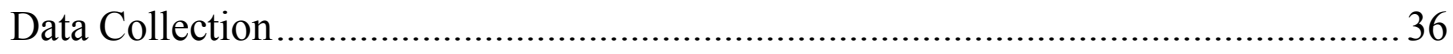

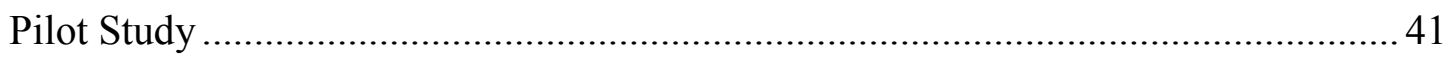

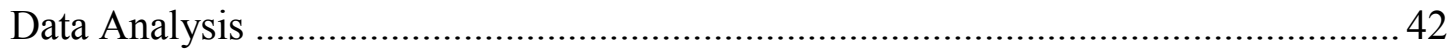

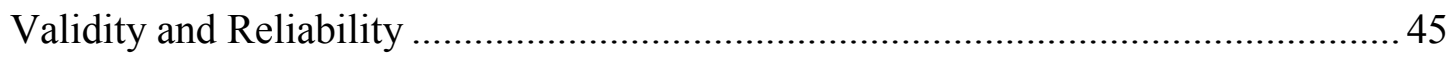

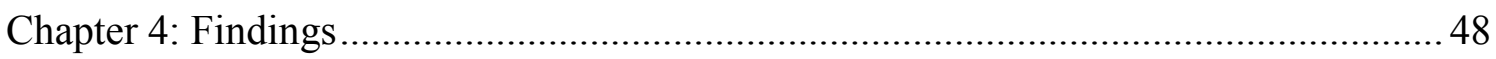

Sam: Of Trombones, Derives Stuff, Refresh Buttons, and Timelines ........................ 49

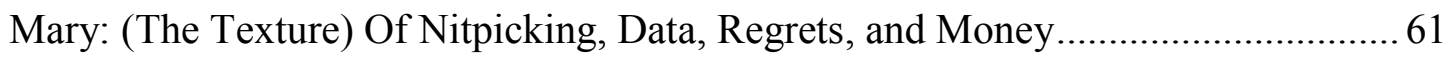

Melanie: Of Skinny Houses, Snow Pants, and a Carrot ……………………............. 70 
Tami: Of Snow Patting, Sprung Up, Volunteers, and Pamphlets ............................ 76

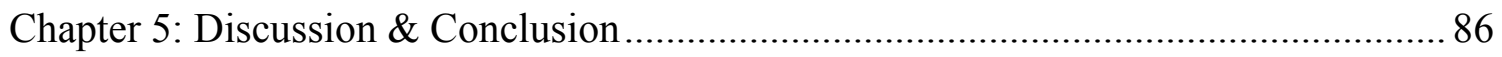

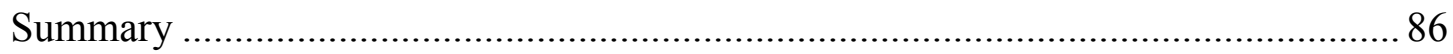

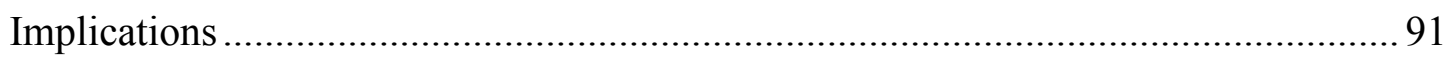

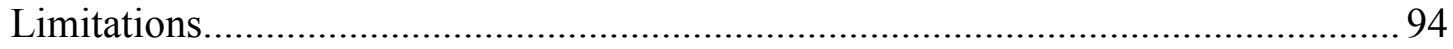

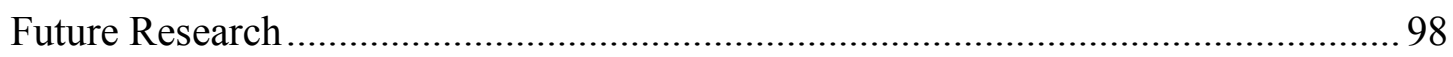

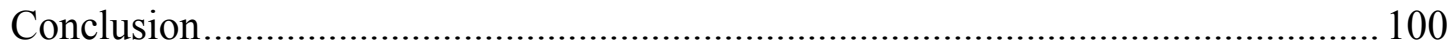

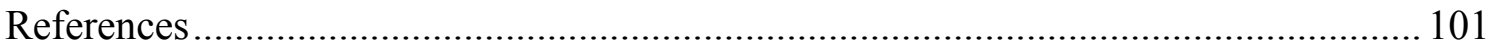

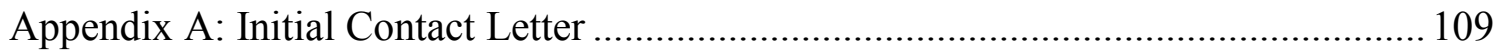

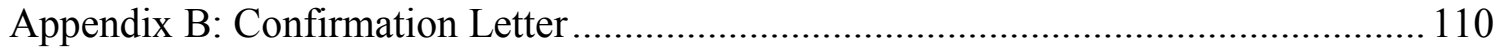

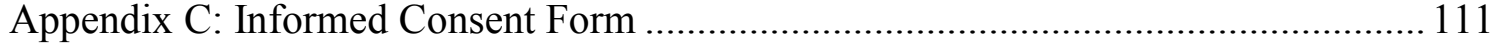

Appendix D: Phase 1 Video Representational Gesture Identification Form ................ 114

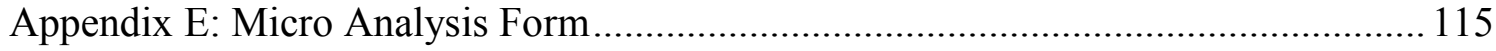

Appendix F: Phase 2 Guiding Interview Questions.................................................. 116 


\section{List of Tables}

Table

$1 \quad$ Data Generated from Phase 1 Video Recording .................................. 43

2 Data Generated from Phase 2 Interview Audio Recording ................... 43

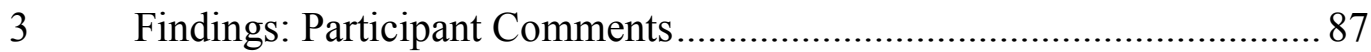

$4 \quad$ Findings: Participant Comments Effects on Analysis .......................... 89 


\section{List of Figures}

Figure

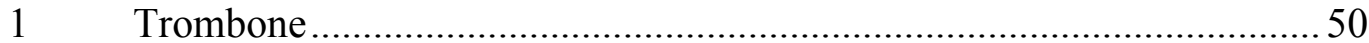

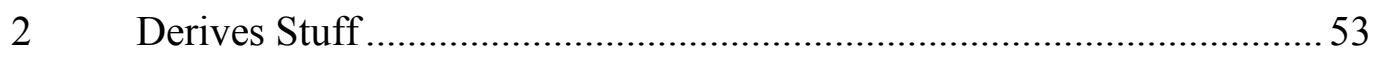

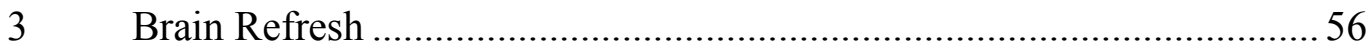

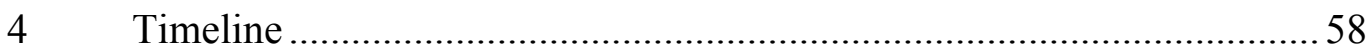

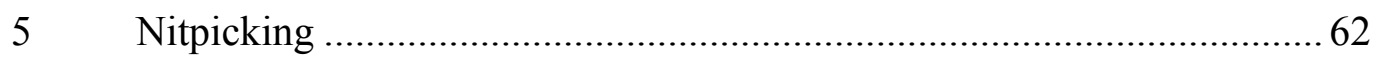

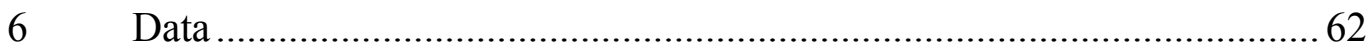

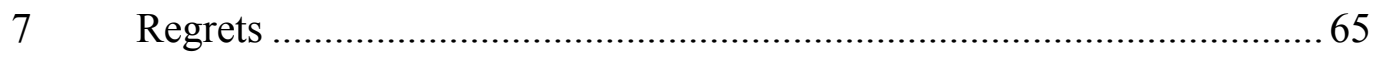

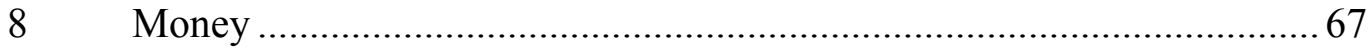

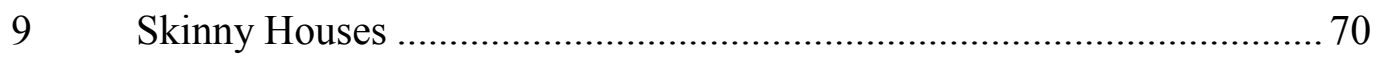

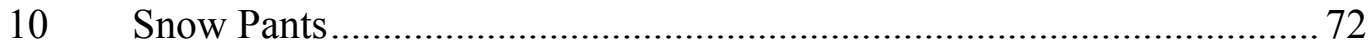

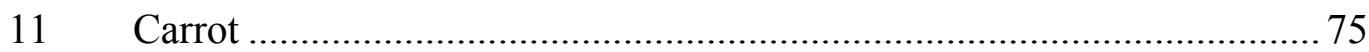

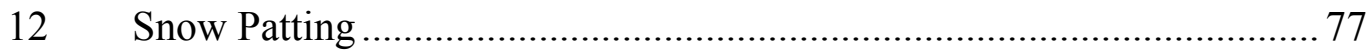

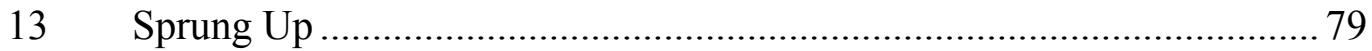

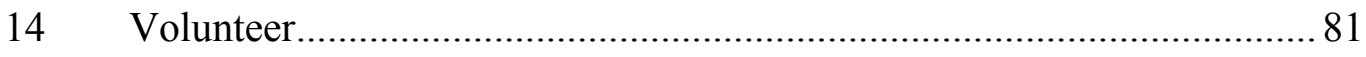

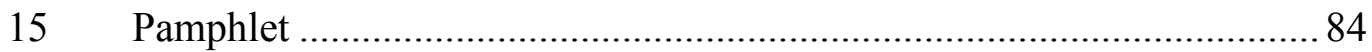




\section{Chapter 1: Introduction}

When you watch people talk, at times their hands will take on shapes and movements that express related speech content. For example, on one occasion, my friend Gary, a public education administrator, talked about the importance of cooperation between teachers and administrators. I noticed as he said cooperation, in synchrony his fingers interlaced, palms up, at chest height, with thumbs toward me. It reminded me of the hand gesture used in a popular children's nursery rhyme, "Here is the church, here is the steeple, open the door and see all the people." I saw Gary's entwined fingers - as expressing people working together. On another occasion, Molly, a fellow graduate student, told me about a research paper she wrote about how an artist's sense of identity is tied to her artwork (2007). I noticed that as she said artist identity, in synchrony her fingers were interlaced, palms down, at waist level, with thumbs facing toward herself. This time I casually asked Molly whether she had held any mental imagery at the moment that she produced the artist-identity-gesture. After a slight pause, she told me that she had a mental image and described it as the tightly woven strands of a rope. Molly explained to me that her entwined fingers were the physical expression of that mental image - fingers as inseparable strands of a rope, like how she had found in her research that an artist's identity is inseparable from his or her work.

Scholars use the term "representational gesture" to define these types of hand shapes and movements used to express speech content as spontaneously and unwittingly produced in synchrony with speech, in shared expression and meaning (Ekman \& Friesen, 1969; McNeill, 1985, 1992, 2000; Kendon, 2000, 2004). According to 
representational gesture production theory, mental imagery plays a role as fueling the gesture. Scholars theorize that on a cognitive processing level, both imagistic and linguistic forms of thinking occur as we speak, and coordinate in tandem, where linguistic thinking fuels the spoken words and imagistic thinking in the form of mental imagery fuels the representational gesture (McNeill, 1985, 1992; de Ruiter, 2000; Krauss, Chen, and Gottesman, 2000; Kita \& Özyürek, 2003; Hostetter \& Alibali, 2008).

At the time I noticed Gary's and Molly's gestures, I was also taking a course taught by Communication professor Dr. Ritchie titled, "Gesture and Meaning in Everyday Talk," and an idea for my thesis began to percolate. While in Dr. Ritchie's class, I was primed to notice the representational gestures that friends and family produced as they spoke to me, like I did with Gary and Molly. As one who thinks in mental images myself, I was intrigued about how other speakers, if asked, would talk of the mental imagery that might be fueling their gestures, and what their comments might add to the understanding of mental imagery. Could this be a topic and method used for a study?

The final gestural incident that resulted in the choice of this topic and method of data collection for my study occurred during a casual conversation with my daughter, JoAnna. As she said imagination, in synchrony both of her hands, palms out, moved in a fanning arc that started at face level, ending out at her sides at waist height. When I asked JoAnna whether she had any mental imagery associated with the representational gesture, she said that she did. JoAnna explained that she was mimicking a SpongeBob cartoon 
segment she had seen in which, as SpongeBob said imagination, a colorful rainbow appeared between his hands as he moved them up and out in an arc-like manner.

Although scholars contend that representational gestures are spontaneously produced while speaking with little or no awareness by the speaker (McNeill, 1985, 1992; Krauss, 1998; Kendon, 2000, 2004), the fact that both Molly and JoAnna could recall and respond to my questions about their mental imagery, combined with my piqued curiosity, inspired me to move forward and conduct a study that explores how participants talk about mental imagery and gestural awareness, and what their comments might add to our understanding of representational gestures produced in everyday talk.

\section{Rationale for the Study}

Studies show that mental imagery, both visual and motor, give rise to, i.e., fuel, the production of representational gestures (Hostetter \& Alibali, 2008; Kita \& Özyürek, 2003; LeBaron \& Streeck, 2000). Mental imagery plays a fundamental cognitive role as fueling a representational gesture, as Bach, Griffiths, and Weigelt (2010) aptly summarize: “. . . findings demonstrate that directly perceiving or thinking about an object activates information about its shape, which in turn feeds into the motor system and elicits congruent movements in space" (p. 10). Hypotheses of representational gesture production suggest that working in cognitive tandem, imagistic and linguistic thinking interact to result in co-expressed gesture and speech (McNeill, 1992; Kendon, 2000, 2004; Krauss et al., 2000). Scholars have created process models that graphically illustrate the cognitive flow of linguistic and imagistic thinking, and how they coordinate to produce co-occurring gesture and speech (see de Ruiter, 2000; Krauss et al., 2000; Kita 
\& Özyürek, 2003; Hostetter \& Alibali, 2008). Observational studies show that there is synchrony and semantic connection between representational gestures and speech (McNeill, 1992, 2005, Kendon, 2000; 2004). Other studies explore, for example, the different types of mental imagery - visual, motor, and mental simulations - and how the type of mental imagery affects the frequency and/or ease of representational gesture production (Feyereisen \& Havard, 1999; Beattie \& Shovelton, 2002; Alibali \& Kita, 2010).

While studies of representational gestures employ a variety of data collection and analytical methods, including researchers' observations, interpretations, and quantitative and qualitative analyses, a type of data collection and analysis that appears to be lacking, and one that I will explore, is using comments from the participants themselves as data for analysis. In my study, I filter participant comments about their representational gestures through the theoretical lens of gesture production, specifically theories pertaining to mental imagery and gestural awareness. Patton (2002) explains that a combination of observation, content analysis, and interviews can generate useful and credible qualitative data (p.5). During interviews, participant responses permit the researcher to capture as "data" the thoughts of the participant (Patton, 2002, p. 21). My study attempts to gain insights about representational gestures by analyzing participant comments regarding mental imagery and gestural awareness of their own representational gestures.

The following two studies illustrate how the approach to the study of representational gestures might be complemented by using participant comments to 
clarify or expand a researcher's analysis. In one study, McNeill (1985) observed the representational gesture of a nine-year-old boy retelling a segment of a Ghanaian folktale. In the story segment, a boy named Anansi is trapped inside a fish, waiting to be rescued by six sons. As the nine-year-old storyteller said, “. . . and they [rescuers] wanted to get where Anansi was ..." McNeill noted that in synchrony "both hands held up and facing each other; the left hand is motionless, while the right is 'fluttering' back and forth." McNeill offered this initial analysis of the young storyteller's representational gesture:

The gesture exhibited two objects that stood apart, one of which was motionless, whereas the other fluttered back and forth ineffectually. If the nonmoving object [hand] on the left is Anansi imprisoned inside the fish, the moving object [fluttering hand] on the right is the sons collectively setting out on the rescue mission, and lack of closure of the objects [both hands], the inaccessibility of Anansi inside the fish. (p. 369)

I wondered: if McNeill's study were designed to use the young storyteller's comments about his rescue-gesture as data for analysis, how would his comments have affected McNeill's subsequent analysis? In the other study, McClave (1998) observed that as a participant said that her cat was black, her right hand, which had been held in a flat open form, five fingers extended beside her right cheek, changed to a closed fist. McClave (1998) noted that, “This gesture invites speculation about the conceptualization of an absence of light or greater density" (p.75). Again, I wondered: if McClave's study had been designed to use the participant's comments about her black cat-gesture, how would her comments have affected McClave's subsequent analysis?

It can be argued that McNeill provided an accurate and defensible interpretation and analysis of the young storyteller's representational gesture, and that McClave's speculation was adequate as well; but, again, I am compelled to ask: What if McNeill and 
McClave were to have actually asked the young storyteller and the cat owner (as I had asked Molly and JoAnna) to talk about the mental imagery associated with their representational gestures? If so, what could McNeill and McClave have learned in addition to what they observed? How would their subsequent analyses have been affected? Can utilizing participant responses as data ultimately enhance understanding?

Conversation analysis (CA) scholars Waring, Creider, Tarpey, and Black (2012) argue that participant comments can "confirm CA analysis, explain CA analysis, and uncover what is not made evident in the initial CA analysis" (p. 479). Pomerantz (2005), also a scholar in the field of conversation analysis, asserts that the researcher's analysis of participants' conversations based on observation and video recording review only, could be enhanced by the participants' comments as together they watched and discussed the video recorded conversations. These comments, Pomerantz (2005) explain, can enhance the researcher's "analytical claims and/or for opening up avenues for investigations that otherwise might go unnoticed" (p. 93).

For example, Pomerantz (2005, pp. 108-109) cited a study conducted by Lutfey and Maynard (1998) that analyzed the conversation between an oncologist and a patient with HIV. Lutfey and Maynard (1998) concluded that, based only on their initial analysis, the oncologist was somewhat unsuccessful in steering the patient with HIV to consider hospice care as an option. During the conversation the researchers observed that when the oncologist mentioned hospice, the patient and his partner shifted the topic to nursing homes. However, in a post-interview, using a video recording of the conversation to stimulate the doctor's comments, the oncologist told the researchers, "Sometimes I use 
the discussion of hospice not so much because it's important to me that the patient accept a home hospice program, but ... to get the conversation really directed where you want it to go, which is on death and dying issues" (Lutfey \& Maynard, 1998, p. 325). Pomerantz (2005) noted that the oncologist's video-stimulated comments provided supplemental data for the researchers, who, without the addition of the oncologist's comments, initially inferred that the oncologist was unsuccessful in steering the patient to consider hospice. Therefore, the comments from the oncologist added additional information (data) that affected the researchers' subsequent analysis. If CA scholars find that using participants' comments can enhance analysis, can gesture scholars use video recordings and participant interviews to enhance analysis as well?

\section{Purpose of the Study}

The purpose of my study is to gain a better understanding of mental imagery and gestural awareness associated with representational gestures used in everyday talk. In addition to my observations and initial analyses of participants' representational gestures, I use a data collection method little used in gesture studies that incorporates participant comments as data for subsequent analysis. My study also examines the ways that their comments might affect my subsequent analysis. What might participant comments reveal about their mental imagery and gestural awareness that is not available to me through observations alone? To explore these questions, I video recorded participant dyads in everyday conversation, and then reviewed the video recordings to select segments where representational gestures had been produced, and to make an initial analysis of the type of gesture and its associated mental imagery. Then participants were invited back for 
individual interviews where together we watched the selected segments and I asked them to respond to questions about their mental imagery and gestural awareness of the representational gestures in question. Their comments were incorporated into my subsequent analysis.

\section{Research Questions}

Derived from the rationale and the purpose of my study, the primary research questions are:

RQ1) In what ways do participants talk about the mental imagery and gestural awareness associated with their representational gestures produced in everyday talk?

RQ2) In what ways do participant comments affect my analysis?

The next chapter provides the theoretical foundation for this study. It reviews

literature pertaining to representational gestures, mental imagery, gestural awareness, and the use of participant comments as data for analysis. 


\section{Chapter 2: Literature Review}

In order to contextualize the ways participants talk about mental imagery and gestural awareness, and how their comments affect my analysis, this chapter reviews research regarding the definition of representational gestures, mental imagery and its role in gesture production, and gestural awareness. The chapter also examines research that uses participant comments as data.

\section{Representational Gestures}

Scholars theorize that representational gestures used in everyday talk are more than hands flailing about randomly as a person speaks. Indeed, they are hand shapes and movements that are spontaneously and unwittingly produced in synchrony with speech in shared expression and meaning (Ekman \& Friesen, 1969; Kendon, 2000; 2004; McNeill, 1985, 1992). While Ekman and Friesen (1969) considered representational gestures as a form of nonverbal behavior, Kendon (2004) and McNeill $(1985,1992)$ argue that representational gestures are not nonverbal, but very much "co-verbal" - to act as a part of language where they co-occur with speech in an interplay that involves linguistic thinking that fuels speech, and imagistic thinking that fuels representational gestures.

To define representational gestures using a generally accepted typology, it might help to first distinguish how they differ from other types of gestures that commonly cooccur with speech, and are not associated with mental imagery, such as "deictics," “emblems," and "beats" (McNeill, 1992, 2005); and "interactive" or "conversational" gestures (McNeill, 2000; Cassell \& McNeill, 1991; Bavelas, 1994; Streeck, Grothues, \& Villanueva, 2009). Deictics are pointing gestures, such as when a speaker points in space 
while referring to an object, person, or a place in time (McNeill, 1985, 1992). Beats are rhythmic flicks of the hands that move in time with speech, have no standardized hand form, and are often used to emphasize words or phrases while speaking, "the equivalent of using a yellow highlighter on a written text" (McNeill, 2005, p. 40). Emblems are hand shapes and movements used with or without speech, have a standardized form, and a fixed meaning that is group shared or culturally specific, such as the Western "thumbsup-gesture" that signifies "things are fine" (Efron, 1941; Ekman \& Friesen, 1969; McNeill, 1985). Interactive or conversational gestures serve to regulate discourse (as in turn-taking) (McNeill, 2000; Cassell \& McNeill, 1991; Bavelas, 1994; Streeck et al., 2009). They do not provide descriptive information about the content of speech, but function to regulate the conversation between a speaker and listener, such as a speaker's hand unfolding toward her listener to suggest (without words) "it's your turn to talk," or a gesture that appears to "hand over" new information as a speaker reiterates a point just made (Bavelas, 1994, p. 213).

Deictic, beat, emblem, and conversational gestures are most often defined in terms of how they function in conversation, as mentioned above. On the other hand, representational gestures and subsets "iconic" and "metaphoric" gestures are unique in form and express features associated with speech content (McNeill, 1985; 1992; Kendon, 2000, 2004; de Ruiter 2000; Krauss et al., 2000; Hostetter \& Alibali, 2008). The features that iconic and metaphoric gestures express stem from mental imagery. Held in memory and drawn upon during speech planning, mental imagery fuels the production of a representational gesture (de Ruiter, 2000; Krauss et al., 2000; Kita \& Özyürek, 2003; 
Hostetter \& Alibali, 2008). It is important to note that I use the generally accepted terms representational, iconic, and metaphoric gestures in my study. Cienki and Müller (2010, p. 24) suggest that terms used by researchers to identify each type of gesture be "clear and appropriate" for the goals of a particular study. McNeill's (1992) terms of representational, iconic, and metaphoric are appropriate categories for my study because their definitions include references to mental imagery, and they are considered the most commonly used terms in the field of gesture research (Becvar, Hollan, \& Hutchins, 2008, p. 121). The next section defines iconic and metaphoric gestures in detail.

\section{Iconic and Metaphoric Gestures}

McNeill (1992) posits that as a person speaks, iconic gestures depict features of concrete referents, and metaphoric gestures depict features of concrete referents that are associated with abstract referents. A concrete referent has features that are available to the senses (Friedlander, 2012). A concrete referent, such as a person, an object, or an action has numerous physical or tangible features, such as its size, shape, and manner of motion that hands can depict. An example is hands facing each other as if holding a sphere while a speaker says round ornament. An abstract referent, such as when a speaker says cooperation or love, is an idea or a concept. Ideas and concepts have no direct tangible features available to the senses. Their meanings can be imprecise and even can change over time (Friedlander, 2012). An abstract referent can have an associated concrete referent that does have features that can be depicted via an iconic gesture: for example, a speaker's entwined fingers depicting the abstract concept of cooperation 
concretely as people coming together in cooperation. McClave (1991, p.5) provides the following definition and examples of iconic and metaphoric gestures:

Iconic refers to gestures that depict in form or movement some aspect of the [concrete] semantic content of speech - for example, while saying "jumping up and down" Speaker C moved her right hand up and down. Metaphoric gestures are like iconics insofar as they pictorially depict some aspect of a referent. Their referents, however, are abstractions. An example is Speaker B's gesture that cooccurred with her utterance of the word "black" referring to her cat's face. Before "black" her right hand was in a handshake beside her right cheek. As she said "black," she closed her hand.

Iconic gestures. Four examples of observations of iconic gestures provided by scholars include: 1) a speaker traces a circle in the air while saying, "round ornament" (hand depicting the round shape of concrete referent ornament) (Goldin-Meadow, 2003, pp. 6-7); 2) a child's hands spread apart as she refers to a row of checkers manipulated by an experimenter while saying, "All you did was spread them out" (hands depicting the concrete action of spreading) (Goldin-Meadow, 2003, pp. 6-7); 3) a speaker holds his hands a small distance apart (indicating size) while describing a fish (concrete referent) as tiny (Bavelas,1994, p. 205); and 4) a participant's right hand moves upward, palm up, with fingers and thumb spread apart while describing a cartoon character climbing up a drainpipe by saying, "... and he goes up through the pipe this time," (hands depicting the concrete action of moving up) (McNeill, 2005, pp. 89-90).

Iconic gestures can be direct or additive. In the examples above, the iconic gestures directly depicted visual and motor features of the spoken concrete referent - its shape, action, size, or manner of motion. But an iconic gesture can add information about a concrete referent that was not expressed in speech (McNeill, 1992; Goldin-Meadow, 
2003). Goldin-Meadow (2003) provides this example: as a speaker exclaims, "There's a spider running across the counter!" one of his hands, with five wriggling fingers, moves above the counter. Goldin-Meadow (2003) explains that the speaker's iconic spidergesture added information about the spider that was not expressed in words. She notes that the spider-gesture carries additional information about the spider - its form (five fingers representing many legs), and how the spider moved (wriggling fingers), as it directly depicted the spider's path (hand moving above the counter); and its location (hand over the counter) (p.24).

Bavelas (1994) provides the following example of an additive iconic air-writinggesture observed in a study (using a notation style developed by McNeill, 1992, where the gesture is notated in brackets under its underlined, synchronized, word or phrase):

Student A says to Student B:

"I'm taking a couple of, ah, psych courses, Drugs and Behavior, so that's how they got my name."

[writes in air]

Bavelas (1994) explains that prior to the study, participants were asked to fill out and sign consent forms. At the beginning of one of the experiments, as Students A and B were getting acquainted, Student A produced the air-writing-gesture while saying "that's how they got my name." Bavelas observed that neither the word "form" nor "signed" had been spoken in that short phrase, but that it was the additive iconic air-writing-gesture that carried the information of filling out and signing a form (p.203). Summed up, iconic gestures depict visual and motor features of concrete referents in a direct or additive manner. 
Metaphoric gestures. Metaphoric gestures are defined as hands that depict concrete features associated with abstract referents (McNeill, 1992; Cienki \& Müller, 2010). The association between a concrete feature-based metaphoric gesture and its abstract referent in speech is similar to how linguistic metaphors conceptualize something abstract by associating it to something concrete. For example, Lakoff and Johnson (1980) explain that the abstract concept of love attraction can be conceptualized in concrete terms of forces of electricity and gravity, as when a speaker says, "I could feel the electricity between us," or "They gravitated to each other immediately" (p. 106). Similar to a linguistic metaphor, Cienki and Müller (2010) offer this interpretation of a metaphoric gesture: a speaker who makes a straight vertical line in the air with a flat hand as he says "truth," is associating the concrete physical feature of straight to the abstract concept of truth (pp. 10-11). Cienki and Müller (2010) also note that a metaphoric gesture can be observed when two concrete referents are associated with each other. An example is when a speaker's hands trace an hour-glass in the air while talking about a woman's body. In this example, both referents are concrete, both have physical features that can be depicted by a speaker's hands, as they are associated to one another (p. 5). Summed up, metaphoric gestures depict physical features that are associated with concrete or abstract referents.

\section{Iconic and metaphoric gestures are observed as depicting concrete features.}

For the purpose of observations and interpretations of representational gestures conducted during research, it can be argued that a metaphoric gesture is initially observed as an iconic gesture, i.e., by the concrete features it is depicting that are associated with the 
abstract referent. McNeill (1992) notes that metaphoric gestures "are like iconic gestures in that they are pictorial, but the pictorial content presents an abstract idea rather than a concrete object or event” (p. 14). Müller (1998, as cited by Cienki, 2010) argues that McNeill's metaphoric gesture is essentially a type of iconic gesture distinguished by the fact that the corresponding referent is abstract. And Cienki and Müller (2010) posit that a metaphoric gesture is ultimately an iconic gesture because, in the end, it takes its shape and form from "concrete grounds" associated with an abstract referent (p. 11). In summary, although a distinction exists between iconic and metaphoric gesture definitions, with respect to how they are observed in research, both are seen as iconic as hands that depict features of concrete referents, or hands that depict features of concrete referents that are associated with abstract referents.

Synchrony. Observation and identification of a representational gesture is possible because of the concurrent timing of gesture and speech, or what McNeill (1992) refers to as "synchrony." The production of an iconic or metaphoric gesture occurs at the same time as a spoken concrete or abstract referent (McNeill, 1992). Kendon (1980) further explains that under close examination, the synchrony and production of a gesture can be observed in three phases: 1) a preparation phase, 2) a stroke phase, and 3) a retraction phase. For example, in the preparation phase, a speaker's hand rises from its resting position to begin the stroke phase. The stroke phase is where gesture and speech synchronize to co-express the underlying semantic content, each in its own way. Finally, the gesture ends in the retraction phase as the hand returns to rest. Thus, synchrony between gesture and speech, as a "communicative duo," not only shows timing and 
shared meaning (Goldin-Meadow, 2003, p. 24), but synchrony also allows a researcher to observe and identify the occurrence of a representational gesture.

Synchrony is also evidence that cognitive processing is occurring during speech and gesture production, in which two forms of thinking, one imagistic and the other linguistic, interact to produce co-expressed gesture and speech (McNeill, 1985, 1992, 2000, 2005). McNeill (2000) proposes a hypothesis that representational gestures emerge from "growth points," as the cognitive beginnings in coordinated thought. In this conceptualization, during the early stages of communicative planning, a growth point is ultimately "unpackaged" as co-expressed speech and gesture (pp. 142-148). McNeill (2005) states:

... gesture and speech express the same underlying idea unit but express it in their own ways, their own aspects of it, and when they express overlapping aspects do so in distinctive ways. It implies that at the moment of speaking, the mind is doing the same thing in two ways, not two separate things. (p. 22)

Growth point theory suggests that imagistic and linguistic thinking interact to enable "language to influence imagery and imagery to influence language as the utterance unfolds in real time” (McNeill, 2000, p. 146). Kendon (2000) puts forth this supporting argument:

If language is a cognitive activity, and if, as is clear, gestural expression is intimately involved in acts of spoken linguistic expression, then it seems reasonable to look closely at gesture for the light it may throw on this cognitive activity. (p. 49)

Over the years, McNeill's $(1985,1992,2000,2005)$ theoretical conceptualization of imagistic thinking have been extended by scholars who posit theories about embodied 
cognition, mental simulations, and mental imagery (Barsalou 1999; 2008; Gibbs, 2006;

Hostetter \& Alibali, 2008; de Ruiter, 2000; Krauss, et al., 2000; Kita \& Özyürek, 2003;

Alibali, 2005) as the mental activity that serves to fuel the production of representational gestures. Because my study explores how participants talk about the mental imagery and awareness associated with their own representational gestures, definitions and key theories of mental imagery, including its origins, characteristics, and its role in representational gesture production are reviewed next.

\section{Mental Imagery}

Embodied cognition and mental simulations. A framework in cognitive science referred to as embodied cognition proposes that mental imagery originates from our perceptions and actions in the real world. In the real world, as our bodies interact with the environment, our perceptions and actions enable us to know what we see, to store our experiences in memory, and to recall them as needed for speech (Barsalou, 2008) and gesture (Hostetter \& Alibali, 2008). Memory is stored as visual and motor representations in the form of mental simulations that can prime the production of iconic gestures (Bach et al., 2010; Gibbs, 2006; Hostetter \& Alibali, 2008; Barsalou, 1999, 2008). A speaker draws upon these types of memories that resemble "short films," to formulate "conscious thoughts" as speech is developed (Baumeister \& Masicampo, 2010).

With respect to representational gestures, Hostetter and Alibali (2008) describe mental simulations as "an analogue representation of a perceptual object or motor event" (p. 499). In other words, stored in memory, mental imagery as mental simulations are similar to, or bear a likeness to, real world perceptions and bodily movements. Drawn 
from memory during speech planning, mental simulations are activated by similar cognitive mechanisms that allow our bodies to perceive and act in the real world. These embodied mental simulations become the fuel for the production of representational gestures. Hostetter and Alibali (2008) describe two aspects of mental imagery, 1) motor and 2) visual. Motor mental imagery is derived from one's bodily experiences and movements in the real world, and visual mental imagery is derived from perceptions of objects and their actions in the real world (p. 499). These two types are explored in more detail next.

Motor mental imagery. Casasanto and Boroditsky (2008, p. 579) describe motor mental imagery as "mental representations that result from physical experience." Stemming from embodied cognition and stored in memory, motor mental imagery derives from "our bodies in motion" where the imagery represents the body as the "generator of acting forces" (Hostetter \& Alibali, 2008, p. 500). Research in embodied cognition has shown that brain areas activated by bodily movement in the real physical world are also activated when a person imagines movement (Jeannerod, 1995, p. 1420, 2001, as cited by Hostetter \& Alibali, 2008, p.500). For example, when a speaker uses iconic gestures like gripping and swinging while he describes to someone how to swing a tennis racquet, he is accessing and activating motor mental imagery. Alibali and Kita (2010) provide this example: when referring to a cup, a speaker's gesture may depict motor aspects of how his "body interacted with the cup (such as gesturing picking up the cup, holding it, or tilting it)" (p. 6). LeBaron and Streeck (2000) showed how bodily interaction with an object in the real world, in real time, became an iconic gesture co- 
expressed with speech at a later time when the object is not present. They observed that an instructor in a do-it-yourself workshop held and manipulated a scraper tool to show students how to use it. Later the instructor produced iconic gestures similar in form as he referred to the scraper tool.

Visual mental imagery. While motor mental imagery is derived from bodily movements in the real world, the other basic form of mental imagery, visual, is derived from perceptions of objects and their actions in the real world (Hostetter \& Alibali, 2008). Visual mental imagery consists of perceptual information about an object's physical features, such as size, shape, color, and manner of motion derived from the real world and stored in memory (Hostetter \& Alibali, 2008, p. 504). Visual mental images can be retrieved at will, viewed fully, or with focus shifted - just as in the real world. These visual mental images can be transformed, or rotated, and their movements can be simulated (Mast \& Kosslyn, 2002; Peterson et al., 1992, as cited by Hostetter \& Alibali, 2008, p. 499). Alibali and Kita (2010) describe visual mental imagery as "action simulations," consisting of information about physical attributes and movements of objects derived from the real world that can eventually be represented as iconic gestures co-expressed with speech (p.6).

\section{Representational Gesture Production}

Scholars provide myriad theoretical cognitive models showing how motor and visual mental imagery fuels the production of representational gestures co-expressed with speech. For example four models include: 1) Gesture as Simulated Action (Hostetter \& Alibali, 2008), 2) Sketch Model (de Ruiter, 2000), 3) Lexical Gesture Process Model 
(Krauss's et al., 2000), and 4) Interface Model (Kita \& Özyürek, 2003). These cognitive process models of gesture/speech production graphically show how during speech planning, mental imagery and linguistic propositions drawn from memory and brought into working-memory, interact to result in co-expressed gesture and speech. The models are similar in that each one begins with the conceptualization that a representational gesture originates in mental imagery that is held in long-term memory, and then brought into working memory to "cooperate" with speech planning. The models differ in how and when mental imagery and linguistic thinking interact.

In Gesture as Simulated Action (GSA), Hostetter and Alibali (2008) conceptualize that motor and visual mental imagery drawn from real world perceptions and actions are held in memory as mental simulations, and activated concurrently during speech planning. Representational gestures are the "by-product of these activated mental simulations" (p. 508). This theory relates back to claims made by Müller (1998 as cited by Cienki \& Müller, 2010) and others who posit that iconic and metaphoric gestures are the result of embodied cognition. In their view, gesturing hands take their form from actions and perceptions of everyday experiences in the real world - like hands, while speaking, that depict the instrumental, motor action of opening a window, or hands that trace a circle in the air depicting the visual round feature of a globe (p. 22).

The Sketch Model (de Ruiter 2000) proposes that representational gesture production is determined by the content of one's mental imagery early on in the speech planning process (p. 293). Mental imagery is converted into "features," held as a "sketch," at the early stages of speech planning (p. 298). Features are "extracted" from 
the sketch, fed into a "motor planner" that provides the fuel for the production of a representational gesture (pp. 294-297). The Lexical Gesture Process Model (Krauss et al., 2000) proposes that mental imagery and linguistic thinking have a closer working relationship, in that representational gestures originate from features of mental images and mental propositions that are both part of a "source concept" during the early stages of message planning (p. 268). In this tight association, Krauss (1998) notes that representational gestures are "a medium for conveying semantic information - the visual counterpart of words” (p. 54). Finally, the Interface Model (Kita \& Özyürek, 2003) proposes that mental imagery and linguistic thinking have a shared influence on each other; that representational gestures arise from mental imagery that can be influenced by linguistic thinking.

Linguistic metaphors, texts and gesture production. With respect to the influence of linguistic thinking on mental imagery and representational gesture production, scholars believe that our brains are so wired for thinking in mental images that even hearing linguistic metaphors and reading texts can activate mental images (Gibbs, 2006; Bach, Griffiths, Weigelt, \& Tipper, 2010). In an example of the close relationship of linguistic metaphors to mental imagery, Gibbs (2006) claims that when a listener hears and attempts to make sense of a verbal linguistic metaphor, an automatic mental construction occurs whereby the listener imagines performing the bodily actions referred to in the metaphor. For example, in one study, he asked a participant to respond to the metaphor to "chew on the idea." The participant said that she could imagine her jaw moving up and down. Gibbs (2006) posits that in making sense of linguistic metaphors, "cognitive 
simulations" are fundamentally embodied, drawn from real-life experiences (p. 435). And, although participants reported that it is easier to conjure up a mental image from a non-metaphorical phrase, such as "grasp the branch," as compared to a metaphorical phrase, such as "grasp the concept," Gibbs (2006) argues that nonetheless, people imagine themselves participating in the metaphorical actions (p. 446).

Even reading texts can generate mental imagery that can fuel a representational gesture. Hostetter and Alibali (2008) argue that, as carriers of meaning, words may be tied to perceptual and motor experiences in the real world (p. 497). Research by Bach et al. (2010) showed how reading words can activate mental imagery that can fuel an iconic gesture. They explain that reading "close the drawer" can prime a mental image of pushing one's hands forward to close the drawer, which could provide the fuel for the production of a motor-based iconic gesture. Bach et al. (2010) also found that reading words that contain no direct visual features, such as the mention of a round or circular shape, can activate a mental image that can lead to a visually-based iconic gesture. They found that as participants read phrases that contained words like "carousel" and "billboard" (which contain no direct cues about shape) participants produced a round or rectangular iconic gesture, respectively, when talking about what they had read (p. 10).

These findings relate to research by Parrill, Bullen, \& Hoburg (2010) who found that participants in different experimental groups who either watched a video or read a text, produced similar amounts of representational gestures as they retold the story to the researchers. The researchers concluded that, because of the embodiment of language comprehension (which holds similar claims about embodied cognition and mental 
imagery) even reading and recalling texts activates mental imagery as much as watching a video (p. 3131).

Influences affecting representational gesture production. Scholars propose a number of influences that can affect the production of representational gestures by speakers in everyday conversation. These influences include such things as 1) type of mental imagery (Hostetter \& Alibali, 2008; Feyereisen \& Havard, 1999), 2) properties of speech content (Beattie \& Shovelton, 2002), 3) its ease or preference of use (GoldinMeadow, 2003), and 4) overcoming a gesture threshold (Hostetter \& Alibali, 2008). Hostetter and Alibali (2008) suggest that the type of mental imagery can influence the production of a representational gesture. Sometimes motor mental imagery may have a stronger effect on the production of a representational gesture than visual imagery, for example. Hostetter and Alibali (2008) claim it may be easier, even more efficient, for a speaker to talk about the steps involved in how he ties a shoe using a combination of gestures and words, rather than by using words only. In addition, Feyereisen and Havard (1999) found that speech content associated with motor mental imagery resulted in more representational gestures than speech content that involved visual mental imagery. For example, participants' responses to questions that would activate motor mental imagery, such as "Could you explain how to change the wheel of a car, or to repair the tire of a bicycle?" resulted in more motor-based iconic gestures than questions based on visual mental imagery, such as "Could you describe a favorite painting or sculpture?" (p. 159). Responses relating to questions based on abstract content, such as "What do you think 
about a single currency in Europe?" were found to result in the fewest representational gestures produced (p. 166).

In related research, Beattie and Shovelton (2002) explored properties of speech content and asked, "What properties of talk are associated with the generation of spontaneous iconic hand gestures?" They looked at the occurrence of iconic gestures in relation to the level of "imageability" of words and phrases. Imageability was defined as "the ease or difficulty with which a 'speech unit' arouses a mental image" (p. 409). They found that words and phrases that were rated higher in imageability had the effect of increasing the occurrence of iconic gestures during speaking.

Goldin-Meadow (2003) suggests that ease of use is what governs whether a representational gesture is used in place of or to complement words to communicate an idea, i.e. when it seems that words alone just can't do it justice. She explains: ... by and large we are constrained to the words that our language offers. And sometimes those words fail us. It is difficult, for example, to rely exclusively on words to describe the coastline of the United States (Huttenlocher, 1973, 1976 as cited by Goldin-Meadow, 2003). A gesture, unencumbered by the standards of form that language imposes and able to take advantage of visual imagery, can convey the shape of the coastline far better than even a large number of words.” (p. 24)

In a final example of what can influence the production of a representational gesture, Hostetter and Alibali's (2008) GSA framework proposes the notion of gesture threshold, the point at which mental simulations at the "pre-motor" and "motor areas" of cognitive processing during speech planning are strong enough that a gesture will emerge. The idea of a gesture threshold explains why "representational gestures occur 
some of the time and not at other times while speaking," i.e. it is "the level of activation beyond which a speaker cannot inhibit the expression of simulated actions as gestures" (p. 503). Taken together, the cognitive and influential theoretical claims of representational gesture production mentioned in this section are used in my study to provide a way to contextualize participant comments as they talk about mental imagery and gestural awareness.

\section{Gestural Awareness}

Pertinent to my study, I had to ask myself: Will participants have awareness of producing the iconic or metaphoric gesture in question, and will they be able to view a video recording of it, recall producing it, and respond to my questions about mental imagery and gestural awareness? An overall definition I used for my study is from Ekman and Friesen (1969), who define gestural awareness as "whether the person knows he is engaging in a particular nonverbal act at the moment he does it, or whether he can recall with any ease what he has done" (p. 53). Scholars hold different perspectives about aspects of gestural awareness including levels and types of awareness. For example, Ekman and Friesen (1969) consider speakers to be more aware of producing emblems and deictic gestures. They state that as a more conscious and intentional communicative behavior, "People are almost always aware of their use of emblems, can repeat the emblem if asked to do so, and will take communicational responsibility for it" (p. 63). Cassell (1998) posits that a deictic gesture used in a task-orienting request such as when a speaker wants someone to move a chair, points to a location and says "move that over there," is consciously and intentionally produced, and therefore easier for a speaker to 
remember using it when asked at a later time (p.3). Ekman and Friesen (1969) can only speculate that a speaker's level of awareness of using "illustrators" (their term for representational gestures), is of a lower level compared to the awareness of producing emblems. They suggest that, "The person using an illustrator may be slightly less aware of what he is doing, and his use of illustrators may be somewhat less intentional" (p. 69).

With respect to intentionality of producing a representational gesture, some scholars suggest that representational gestures are unplanned and unwittingly produced (Ekman \& Friesen, 1969; McNeill, 1992). Bach et al. (2010) claim that representational gestures are produced without "conscious intention" while other scholars claim there may be a level of intention (Ekman \& Friesen, 1969; Streeck, 1993). Ritchie and NegraBusuioc (2014) coined the term "spontaneously intended," to refer to the seemingly intentional, yet spontaneous nature of speakers using linguistic metaphors during conversation (p. 173). This term could be used to describe the intentionality of producing a representational gesture, because similarly, the production of representational gesture appears intentional as it is produced in synchrony with co-expressed speech.

Drawing from the perspective of a nonconscious behavior, a representational gesture is like a "behavior without awareness," where behavior is defined as "anything that the individual does that is publicly observable" (Adams, 1937, p. 383). Schooler and Smallwood (2007), describe a nonconscious behavior as produced with little or no awareness, and add that it is automatic as opposed to controlled. Schooler and Smallwood (2007) note, however, that even nonconscious behaviors, or "automatic activities," are produced with some level of awareness of doing so (p.4). 
Conscious and unconscious aspects of gesture production. In research of an unusual and specific context, Cole, Gallagher, and McNeill (2002) provided evidence of gesture production as both conscious and unconscious in nature. The study involved a physically disabled man, IW, who claimed he could only gesture during speech using conscious intention. But under experimental conditions, the researchers observed that IW appeared to gesture in an unconscious manner. IW told the researchers that in order to move his hands he had to physically see them to consciously direct them to move. For example, to pick up a cup, he told the researchers, he would have to see both the cup and his hands, and to think through every move to accomplish the task - from visualizing the shape of his fingers, to sensing the strength of his grip around the cup, to mentally calculate how to reach and pick it up (p. 52). Under experimental conditions, when IW narrated the plot of a cartoon he had just seen (using conscious intention), Cole et al. (2002) found that IW gestured in a seemingly normal manner. But when Cole et al. (2002) placed a blind over IWs hands so that he could not see his hands, as expected, IW did not move his hands as he narrated the same cartoon story. When the researchers asked IW why he did not move his hands, IW said that he made a conscious choice to not move them because he could not see the space that they were in, making it unsafe to move them (p. 55). But when the researchers assured him that it would be safe to move his hands even though he could not see them as he had claimed he needed to in order to gesture, IW began to gesture in a normal manner as he spoke.

For example, when IW talked about a segment of the cartoon in which a trolley chased Sylvester the Cat, Cole et al. (2002) observed IW using his right hand as the 
trolley and the left hand as Sylvester, noting that "the right 'chased' the left across the gesture space in alternating left-hand, right-hand strokes" (p. 57). Cole et al. (2002) reflected that: "Once IW allowed his gestures to get under way, they seemed to have a mind of their own. That is, they did not seem to be under IW's attentional, conscious control, and they were consistent with normal measurements in terms of timing and shape, relative to IW's speech acts" (p. 56). Cole et al. (2002) speculated that there must be something more at play in IW's gesture production than the conscious control of his movements. They theorized that IW's gesturing in this circumstance showed that gestural movement is not dependent on his conscious control, but that gesturing is the result of integrated and unconscious thought and language processes that are involved in coexpressed gesture and speech (p. 58).

Streeck (1993) notes the perplexities of exploring gestural awareness including consciousness and intentionality of production in the following paragraph:

It may not always be clear whether a gesture "was intended," was "part of the original plan," or just a spill-over from mental activity leaking during moments of perturbation and uncertainty. But however that may be, we can certainly note that speakers for better or worse make something with their hands, something that is subsequently "there" to be seen, by self and others. (p. 293)

Streeck's (1993) quote above alludes to the continuing scholarly discussion about characteristics of representational gesture production and gestural awareness as being automatic, unconscious, intentional, and/or conscious in nature. A speaker's gestures that can be "seen" by "self and others" (as Streeck mentions above), and a participant like IW who can comment about consciousness related to gesture production, is an invitation for exploration to a researcher like me - to explore gestural awareness along with mental 
imagery, with the hope of better understanding representational gestures. Finally, because I use participant comments about their own mental imagery and gestural awareness as data for analysis, the last section reviews literature pertaining to this type of research method.

\section{Using Participant Comments as Data}

There is an ongoing discussion between scholars, especially in the field of conversation analysis (CA), about using participant comments as data. This discussion is relevant to my study because I use participant comments as data to explore the mental imagery and gestural awareness of representational gestures. Patton (2002) states that along with a researcher's observations, participant interview responses can provide useful and credible data for analysis (p.5). CA scholars such as Pomerantz (2005); Waring et al. (2012); and Lutfey and Maynard (1998) have offered their supporting arguments as well: Pomerantz (2005) argues that participant comments can be valid in CA research and appear to complement analysis by confirming, explaining, and uncovering what is unavailable to a researcher's observations and initial analysis. Pomerantz (2005) states that participant comments could be useful to help the researcher understand a "puzzling" observation, or serve to validate, confirm, explain, or expand upon an initial analytic claim (p. 112). Waring et al. (2012) argue that participant comments can be useful in CA to explain an ambiguous observed conversational interaction, adding that participant comments can reveal the underlying motivations and intentions of a speaker that could complement what a CA researcher observes and initially analyzes, that then results in an expanded subsequent analysis. Waring et al. (2012) suggest that participant comments 
can complement CA by confirming, explaining and uncovering what is not evident in initial analysis (p. 479). Lutfey and Maynard (1998) argue that researcher observations and video recordings of a conversation could be enhanced by comments from the participants themselves as researcher and participant review the video together, uncovering during the interview what is unavailable to a researcher's observations and initial analysis alone.

For example, a study by Woodzicka (2008) showed how participant comments were pertinent to the researcher's analysis of false smiling and reasons for doing so. Woodzicka's (2008) study involved video recording participants during a mock job interview, and then using participants' "video stimulated comments" (Pomerantz, 2005) to explore and analyze awareness and reasons for false smiling. Participants were shown video clips of themselves during the mock job interview in which they had smiled (both genuine and false smiles), and were asked by the researcher whether they were aware of having produced the smile or not. Finally because the study's focus was on false smiling, participants were asked questions about their reasons for false smiling.

Woodzicka (2008) found that when participants viewed the video clips, slightly more than half (52\%) of the participants reported being aware of having smiled when they were shown the video clips of the mock interviews (p. 115). And participants were able to reflect and comment about specific reasons for false smiling. Categories and themes that emerged from participant responses for false smiling included: as a filler; to mask negative emotions; to appear enthusiastic; to ease tension; to please the interviewer; out of habit; and don't know (Woodzicka, 2008, p. 117). Woodzicka's (2008) 
methodology showed that using participant comments as data was pertinent to analysis and to the understanding of reasons for false smiling.

However, Pomerantz (2005) also argues that research that uses participant comments as data - taking comments on "face value," and not to consider how or why the comments came about - can result in a subsequent analysis that is not related to the aims of the research (p. 112). Waring et al. (2012) hold the concern that as a method of data collection, there can be an analytical disconnect between the data collected by a researcher's observations and the data collected from the "self-reports" of participants. For example, how issues pertaining to memory and recall, and the social nature of the interview environment itself can have an effect on the validity of a participant's comments (Ford, 2012; Mills, 1940). These limitations are discussed further in the Discussion Chapter.

\section{Conclusion}

This chapter reviews relevant research on representational gestures, mental imagery and its role in gesture production, gestural awareness, and using participant comments as data for analysis, to establish the theoretical framework for my study. The literature shows that gesture researchers can identify and interpret representational gestures by observing a speaker's hand shapes and movements synchronized and coexpressed with speech; determine whether they are iconic or metaphoric; and whether they are direct or additive to co-expressed speech. Based on observations and analyses, gesture researchers seek evidence and provide theories of cognitive processing and how mental imagery and other influences can fuel the production of a representational gesture. 
However, researchers who complemented observations with participant self-reports, such as Woodzicka (2008), found that using participant comments as data was essential to understanding reasons for false smiling; and Lutfey and Maynard (1998) found that participant comments clarified an initial analysis of a conversation of why an oncologist chose to talk to a patient about hospice.

A review of the literature reveals that, although there is abundant research on representational gestures based on observations and analyses, there is little if any that use video recordings and interviews to solicit participant comments as data for analysis. My study attempts to use this line of inquiry to better understand the mental imagery and gestural awareness of representational gestures. The next chapter discusses the methods used to seek answers to my research questions: In what ways do participants talk about the mental imagery and gestural awareness associated with their representational gestures produced in everyday talk? And, in what ways do participant comments affect my analysis? 


\section{Chapter 3: Methods}

\section{Introduction}

This study explores ways participants talk about the mental imagery and gestural awareness associated with representational gestures used in everyday talk, and how using their comments, as data, affect my subsequent analysis. Data for analysis was collected in two phases. For my initial analysis, I identified and analyzed iconic and metaphoric gestures from video recorded conversations between two dyads (Phase 1 video recording). For subsequent analysis, I collected and analyzed participant comments from four individual audio recorded interviews (Phase 2 interview). During the interview, I showed each participant segments of the videos in which they had produced a representational gesture in order to stimulate comments. This chapter discusses how these data were collected and analyzed, including the study's qualitative approach, methods, and procedures. It also includes initial insights gained from a pilot study I conducted, and closes with a section about guiding principles of sound qualitative research that are relevant to my study.

\section{Qualitative Approach}

A qualitative approach is the most appropriate way to address my research questions and to gather and analyze the data for my study. Such an approach allows me to video record and observe participants producing representational gestures in everyday, natural-like conversation, and to interview them later about their mental imagery and gestural awareness using open ended and probing questions. Qualitative and quantitative research share basic considerations and methodologies, such as systematic research 
design and concerns of validity and reliability. The strengths of using a qualitative approach make it best suited for a study that attempts to explore, describe, and analyze "particular human behaviors and phenomena" often conducted with a smaller sample or collection of data, in a typically more naturalistic or real-world setting. (Patton, 2002, p. $39-42)$.

Role of the researcher. The role of a researcher in qualitative research is as an "instrument of data collection" (Patton, 2002, p.51). Thus, I was a "nonparticipant" observer (Baker, 2006) while reviewing the Phase 1 video recordings of dyads in conversation; and I strove to be an objective interviewer during the Phase 2 interviews. As a nonparticipant observer viewing the Phase 1 video recordings, I systematically identified and selected a participant's iconic and metaphoric gesture segments from the video recordings to show them to the participant in the Phase 2 interview in order stimulate comments. As each participant and I watched his or her segments of the Phase 1 video recording, I used a set of guiding interview questions to solicit video-stimulated comments in an objective, unbiased manner.

\section{Participants}

I recruited four Portland State University (PSU) students for the study. Three were current undergraduate students, and one was a PSU graduate. Two of the undergraduate students were enrolled in the Communication program. Participant requirements were that they were PSU students, native English speakers, and were able to engage in an everyday conversation. Participants were recruited as dyads where at a minimum they were acquainted with each other prior to meeting for the study's Phase 1 
video recording sessions. Pairing the participants with someone they already knew helped to establish a more natural and comfortable setting for the conversational interaction needed for the study (as advised by Dr. Robinson, personal communication, 2013). This type of sampling is referred to as "convenience or purposeful sampling" (Patton, 2002). According to Patton (2002), convenience sampling is a very common and appropriate sampling strategy that allows for expedient access to the recruitment of participants in a qualitative study. I recruited participants via an initial email (see Appendix A: Initial Contact Letter). After they responded to the invitation and we secured a video recording date and time, I sent each participant a Confirmation Letter with details about the research, including the Informed Consent Form to review (see Appendix B: Confirmation Letter, and Appendix C: Informed Consent Form).

A note about the sample size. I consulted with my thesis advisors about the rapidly growing amount of data accumulated from the Phase 1 video recordings and the Phase 2 interviews. As I began the analysis, it became apparent that the amount of data collected would be adequate because already 46 representational gestures had been identified from the four participants in the Phase 1 video recordings; and recurring categories, as well as new categories, began to emerge from analysis of the Phase 2 interview data (Patton, 2002). I discussed some of my findings with my advisors and we concluded that I had an appropriate sample size and amount of data to adequately address my research questions. We agreed that qualitative research is more about depth than breadth; therefore, my sample size provided enough credible data for analysis. 


\section{Data collection}

Site of study. I conducted the Phase 1 video recordings and Phase 2 interviews in the Communication Research Collaboratory, located in the Department of Communication at PSU. The Collaboratory is designed to feel like a casual living room with sofa-like chairs facing each other for relaxed conversation, a small table, a wall mirror, some wall art, and accent plants. The Collaboratory also has four visible video cameras mounted in each of its corners. Two chairs faced each other with a small table in between, and two video cameras were mounted such that each camera faced a participant front on. The Control Room, where the Phase 2 interviews were conducted, is adjacent to the Collaboratory. It is a small space filled with computers and other electronic equipment used for data collection, but provided comfortable and quiet setting for the interviews. Two chairs faced the computer monitor so that the participant and I could together view the selected segments of the Phase 1 video recording of the participant's representational gestures.

Phase 1 video recording data collection. I video recorded participant dyads for 20 minutes. A 20-minute video recording gave participants enough time to acclimate to the setting and cameras and was long enough to collect data (Wiemann, 1981; Latvala, Vuokila-Oikkonen, and Janhonen, 2000; Quan, 1990), but not too long as to fatigue participants. The first dyad, Sam and Mary (names are aliases), was video recorded on February 4, 2014. The second dyad, Melanie and Tami (names are aliases), was video recorded on February 11, 2014. I welcomed participants as they arrived for the video recording, and asked them to read the Informed Consent Form. While they were reading 
in the waiting area, I turned on the cameras in the Collaboratory. This was done as not to distract the participants once they were seated (Dr. Robinson, personal communication, Jan, 2014).

I reminded the participants that the purpose of my study was to explore everyday conversation between friends. I did not tell them what the focus of my study was so as not to make them self-conscious about their gestures (which could adversely affect the naturalness of their gesture production and the credibility of the resulting data). Then I answered any additional questions they had and they signed their Informed Consent Forms. I invited participants to make themselves comfortable in the lab, asked them to turn off their cell phones, and then to talk for 20 minutes about anything they wished. To get things started, I suggested that they talk about student life or about what makes for a good relationship (Dr. Ritchie, personal communication, 2014). At the conclusion of the Phase 1 video recording, I thanked the participants, gave them each a copy of their signed Consent Form, and scheduled their return date and time for the Phase 2 interview.

Reactivity to a video camera. Video recording as a method of data collection has been used extensively since the late 1960s (Erikson, 2011), and research shows that reactivity (camera awareness and resulting behavioral changes) to being video recorded has no serious difficulties as a method of data collection (Wiemann, 1981; Latvala et al., 2000; Quan, 1990). For example, in a noteworthy study, Wiemann (1981) concluded that unconscious behaviors, such as gestures or head-nods, were not discernibly affected by video recording. And even if there was heightened awareness of being video recorded, within minutes reactivity to it diminished. Wiemann (1981) found that participants' 
anxiety waned, and their behaviors became more natural, as they acclimated to the camera. Other studies confirm that reactivity diminishes within minutes (Latvala et al., 2000), and that over time, participants become comfortable being video recorded (Quan, 1990). While there is still some debate about reactivity during video recording, the benefits to the researcher are that observations can be captured and can provide rich data that can be reviewed multiple times for various analytical purposes (Latvala et al., 2000). As I reviewed my Phase 1 video recordings, I also noticed that after a few initial comments about the cameras or the lab setting, participants soon settled into natural conversational behaviors.

Post Phase 1 video data collection and initial analysis. After the Phase 1 video recording, and before participants returned for the Phase 2 interview, I transferred each camera's memory chips to the computer in the Control Room. I then systematically viewed the Phase 1 videos to select iconic and metaphoric gestures that would be used to stimulate comments from participants during the Phase 2 interviews. Identification of iconic and metaphoric gestures was based upon the study's established theoretical framework, and aided by the Phase 1 Representational Gesture Video Identification Form (see Appendix D) that I created for my study. Using the form, for each participant I identified the iconic and metaphoric gestures, the time on the video they occurred, the synchronized words or phrases, and I noted my initial analysis of the mental imagery associated with the gestures. This initial analysis of mental imagery became the data used to address my research question about how participant comments can affect a researcher's subsequent analysis. 
Phase 2 interview data collection. I audio recorded each 30-minute Phase 2 interview using a cell phone app called Easy Voice Recorder. I referred to the Phase 1 Video Representational Gesture Identification Form completed earlier, and to a set of guiding questions to solicit participant comments (see Appendix F: Phase 2 Guiding Interview Questions). I then played the selected segments of the Phase 1 video starting 10 seconds before the time on the video that they occurred (to give context to the gesture) to stimulate participant comments. Sam and Tami returned the same day they were video recorded, as my study was designed to accommodate. Due to participant scheduling conflicts, Melanie's and Mary's Phase 2 interviews had to be conducted on different days. Melanie's was conducted two days later (February 13, 2014), and Mary's interview was conducted 10 days later (February 14, 2014). These delayed Phase 2 interviews raised questions of participant memory and recall which are addressed in the Discussion Chapter. As each Phase 2 interview began, I strove to make the participant comfortable. I revealed that the actual focus of the study was on mental imagery and awareness associated with their representational gestures. I provided brief definitions of mental imagery, iconic and metaphoric gestures, and explained that the ensuing interview would consist of viewing segments of the Phase 1 video and having the participant respond to questions about his or her mental imagery and gestural awareness. The participants were assured that "there were no right or wrong answers."

Interview guide. I developed the Phase 2 interview questions to capture quality data in a neutral and unbiased manner, and to provide a framework in which participants could respond comfortably and accurately. Patton (2002) refers to this method as a 
"general interview guide approach." An interview guide makes best use of limited time available and makes data collection more systematic, ensuring appropriate topics will be explored (p. 340-343). I created interview questions that were based on the particular goals of my research. As Lopez (2007) notes: "Questions that the researcher has thought through ahead of time tend to work best when they are logical within the domain of the topic and address only one aspect at a time" (n.p.). Each interview question focused on a particular aspect of mental imagery and gestural awareness, but also left room for additional topics as they might emerge.

Video-stimulated comments. During the Phase 2 interview, I showed segments of the Phase 1 video recording where the participant produced an iconic or metaphoric gesture in order to stimulate participant comments. Pomerantz (2005) refers to this type of response scenario as eliciting "video-stimulated comments." Each video segment viewed included the representational gesture itself with a few seconds immediately before and after the gesture that captured the preparation, stroke, and retraction phases of the gesture, and to give the gesture semantic context. I paused, rewound, and replayed the segments as many times as participants needed. I referred to the set of guiding questions to ask participants about their hand shapes and movements and mental imagery associated with the representational gestures in question, and to talk about their gestural awareness. At the conclusion of the Phase 2 interview, I asked participants whether there was anything else they cared to add. Using this kind of question at the end of an interview can elicit additional unanticipated comments that can prove to be relevant to the data already collected (Patton, 2002, p. 379), and that might be unanticipated by the 
researcher. Finally, I thanked the participants, and each received a small token of my appreciation in the form of a Starbucks coffee card. Taken together, the video and audio recordings, the data collection forms, and transcriptions of these recordings became data for analysis.

Transcriptions. It is important to note that transcriptions of the Phase 1 video recordings and Phase 2 interview audio recordings proved essential during analysis. Electronic files were sent to and transcribed verbatim by Cabbage Tree Solutions (outsourced transcription service) into a Microsoft Word document. The transcriptions included the name of the speaker, spelled out speech fillers, such as "ums" and "ahs"; pauses shown as “..”, “...”, or “--"; and laughter indicated as "(laughter)”. I selected a level of detail for transcription that was appropriate for my study's research questions (which was focused on how participants talked about their mental imagery and gestural awareness), not the more elaborate transcription level used for other kinds of research, such as conversation analysis, that can include features such as pitch, emphasis, pauses, breath, and simultaneous speech. As Tracy and Naughten (1994) note, the type and level of transcription is dependent upon the aims of the research.

\section{Pilot Study Insights}

I conducted a pilot study using my young-adult daughter and an adult friend of mine to test the methods and procedures planned for my study. A Phase 1 video was recorded for 35 minutes in the Collaboratory, and the Phase 2 interviews were audio recorded in the Control Room for 30 minutes. With assistance from Dr. Ritchie and Dr. Robinson, I determined how to best set up the furniture and video equipment, and how to 
operate the cameras in the Collaboratory, and how to operate the viewing devices in the Control Room. The pilot study allowed me to practice working with the video equipment, interacting with the participants, and using the various data collection forms I had designed for the study. Debriefing with Dr. Ritchie, Dr. Robinson, and the study participants allowed me to determine how long the Phase 1 video recorded conversation and the Phase 2 audio recorded interview needed to be. For example, 35 minutes was too long for a Phase 1 video recording, as the pilot study participants began to show signs of fatigue (long pauses between topics after about 20 minutes). So I determined that 20 minutes would be an adequate amount of time for a Phase 1 video recording session. Based on the 30-minute pilot study Phase 2 interviews, I decided that 30 minutes was adequate for participants to respond to my interview questions. It also became evident how long it took me to review, analyze, and prepare the Phase 1 video segments for the Phase 2 interviews. I determined that I needed at least three hours before a participant returned for the Phase 2 interview because the Phase 1 video recording first had to be downloaded from the lab camera to a computer, converted to a Quick Time Movie format, and then reviewed to time stamp and to conduct an initial analysis of iconic and metaphoric gestures to be used in the Phase 2 interview.

\section{Data Analysis}

Data for initial analysis consisted of the four front on videos (one for each participant) and two audio transcriptions of the Phase 1 video dyads. Data for subsequent analysis consisted of four Phase 2 audio recorded interviews, four transcriptions of the Phase 2 interviews. Table 1 indicates the amount of video data in minutes:seconds 
generated from each dyad, and the number of 12 point, single-spaced pages of transcribed dialogue. The center column in Table 1 indicates the names of the participants in the dyad and the number of representational gestures initially identified for each. Table 2 indicates the amount of interview data per participant in terms of minutes:seconds of audio recordings and number of 12 point, single-spaced pages of transcribed dialogue.

Table 1

Data Generated from Phase 1 Video Recording

\begin{tabular}{|l|l|l|}
\hline $\begin{array}{l}\text { Minutes:seconds of Phase 1 } \\
\text { front-on video recording }\end{array}$ & $\begin{array}{l}\text { Participant dyads / \# of } \\
\text { indentified representational } \\
\text { gestures }\end{array}$ & $\begin{array}{l}\text { Number of 12 pt, single-spaced } \\
\text { pages transcribed from Phase 1 } \\
\text { video recording }\end{array}$ \\
\hline 22:50 ea. $=45: 40$ & Sam $/ 8$ and Mary $/ 12$ & 12 \\
\hline 24:53 ea. $=49: 46$ & Melanie $/ 12$ and Tami $/ 14$ & 14 \\
\hline Total $=94.06$ min:sec & Total $=46$ gestures & Total = 26 pages \\
\hline
\end{tabular}

Table 2

Data Generated from Phase 2 Interview Audio Recording

\begin{tabular}{|l|l|l|}
\hline $\begin{array}{l}\text { Minutes:seconds of Phase 2 } \\
\text { interview audio recording }\end{array}$ & Participant & $\begin{array}{l}\text { Number of 12 pt, single-spaced } \\
\text { pages transcribed from Phase 2 } \\
\text { interview audio recording }\end{array}$ \\
\hline $34: 07$ & Sam & 17 \\
\hline $30: 03$ & Mary & 15 \\
\hline $27: 41$ & Tami & 14 \\
\hline $25: 53$ & Melanie & 10 \\
\hline Total = 117.44 min:sec & & Total = 56 pages \\
\hline
\end{tabular}

Additional Phase 1 video recording data analysis. Analysis of the iconic and metaphoric gestures identified in the Phase 1 video recording was aided by the completed Representational Gesture Video Identification Forms (mentioned earlier) and the Micro Analysis Forms (see Appendix E: Micro Analysis Form) that I created based upon 
McNeill's iconic and metaphoric gesture coding scheme (1992, pp. 377-381). The Micro Analysis Form aided in the systematic description of the representational gestures that are used in the Findings chapter. As I reviewed the Phase 1 video, on the Micro Analysis Form, I notated the phrase associated with each representational gesture, the type of gesture, and bolded and underlined the words that synchronized with the gesture. Under the line, I noted the physical description of the gesture in brackets. These notations are used in the Findings chapter as well.

Phase 2 interview analysis. I read through the Phase 2 interview transcripts line by line, multiple times, labeling fragments of participant comments to tease out categories that related to my research questions about mental imagery and gestural awareness (Sheperis, Young, \& Daniels, 2010, p. 121). To address my second research question about how participant comments affect my subsequent analysis of a gesture's mental imagery, I noted how their comments compared to my initial analysis that I had made from the Phase 1 video recordings. Using the "Review Tab" and "New Comment" features in Word, I created running notes. At first pass, I gave priority to participant comments regarding motor and visual mental imagery, mental simulations, and comments related to gestural awareness. In subsequent passes I continued to make notes of categories of participant responses, any emerging categories, and how their comments differed from my initial analysis. I also added my own comments about the data as well, which Miles and Huberman (1984) refer to as "memos." Memos are insights and ideas that spring up as a researcher is pouring over the data. Memos help to identify emerging codes, categories or themes. As Miles and Huberman (1984) point out: "Memoing helps 
the analyst move easily from data to a conceptual level, refining and expanding codes further" (p.71).

Analytic Induction. Patton (2002) defines this type of analysis as "analytic induction." Analytic induction involves analysis of data that is driven by existing theory. It is part deductive and part inductive. At first, data are analyzed in terms of theorydriven concepts, as was the case in my analysis. Patton (2002) states, "After or alongside this deductive phase of analysis, the researcher strives to look at the data afresh for undiscovered patterns and emergent understanding ..." (p. 454). The analytical process is multi-layered in that one pass through the data can begin to identify a "first level of coding" and in subsequent passes a researcher can begin to see the emergence of new categories, patterns and themes (Miles \& Huberman, 1984, p. 67-68).

\section{Validity and Reliability}

Sound qualitative research is based on fundamental principles of validity and reliability (Babbie, 2007). Thirty years ago qualitative researchers Lincoln and Guba (1985) suggested that concepts of validity and reliability (associated with quantitative research) be conceptualized for qualitative research in terms of "neutrality, truth value, consistency, and applicability." Neutrality refers to the researcher's objective collection of data, i.e., "that the investigator does not set out to prove a particular perspective or manipulate the data to arrive at predisposed truths" (Patton, 2002, p.51). Truth value refers to how accurately the findings reflect the data collected. Consistency refers to whether the findings would be consistent were the study replicated. Finally, applicability refers to the transferability of the findings to other research contexts, i.e., to the extent to 
which the findings of one study can be applied or transferred to other research settings (Lincoln \& Guba, 1985, p. 81).

More recently, Tracy (2010) added to the definition, arguing that good qualitative research can be conceptualized in terms of eight key markers: 1) that the study topic strives to be relevant and significant; 2) the study uses sufficient data collection and analysis processes; 3 ) the researcher is self-reflective about biases, and is transparent about methods and challenges; 4) the study is based on concepts of trustworthiness and dependability; 5) findings could be transferable; 6) the research strives to provide contributions to theory, methodology, and application; 7) the research design and implementation is ethical; and finally 8) the methods and procedures relate to the study's goals, and there is a meaningful connection between the study's literature, research question, methods, analysis, and finding interpretations.

I strove to address and follow the principles of sound qualitative research mentioned above throughout the stages of my study. For example, I based my research questions on the goal of contributing to theory and methodology, and designed procedures and data collection tools with objectivity and replicability in mind. I followed the ethical IRB requirements of using participants in research, and conducted my study with self-transparency about the study's data collection and procedural methods, and acknowledged the challenges related to using participant comments as data. At every stage, I provided drafts of chapters to my thesis committee chair for feedback, and consulted with my other thesis committee members for guidance and feedback along the 
way as needed. I also had a fellow Communication graduate student read a draft of my thesis and provide feedback.

As data from the Phase 2 interviews reveal, the participants in my study were able to recall and talk about mental imagery and gestural awareness associated with their representational gestures in descriptive, explanatory, and self-reflective ways; and that their comments affected my subsequent analysis. These findings are provided next. 


\section{Chapter 4: Findings}

\section{Introduction}

My study explores the ways participants talk about the mental imagery and gestural awareness associated with their own representational gestures, and how using their comments as data affects analysis. During the Phase 2 interviews, participants talked about their mental imagery and gestural awareness in ways that were descriptive, explanatory, and self-reflective; and their comments served to confirm, clarify, and expand my initial analysis. Findings indicate that participant comments support theories of mental imagery and gesture production, and claims regarding embodied cognition. In addition, findings reveal participants' use of linguistic metaphors to describe their mental imagery. Thus, findings suggest that participant comments can expand analysis and understanding of representational gestures in ways that could not be achieved by my observations and analysis alone.

Thirteen representational gestures, one deictic, and one emblem (out of a total of 46 gestures I initially identified in the Phase 1 videos) are featured in this chapter as the most suitable examples to present because of the length and relevant content of the participants' comments. During the Phase 2 interviews some of the participants' comments were as short as a "yes" or "no," and other comments were outside the scope of this study. The 13 representational gestures selected for presentation in this chapter were long enough to provide a sufficient amount of data that was relevant to the research questions. I chose the deictic gesture to present because of the unanticipated finding that the participant talked about it in terms of mental imagery (not usually discussed this way 
in the literature). I chose the emblem to present because it addresses my second research question and shows how the participant's comments about it were pertinent to my initial and subsequent analyses.

Presentation of findings. To retain the context of the participants' comments and the flow of the findings, they are presented by participant (all names are pseudonyms): Sam - gestures \#1-4; Mary - gestures \#5-8; Melanie - gestures \#9-11; and Tami gestures \#12-15. Findings are presented in three steps: 1) A paragraph derived from the conversation in the Phase 1 video that sets the scenario in which the gesture was produced and that includes my initial analysis of the representational gesture's mental imagery; 2) pictures with captions of the participant's representational gesture captured from the Phase 1video, followed by its synchronized word or phrase, with a bracketed description of the gesture's hand shape, location, and movement. Step 2 also includes the participant's quotes from the Phase 1 video that synchronized with the gesture; and 3) the participant's comments about mental imagery and gestural awareness from the Phase 2 interview, and includes my subsequent analysis as a result of the their comments.

\section{Sam: Of Trombones, Derives Stuff, Refresh Buttons, and Timelines}

Gesture 1. Trombone. In the Phase 1 video, Sam talked to Mary about pursuing a degree in music performance in college. He questioned, however, the value of all the time and practice it would take to "sound good" during a performance. Synchronized with his phrase, "Do I sound good?" I observed that Sam held both fists, slightly curled at mid-torso, and moved them in a circular fashion. My initial analysis was that Sam's hands associated and iconically represented the action of a celebratory "happy dance," so 
to speak, to the abstract phrase "Do I sound good" after a lot of practice. Thus, I initially concluded that Sam's representational gesture I deemed "happy-dance-gesture" (and later renamed as you will see) was metaphoric and fueled by a motor mental image featuring arms moving about in a happy dance manner (LeBaron \& Streeck, 2000).

Figure 1. Trombone. “. . . do I sound good?” (2:24 on Phase 1video)

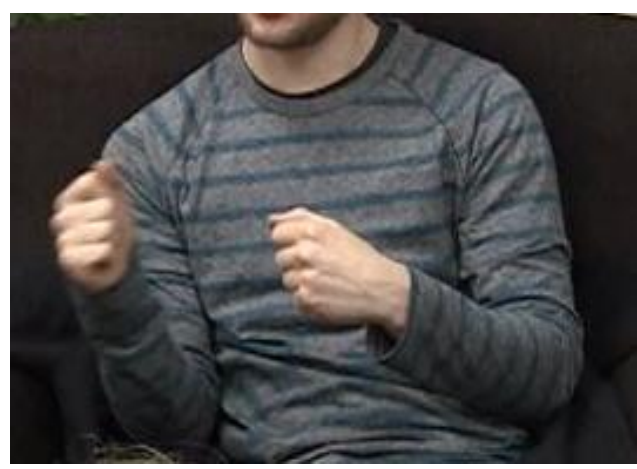

Caption 1. BH fists rotate above waist.

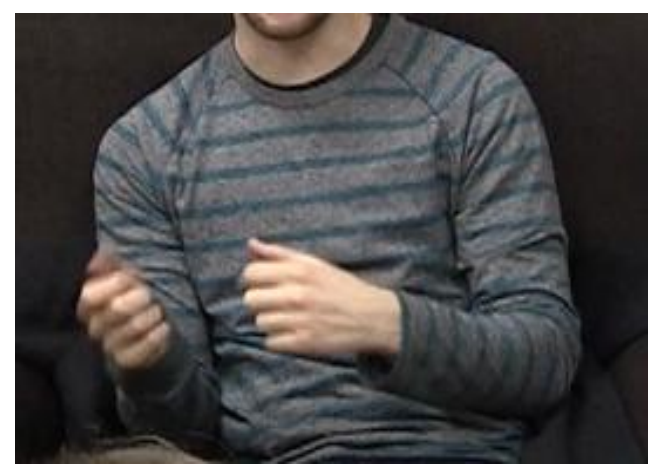

Caption 2. Fists move in small circles.

"... and the entire time you're thinking do I sound good?"

[BH in fists, slightly curled, thumbs up, under R shoulder area, slightly above waist level (Caption 1). Fists move back and forth, up and down in a small round circles (Caption 2).]

(Sam talking to Mary from line 100, Phase 1 video transcript)

It's the opposite of rewarding, like ten hours of practice a day and then you get to go play for an hour maybe for 100 bucks, and the entire time you're thinking, do I sound good? That killed me.

In the Phase 2 interview, I learned from Sam that the happy dance-gesture was metaphoric as I initially analyzed, but it was actually the playing of a trombone, and not the happy dance that I had initially interpreted (thus, it is now referred to as the trombone-gesture). When I asked Sam whether there was any mental imagery associated 
with the trombone-gesture, he said the gesture was "the playing of a trombone" and he described its mental imagery in motor terms.

(Sam from line 110, Phase 2 interview)

That was ah, really loose, mimicking of trombone playing ... Yeah, really loosely like I mean I played trombone for a while, so know exactly what the positions are and stuff ...

This finding ties to theories of motor mental imagery and embodied cognition as fuel for gesture production. LeBaron and Streeck (2000) explain how hands manipulating objects in real-time can become motor-based iconic gestures when referring to the object or action applied to it during conversation. Sam's trombone-gesture derived from real-life experience. The gesture "embodied" his actual playing of the instrument (Barsalou, 2008), i.e. the motor sensation of playing the trombone was held in memory, and then "recalled" and expressed in a metaphoric gesture as Sam associated the gesture with the abstract rhetorical question, "Do I sound good?" (Hostetter \& Alibali, 2008; LeBaron \& Streeck, 2000).

Sam also made self-reflective comments about awareness of producing the trombone-gesture:

(Sam from line 116, Phase 2 interview transcript)

I always feel stupid doing that particular gesture because most people just don't even know what a trombone is ... That one comes out when I, when I talk about a trombone, that one just comes out every time. And I guess I feel stupid making it, so it can't be conscious. (laughter)

Sam's comments suggest that his trombone-gesture is automatically produced when he talks about his trombone, and quips that he feels stupid making it, so it can't be conscious. It was produced without conscious intention (Bach et al., 2010). Schooler and 
Smallwood (2007) use the term "automatic" to define what they refer to as "nonconscious" gestures, those that are produced with little or no awareness, that are not controlled and/or deliberately produced. The finding that Sam feels stupid making the trombone-gesture, suggests that it could be an "outward symbol" of his inner mental processing, not necessarily meant for public view (McNeill, 1992, p. 109). Krauss et al. (2000) use the terms "intrapersonal" and "interpersonal" to describe the motivational functions underlying the production of a gesture. An intrapersonal gesture is more like a personal expression and is not necessarily meant to communicate to a listener. Whereas, an interpersonal gesture in one that can convey information to a listener. My subsequent analysis incorporating Sam's comments, suggests that Sam's trombone-gesture is metaphoric, fueled by motor mental imagery, is intrapersonal, and produced automatically. Sam's comments confirmed and clarified my initial analysis that it was a metaphoric gesture, but also clarified that it represented a trombone playing movement, and thus his comments expanded my subsequent analysis.

Gesture 2. Derives Stuff. In the Phase 1 video, Sam talked to Mary about how he likes the teaching style of a PSU history professor in a class he had taken. He told Mary how the professor ably derived the main points from the vast body of knowledge to cover in a lecture. As Sam said, “... he derives stuff,” in synchrony I observed that his right hand, fingers curled, moved in a pulling down motion. I analyzed Sam's derives-stuffgesture as iconic, direct, and fueled by a motor mental image of the pulling action related to the speech referent derive (McNeill, 1992; Goldin-Meadow, 2003; LeBaron \& Streeck, 2000). 
Figure 2. Derives Stuff. “. . . he derives the stuff” (15:30 on Phase 1 video)

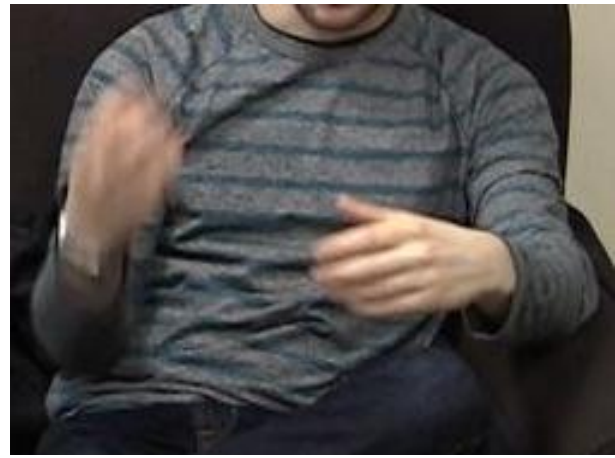

Caption 1. RH, fingers curled.

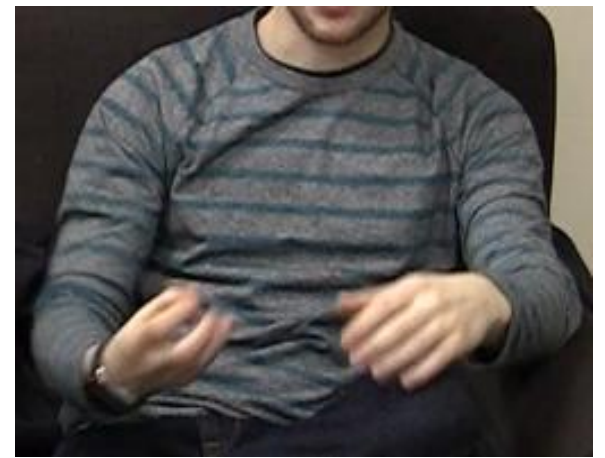

Caption 2. RH pulls down.

"... he goes over the main points and he derives the stuff . .."

[RH starts at R shoulder height, fingers curled facing up (Caption 1), then pulls down to waist height Caption 2.]

(Sam talking to Mary from line 336, Phase 1 video transcript)

Yeah, and he doesn't go over - like if you're going over history - so he doesn't go over every single detail and every date and every little battle that was fought in WW 1, whatever, but he goes over main points and he derives the stuff that we really need to know from it, and then trusts us to read the book ...

In the Phase 2 interview, Sam talked about the mental imagery of his derivesstuff-gesture in linguistic terms using descriptive adjectives and linguistic metaphors. As seen in his quote below, Sam includes the adjective "juicy" and linguistic metaphorical phrases "pulling an idea out of a knowledge cloud" and "lofty ideals." (My interview quotes are included below to show the flow of Sam's comments.)

(From line 347, Phase 2 interview transcript)

Interviewer: . . . what were your hands doing there, or what were you thinking . . ?

Sam: ... it's a pulling of like an idea out of, I guess kind of a knowledge cloud. Interviewer: A knowledge cloud? 
Sam: I don't how else to...

Interviewer: No, that's fine, that's fine. So you sort of see..

Sam: Well I don't know if... it's like pulling like the idea out of somewhere, but also that it's like it's a downward motion for me I think because it's like, out of these lofty ideals, you have this thing that's tangible and that's why I also have my hand like that because it's tangible.

Interviewer: Okay, so this idea of a knowledge cloud, um.. do you have an image in thought?

Sam: Oh, that's - no, that's just kind of why ah.. I think the, the gesture comes from.

Interviewer: Okay, okay. So you don't see a?

Sam: No, I'm not like.. I'm not, I'm not that nearly that visual. (laughter)

Sam talked about what fueled the derives-stuff-gesture more in terms of a

linguistic metaphor - the pulling an idea out of a knowledge cloud, and as the tangible idea derived from lofty ideals - rather than in terms of specific visual or motor mental imagery. His comments can be tied to cognitive theories of linguistic metaphors. For example, Lakeoff and Johnson (1980) posit that linguistic metaphors are more than a characteristic of language, that in fact people think in metaphors. In turn, Barsalou (1999), Gibbs (2006), and Boroditsky and Ramscar (2002) state that abstract concepts are grounded in, and cognitively associated with, concrete motor activities and visual perceptions derived in the real world. Sam's use of linguistic metaphors to describe his derives-stuff-gesture, indicate that the gesture was grounded in the concrete motor activity of pulling, which was associated with the abstract referents of a knowledge cloud and lofty ideals. 
Compared to my initial analysis of the derives-stuff -gesture as iconic, direct, and motor fueled, with Sam's comments as data, I would now suggest that rather than motor fueled per se, the derives-stuff-gesture can also be understood as being associated with the linguistic metaphors of a knowledge cloud and lofty ideals, because as Sam said, it wasn't a knowledge cloud mental image, but it was the idea of pulling something tangible from it. Sam's comments confirmed my initial analysis that his derives-stuff-gesture showed pulling, but they also result in an expanded subsequent analysis that linguistic metaphors were associated with his motor mental image of pulling.

Gesture 3. Brain Refresh. In the Phase 1 video, Sam told Mary about a media literacy course he took at PSU. One of the course requirements was for students to teach what they had learned in the course to middle and high school students. Sam told Mary how some of the content of the course was not new to him, but helped to refresh what he already knew. As Sam said "refreshing my brain," in synchrony I observed his hands, facing each other, waist height, moved in a circular fashion.

I analyzed the brain-refresh-gesture as metaphoric, and that Sam's circular moving hands showed the concrete action of washing that could be associated with the abstract linguistic metaphor "refreshing my brain." I drew my interpretation from Cienki and Müller (2010), who have written extensively on metaphoric gestures and how they depict abstract referents in terms of physical aspects of something concrete associated with it. For example, in one of their study observations, Cienki and Müller (2010) reported that as a speaker said the abstract word "truth," in synchrony his left hand went flat. They concluded that the flat-hand gesture depicted the physical feature of straight 
which can be associated with the abstract concept of truth, as in the metaphor straighttalk which refers to talking truthfully (pp. 10-11).

Figure 3. Brain Refresh. “. . . refreshing my brain” (9:53 on Phase 1 video)

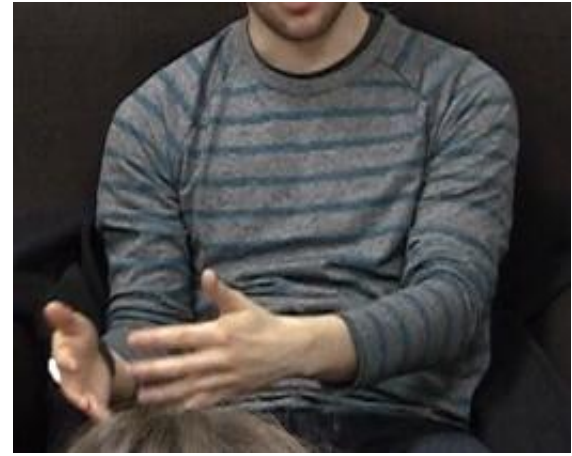

Caption 1. BH face each other.

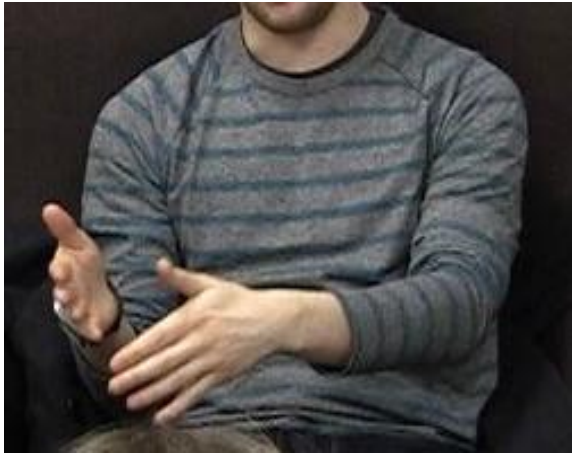

Caption 2. BH circle ccw.

"I was learning these concepts, actually over again, but refreshing my brain ..." $[\mathrm{BH}$, fingers spread, hands face toward each other, waist height under right shoulder (Caption 1), circle ccw toward body in a stirring, circular motion.]

(Sam talking to Mary from line 295, Phase 1 video transcript)

And so at the same time I was learning these concepts, actually over again, but refreshing my brain - whatever, and some of them were completely new, I was learning how to teach it to a group of middle schoolers and high schoolers.

In the Phase 2 interview, Sam talked about the mental imagery that fueled his brain-refresh-gesture as being a visual image of a refresh button on a browser, and a motor image of the stirring motion "of stirring things up."

(From line 307, Phase 2 interview transcript)

Sam: Yeah, I think that gesture I think of the refresh button on the browser, (laughter) that's pretty much the reason that I made that gesture.

Interviewer: . . . so you actually visualize then like the computer keyboard or? 
Sam: No, ah... ah.. I think it more like kind of like ah... (breathing) like the refresh button, it's kind of a stirring motion, you're.. stirring things up, bringing something new.

Sam's comments about his brain-refresh-gesture confirmed my initial analysis that the brain-refresh-gesture was metaphoric. My analysis was clarified by Sam's comments about his mental imagery depicted a motor image of stirring and a visual image of a computer refresh button, rather than what I had initially analyzed as a washing motion. In addition, my subsequent analysis was expanded to include the way he talked about his brain-refresh-gesture using linguistic metaphors, and to consider the relationship between linguistic metaphors, mental imagery, and gesture production (Gibbs, 2006; Barsalou, 2008).

Gesture 4. Timeline. In the Phase 1 video, Sam talked to Mary about extending his high school music studies into a music major at PSU, but he had come to realize that a music major was not a good choice for him. As Sam referred back to his high school graduation, in synchrony he placed his hands facing each other, thumbs up, slightly to the right of mid-torso. As I reviewed the Phase 1 video, I analyzed it as a deictic (pointing) gesture indicating a time in the past, by pointing to it in space (McNeill, 1992; Boroditsky \& Ramscar, 2002; Casasanto \& Boroditsky, 2008). Feyereisen and Harvard (1999) define deictic gestures as "pointing movements using the extended finger or the open palm to designate an object or a person, a location, or more abstract referents, such as 'the past time"' (p. 154).

Note: Deictic gestures are not representational gestures and were not a focus of my study. But I was compelled to present this gesture because of the unanticipated findings from Sam's comments during the Phase 2 interview. I initially only chose to use 
this deictic timeline-gesture in the Phase 2 interview with Sam early on as a warm-up explanatory example - to explain to Sam what a representational gesture isn' $t$ - in order to get the Phase 2 interview going. But I included the deictic timeline-gesture here as a finding because as it turned out, unexpectedly, Sam talked about mental imagery associated with it.

Figure 4. Timeline. “. . graduated out of ACMA in music” (2:05 on Phase 1 video)

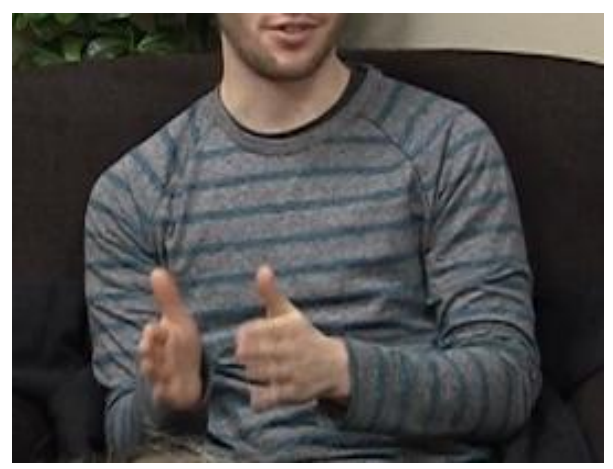

Caption 1. BH held in place.

“... graduated out of ACMA in music..."

[Palms face each other, thumbs up, waist high slightly to R side of mid-torso, held in place (Caption 1).]

(Sam talking to Mary from line 42, Phase 1 video transcript)

Yeah, I came in as, actually in PSU, - graduated out of ACMA in music - came here as a music major, did that for about a term, realized it's possibly the worst major choice in the world.

In the Phase 2 interview, Sam talked about mental imagery associated with his timeline-gesture, and his awareness of producing it. Sam described the mental imagery associated with the timeline-gesture as a timeline that he "sees" in front of him and how he refers to it as he speaks. Sam told me that it is an abstract "visual cue" that occupies a 
mental space in front of him. This comment supports a finding by Frick-Horbury (2002) that a gesture can provide an external "retrieval cue" when referring to a past event (p. 145). Sam said the timeline is more of a theoretical image that enables him to denote a segment of his life, as he stated in his quotes below:

(From line 77, Phase 2 interview transcript)

Um.. so then I like - but I think by pointing out that space, it gives me ah, kind of like a visual cue to say that, "Hey, that's a little bit of this, but I really want to talk about is something else.”

(From line 248, Phase 2 interview transcript)

I just feel like I think how linear I imagine things. (laughter) Well there seems to be a line in front of me, I point to part of the line. (laughter)

(From line 490, Phase 2 interview transcript)

It's kind of.. it's kind of theoretical, but it does sort of occupy some space in front of me.. sort of, right? I'm not like defining it, I'm just saying like.. I'm making that gesture and I'm kind assuming that there's a timeline in front of me of, of everything. . .

Sam's comments indicate that his deictic timeline-gesture had associated visual mental imagery in the form of a line that he sees in front of him and that it acts as a visual cue. This is different from the conceptualization usually found in the literature - that speakers depict the abstract concept of time using a deictic gesture that points to an actual physical space (Boroditsky \& Ramscar, 2002; Casasanto \& Boroditsky, 2008), and "predominantly talk about time as if it were horizontal" (Gentner, Imai, \& Boroditsky, 2000, p. 55) with no mention of mental imagery.

Because I chose to include the timeline deictic gesture in my findings with respect to mental imagery, following are findings with respect to gestural awareness. During the 
Phase 2 interview, Sam talked about awareness of his timeline-gesture as "spontaneously intended" (Ritchie \& Negra-Busuioc, 2014). He described it as something that he uses, and reflects upon why he uses it, adding that was intentionally produced, often used, yet unplanned.

(From line 57, Phase 2 interview transcript)

Well I think I used that gesture as kind of ah.. well that was then and kind of one segment of my life, that's very different from what I'm doing now.

(From line 73, Phase 2 interview transcript)

That kind of points into a.. this is like this bit of a segment of my, of my life story that's right here, kind of thing. That's kind of how I'm thinking of it.

(From line 89, Phase 2 interview transcript)

I did, I know I, I intentionally made that [timeline]gesture. Yeah, well, I mean... if I didn't give a lot of thought to it, it's not like, it's not a premeditated, it was just certainly intentional.

(From line 504, Phase 2 interview transcript)

It's a big thing that I reference to, yeah.

Sam's comments indicate that he is aware of using the timeline-gesture as a "visual cue," noting that he mentally sees and refers to a line he sees in front of him as he is talking. He explains that there is an intentional yet spontaneous use of the gesture to point to a segment on the timeline, i.e. there is a deliberate placement of his hands on the mental image of a timeline as he makes a reference to it when talking to Mary about his time in high school. He also said that he is aware that he often uses the mental visual cue of a timeline as he speaks. 
To summarize, Sam's timeline-gesture that I initially identified as a deictic gesture, and only wanted to use as a warm-up example to get our interview going, was an unanticipated finding that provided evidence of how participant comments can expand a researcher's initial analysis. From Sam's comments, my subsequent analysis is that his deictic timeline-gesture has associated mental imagery of a timeline in front of him, which he uses as a visual cue while speaking. Further, Sam's timeline-gesture is spontaneously intended (Ritchie \& Negra-Busuioc, 2014) and habitual in use. Finally, his timeline-gesture is as an intrapersonal form of expression as opposed to being motivated by an interpersonal communicative intention (Krauss et al., 2000).

\section{Mary: (The Texture) Of Nitpicking, Data, Regrets, and Money}

Gestures 5 \& 6. Nitpicking \& Data. In the Phase 1 video, Mary talked to Sam about her frustration of being an English major in college. She talked about not being comfortable with the scientific approach to the study of a novel because it involved nitpicking and over-analyzing it until the novel was reduced down to nothing but scientific data. As she said "nitpicking," in synchrony both hands faced each other, with fingers curled, at mid-torso, and moved in a circular fashion. As she said "data," in synchrony her hands exploded into open flat fingers, palms toward her body, right hand slightly above the left hand, at center mid-torso. I combined the analysis of the two gestures because of their close occurrence, and an unanticipated finding that Mary described both gestures in terms of textural sensations.

As I reviewed the Phase 1 video, I struggled to interpret Mary's nitpickinggesture as iconic or metaphoric. Was her gesture fueled by a direct motor- mental image 
of pulling something apart, or was it associating pulling with the abstract concept of nitpicking. Regardless, since both concrete and abstract referents can only be observed iconically, I wasn't sure what her curled fingers and the circular movements of her hands had to do with pulling. I analyzed her data-gesture as iconic and direct, possibly fueled by a visual mental image of the tangible feature of the flatness of paper. Recall the cognitive theoretical models of representational gesture production from the prior chapter that include the conceptual stage of "feature selection," in which mental imagery is first converted into "features" of visual and motor images before further cognitive processing into a representational gesture (de Ruiter, 2000; Krauss et al., 2000; Kita \& Özyürek, 2003). But I was curious about Mary's curled fingers in the nitpicking-gesture. What feature of "pulling details of a book apart" were her fingers representing? Perhaps Mary's curled fingers in her nitpicking-gesture showed a clutching of the sides of a book as one pulls, or her fingers could be the showing of a frustration emotion, given that she talked about being frustrated about how literature in college is studied?

Figure 5. Nitpicking

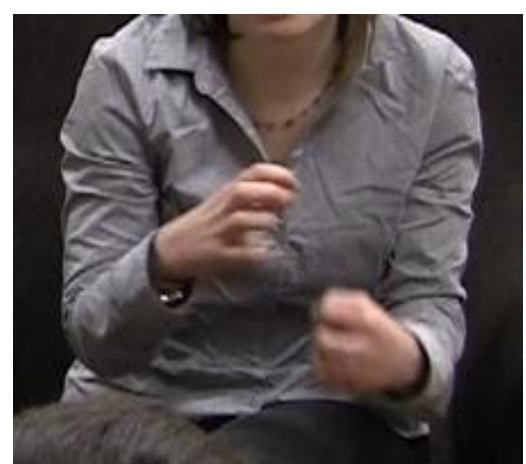

Caption 1. BH fingers curled.
Figure 6. Data (starts at 1:35, Phase 1 video)

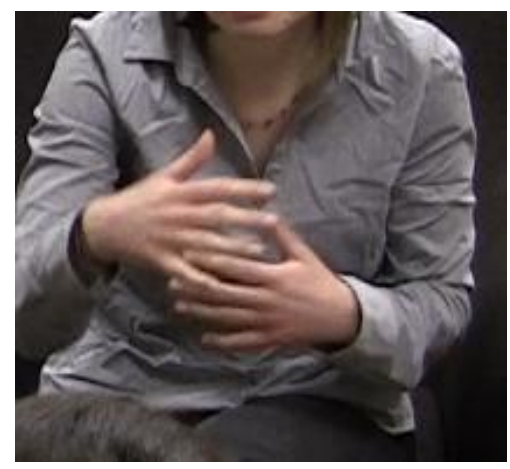

Caption 2. BH open flat. 
5: “. . l like over analyzing and nitpicking ..."

$[\mathrm{BH}$, fingers curled, facing each other between waist and chest, circling (Caption 1).]

6: "It was like just like scientific data ..."

[BH balled, knuckles touching, rotating small circles at "scientific" (carry over from nitpicking gesture) and then explode into open flat fingers, palms toward body, RH on top of LH, chest height (Caption 2).] (Mary talking to Sam, from line 33, Phase 1 video transcript)

I started out as an English major and then I switched to Social Science for a couple of reasons partly because I got frustrated with my fellow English majors including myself, like over analyzing and nitpicking until the novel's no longer a novel. It was like just like scientific data, and if I had wanted that I would be a scientist.

In the Phase 2 interview, Mary used a linguistic metaphorical phrase "pulling apart of a loaf of bread," to describe her nitpicking-gesture. Interesting to note is that her understanding of the word "nitpick" is not technically correct, as the dictionary definition of nitpick is "to criticize by focusing on inconsequential details" (Retrieved on March 26, 2015 from dictionary.com). But then she used textural terms to describe the nitpickinggesture, using words and phrases like "bumpy" and "full of lumps and clumps."

(From line 56, Phase 2 interview transcript)

... nitpicking is like pulling things apart and data is something flat.

(From line 67, Phase 2 interview transcript)

... to me the word nitpicking is like a bumpy word, and this gesture feels bumpy like full of like lumps and clumps, and like you're pulling apart like a loaf of [bread] or something.

(From line 73, Phase 2 interview transcript)

... when you think about the word data, you probably think of something black and white, and this slap gesture, to me feels black and white, because black and white are both colors that lack depth. 
... it's just more of a shape and a texture, it's much more abstract [referring to the mental image associated with data-gesture]

Mary explained to me that the data-gesture, while it showed "flat," was not based on a visual image of flatness of paper, but on a visual image of shape, and the colors black and white that she said "feel flat." Mary's comments about her mental imagery - as texture- and color-based (as opposed to visual- and motor-based) - were unexpected within the parameters of visual and motor mental imagery theory. The way Mary talked about her mental imagery as sensations of textures and colors requires me to add some additional information at this juncture.

Synesthesia. During the Phase 2 interview, Mary explained that she has a brain sensory condition called synesthesia. People with synesthesia perceive and hold in memory real-life experiences in which one of the five senses can trigger and activate another sense. According to Cytowic (2002):

It [synesthesia] denotes the rare capacity to hear colors, taste shapes, or experience other equally strange sensory fusions whose quality seems difficult for the rest of us to imagine. For example, my voice would be not just something that is heard, but also felt, seen, or tasted. A synesthete might describe music whose sound looks like "'shards of glass,', a scintillation of jagged, colored triangles moving in the visual field. Or, seeing the color red, a synesthete might also perceive the "scent" of red. (p.2)

During the Phase 2 interview, Mary shared that often she perceives real-life experiences and conflates the sensory perceptions of sight and sound into textures and colors. Mary's divulging of her form of synesthesia and her other comments during the Phase 2 interview not only clarified my initial interpretations, but provided insight and expanded my understanding about the underlying synesthesia-affected mental imagery that fueled her nitpicking- and data-gestures that the curled fingers in the nitpicking- 
gesture were fueled by mental textural sensations of lumps and clumps; and the datagesture was flat-handed, not because of a visual mental image of data on a piece of flat paper, but because of mental imagery of color - black and white - which she said she perceives as lacking in depth, like paper does.

All of Mary's comments during the Phase 2 interview clarified and expanded my understanding of her nitpicking- and data- gestures. Her comments about textural sensations and affective states also showed that her nitpicking-gesture, her data-gesture, and the regrets-gesture discussed next, support claims of "embodied cognition" (Barsalou, 1999, 2008; Poggi, 2001; Chafai et al., 2007; Hostetter \& Alibali, 2008; Gibbs 2006). Embodied cognition provides a broader framework for understanding what fuels Mary's representational gesture production, that include bodily textural sensations, and affective states, as well as motor and visual mental imagery.

Gesture 7. Regrets. In the Phase 1 video Mary talked to Sam about some small regrets she had about her college course choices. As she said "regrets," in synchrony her flat hands faced each other, in front, at hip level, as they produced a small, vertical, upand-down motion in opposite directions. As I reviewed the Phase 1 video, I analyzed Mary's regrets-gesture as metaphoric, but I was not able to interpret how the shape and movement of her hands represented a concrete feature of a mental image associated with the abstract concept of regret. I did interpret that the closeness of her hands indicated that the regrets were small in nature, as she had mentioned.

Figure 7. Regrets. "I have a number of regrets ... not like anything huge or dramatic ..." (10:24 on Phase 1 video) 


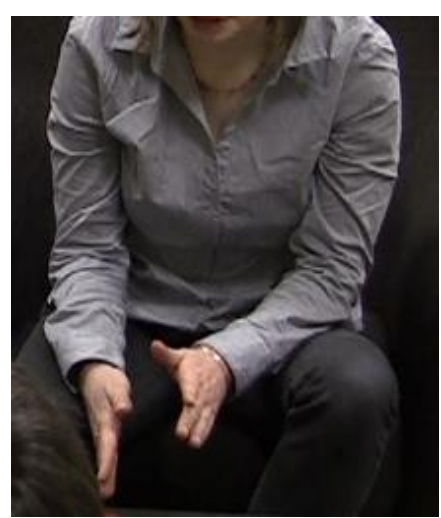

Caption 1. BH face each other.

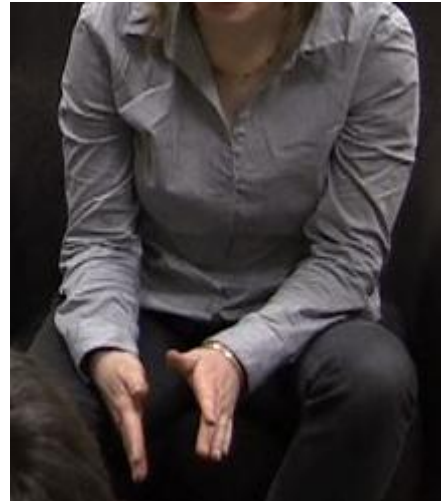

Caption 2. Hands slightly move up and down.

"I have a number of regrets..not like anything huge or dramatic ..."

[BH face each other, below waist (Caption 1), series of small vertical up-anddown motion (Caption 2).]

(Mary talking to Sam, from line 251, Phase 1 video transcript)

I have a number of regrets about my college career, not like anything huge or dramatic or... but just like little things where - I'm like I wish I'd taken the capstone like that...

In the Phase 2 interview, Mary explained that the gesture indicated tension, and she described her mental imagery as a texture that was rough, prickly, and the color gray.

(From line 271, Phase 2 interview transcript)

... I feel like maybe that's indicating tension, like this feels like a really rough texture gesture. Like I can, try to do this, I feel something kind of gray and prickly.

Mary's comments about color, textural sensations, and tension associated with her regrets-gesture, suggest that both synesthesia and embodied cognition are useful frameworks for analyzing her regrets-gesture. Her comments confirmed my initial analysis that the regrets-gesture was metaphoric, but also clarified and expanded my analysis that her regrets-gesture was fueled by visual mental imagery of color, the 
sensation of texture, as well as the affective state of tension. Mary's revelation that her hands were showing tension points to another branch of gesture study related to embodied cognition that specifically claims that gesture can be an expression of internal affective states (Poggi, 2001; Chafai, Pelachaud, \& Pelé, 2001; Krauss, Chen, \& Chawla, 1996).

Gesture and affective states. Ekman (2004) claims that emotions have an outward signal as expressed through facial expression, voice, or bodily movements (p. 45), and hand gestures have been studied as specifically linked to mental states, i.e., hands showing the emotions we feel as we talk (Poggi, 2001; Chafai et al., 2007). Mary's comments about her regrets-gesture suggest that an affective state had an effect on the shape and movement of her hands. Along similar lines, Krauss et al. (1996) argue that, while the main role of representational gestures (which he refers to as conversational hand gestures) is to aid in the formulation of speech, they also can represent “nonsemantic information," such as a speaker's affective state (p. 44).

Gesture 8. Money. In the Phase 1 video, Mary talked to Sam about not having Netflix because she doesn't watch many movies, and she feels that it would be a waste of money to purchase a subscription. As Mary said the phrase "so much money," in synchrony her left hand, with slightly curled fingers, waved from her right side at midtorso, to her left, ending slightly up and open at mid-arm height. As I reviewed the Phase 1 video, I analyzed the gesture as metaphoric, associating a concrete action of pushing money away, fueled by motor and visual mental imagery of pushing dollar bills away.

Figure 8. Money. “. . . so much money” (14:15 on Phase 1 video) 


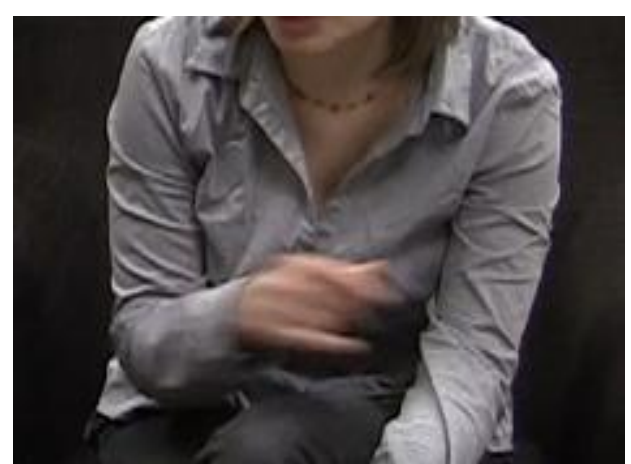

Caption 1. RH waves $L$ to $R$.

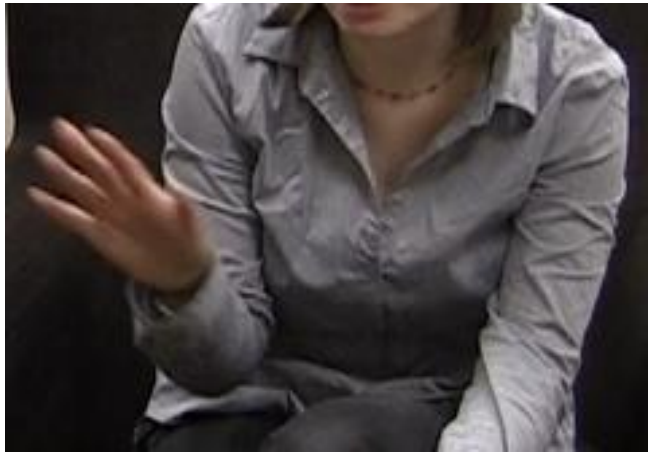

Caption 2. RH opens flat, lightly raised.

"But if I have Netflix, I would just - so much money. ..."

[RH waves horizontal from L to R (Caption 1), ending slightly higher at R, above waist height, with open fingers (Caption 2.)]

(Mary talking to Sam, from line 336, Phase 1 video transcript)

I can't say I'm a movie buff . . I've heard of them but I wouldn't bother to watch them. . . But if I have Netflix, I would just - so much money . . .

In the Phase 2 interview, Mary described her mental image associated with the money-gesture by using the linguistic metaphor, "money down the drain." Important to note is that Mary's comments reflect her synesthesia. In her comments below, she said she doesn't "see" paper dollar bills going down the drain per se (i.e. she has no specific mental image of that), but instead "feels a whoosh," and sees a gray color.

(From line 34,3 Phase 2 interview transcript)

That's like so much money down the drain, whoosh, there it goes. Whoosh.

(From line 346, Phase 2 interview transcript)

Yeah, that gesture I feel like is much more vivid, like whoosh, I can feel the air and the water pushing something away. Like a little gray, like a little gesture like doing something, whoosh, blown away, a gust of wind, or like -

(From line 353, Phase 2 interview transcript)

Oh, no, I didn't see any paper dollar bills, no, nothing like that. 
(From line 358, interview transcript)

I felt, I felt something kind of like gray water and wind pulling something down away from me.

Mary added details about how the angle of the movement of the money-gesture, to her, expressed an affective state of negativity (Poggi, 2001; Chafai et al., 2007; Krauss et al., 1996)

(From line 360, Phase 2 interview transcript)

And for me like an angle going this way is extremely negative because it's not only going down, but it's going away from me, from right to left which is the opposite of the way we read...

(From line 365, Phase 2 interview transcript)

Yeah, it's like extra negative, negative twice, like both going downhill and going like backwards.

Mary's comments confirmed, clarified and expanded my initial analysis of her money-gesture. Again, the textural sensations and colors can be understood within the framework of synesthesia and embodied cognition. With Mary's comments as data, my subsequent analysis of her money-gesture is that it is metaphoric, as I initially analyzed, but it is fueled not by the mental image of pushing dollars away but by mental imagery of a gray color, and textural sensations of air, wind, and water pulling something away. In addition, Mary's comment about the angle and direction of the movement of her moneygesture as representing something negative suggests the influence of an affective state (Poggi, 2001; Chafai et al., 2007). 


\section{Melanie: Of Skinny Houses, Snow Pants, and a Carrot}

Gesture 9. Skinny Houses. In the Phase 1 video, Melanie talked to Tami about the popularity of skinny houses in the area where she currently lives. As Melanie said, "those tall skinny houses," in synchrony both of her hands were held flat, thumbs up, facing each other, head-high and head-width apart. Her hands then moved down starting at head-height, at left shoulder, ending at her waist. As I reviewed the Phase 1 video, I analyzed the skinny-house-gesture as an iconic gesture fueled by the mental visual features of tall and skinny (McNeill, 1992; Goldin-Meadow, 2003). The gesture also directly represented the words tall and skinny - as "the visual counterpart of words" (Krauss, 1998, p. 54).

Figure 9. Skinny Houses. “. . . those tall skinny houses” (8:30 on Phase 1 video)

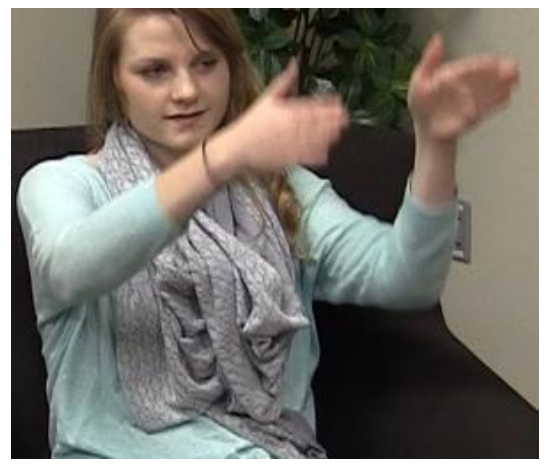

Caption 1. BH at head height.

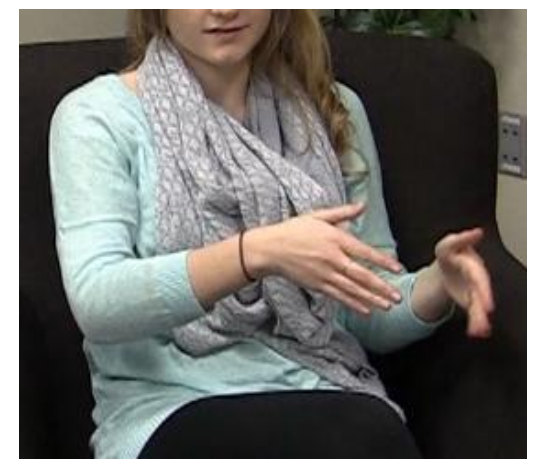

Caption 2. BH move down.

“... those tall skinny houses ..."

[BH flat, face each other head width apart, thumbs up, face height, at left shoulder (Caption 1), and move together straight down ending at waist Caption 2).]

(Melanie talking to Tami, from line 38, Phase 1 video transcript)

Those like tall, skinny houses I feel like they're so in right now. I don't know what it is. 
In the Phase 2 interview, Melanie said that while she produced the gesture, she held a mental image of a skinny house, but that the mental image was not specific to a particular house. She also said that she was aware of producing the gesture.

(From lines 46 and 53, Phase 2 interview transcript)

... I had like an image of it in my mind. ... I think that the tall, skinny houses, I do remember doing that .. .Yeah, I was thinking.. I just - we have a lot of those houses around our house, and it's like they are very just like tall and skinny, and I had like an image of it in my mind. ... not of a particular house, but about like that, of that style.

Melanie was aware of producing the skinny-house-gesture, but was unaware of producing another gesture that occurred shortly after when she said "around our house."

(From line 46, Phase 2 interview transcript)

I think that the tall, skinny houses, I do remember doing that, but then around our house [gesture], I don't remember doing that.

Later in the interview Melanie added this self-reflective remark about awareness:

(From line 316, Phase 2 interview transcript)

Ah, sometimes, I would say just specific ones [gestures] that.. um I think I have, like I have a really strong visual image for it; it's easy for me to remember like.. house is an example.

(From line 319, Phase 2 interview transcript)

Um.. yeah, I guess depending on the gesture, it determines whether or not be aware of it.

Melanie's comments about her awareness of producing the skinny-house-gesture support theories that claim a mental image that is strong and easy to remember has a significant effect on the probability that it fuels a representational gesture (Beattie \& Shovelton, 2002; Hostetter \& Alibali, 2008). Melanie's comments about mental imagery and awareness confirmed, clarified, and expanded my initial analysis that the skinny- 
house-gesture was a direct, iconic, feature-based gesture, but it was based on a nonspecific, strong mental image of a skinny house (McNeill, 1992; de Ruiter, 2000;

Krauss et al., 2000).

Gesture 10. Snow Pants. In the Phase 1 video Melanie listened to Tami as Tami talked about a time when she and her young son played in the snow. As Melanie asked Tami whether her son had snow pants, in synchrony with the words "snow pants," both hands were curled at chest height and jiggled slightly. As I reviewed the Phase 1 video, I analyzed it as an iconic, direct gesture fueled by the visual mental image of holding a pair of snow pants. I was unable to interpret the jiggling motion of her hands. Included is Tami's quote for context.

Figure 10. Snow Pants. (4:06 on Phase 1 video)

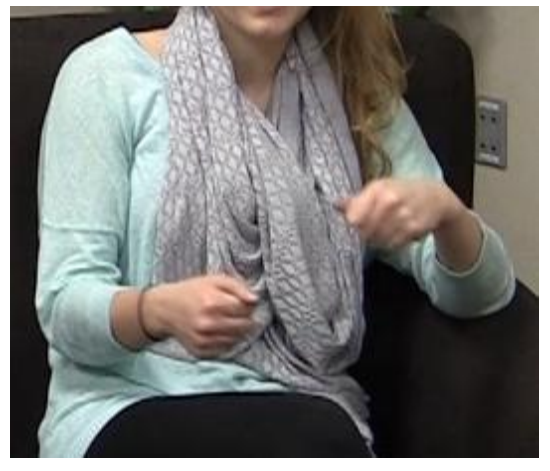

Caption 1. BH closed, L higher.

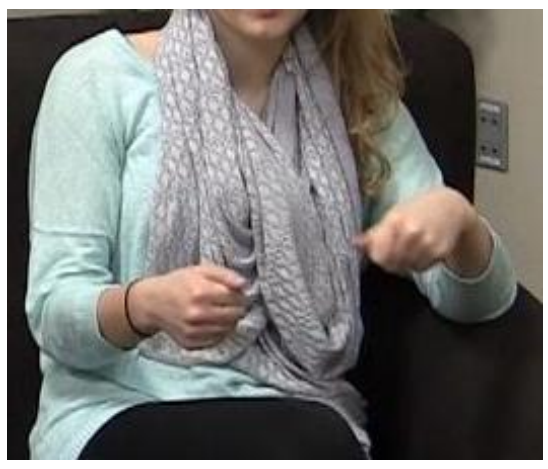

Caption 2. BH jiggle slightly.

"Does he have those ... snow pants?"

[BH closed, palms in, L slightly higher than R, mid-torso, shoulder width (Caption 1), with slight jiggle motion (Caption 2).]

(Melanie talking to Tami, from line 36, Phase 1 video transcript)

Tami: Yeah. My son uhmm ... my son and I went on a walk when like we couldn't drive anywhere. And so we went outside and we walked for mile and a half or something to find some warm food and a little coffee shop. It was so cute. 
He was just so happy the whole time. We're in like this winter wonderland with sledding.

Melanie: Cute! Does he have those... snow pants?

In the Phase 2 interview Melanie described the mental image of the snow-pantsgesture in terms of a mental simulation that included the scenario of a little boy trying to get into huge snow pants.

(From line 156, Phase 2 interview)

I think I was like.. little snow pants, like pulling up little snow pants. . . Yeah. So I imagine like I'm a little kid trying to get into these huge pants ... Yeah, I guess I could like envision like.. a little child pulling on something that's like too big for him and make his legs ... (laughter)

Melanie's comments confirmed my initial analysis that the gesture was the holding of snow pants, and clarified that the jiggling represented a mental simulation of a little kid pulling up snow pants. With Melanie's comments as data, my subsequent analysis is that her snow-pants-gesture is an iconic, additive representational gesture. The gesture is additive because Melanie's hands showed the action of pulling up snow pants, while she doesn't utter any words about the pulling up of snow pants (de Ruiter, 2000; Goldin-Meadow, 2003). Melanie's comments also expanded my subsequent analysis to suggest the she held two mental "viewpoints," one that she is a little kid pulling up snow pants, and another that she can see a little kid pulling up snow pants.

Character and observer viewpoint. Melanie's comment about imagining herself as the little kid pulling up snow pants, as well as seeing a kid pull up snow pants, is an example of one of McNeill's (1992) claims that gestures reveal the "viewpoint" of the speaker as either the "character" or the "observer" of what is being spoken. If a speaker 
holds a character viewpoint, she draws from mental perceptual and motor sensations (similar to claims of embodied cognition), and imagines herself as the agent performing the actions, as hands imitate the character or its actions that are being referred to in speech (McNeill, 1992; Holler \& Beattie, 2002, p. 36; Goldin-Meadow \& Beilock, 2010). If a speaker holds an observer viewpoint, she imagines herself as observing the character or its actions, as her hands depict features of the character or its actions (McNeill, 1992; Holler \& Beattie, 2002, p. 36).

Finally, the way Melanie talked about what fueled her snow-pants-gesture supports theoretical claims of mental imagery as mental simulations. A mental simulation, which includes both visual and motor components, can act to "prime" the production of a representational gesture (Bach et al., 2010). Alibali and Kita (2010, p.6) refer to this type of mental imagery as an "action simulation" - those physical attributes and movements from the real world that fuel the production of a representational gesture while speaking.

Gesture 11. Carrot. In the Phase 1 video, Melanie listened to Tami, as Tami talked about her young son sticking a carrot in a snowman that they had just built. As Melanie responded to Tami with "stuck a carrot," in synchrony Melanie's right hand, clenched at shoulder height, made a small stabbing and wiggling motion. As I reviewed the Phase 1 video, I analyzed Melanie's gesture as an iconic, additive gesture representing the sticking of a carrot in a snowman, as it added an additional "feature" (non-uttered) about wiggling as it occurs (Goldin-Meadow, 2003; de Ruiter, 2000). I analyzed Melanie's carrot-gesture as being fueled by the motor mental image of the 
action of sticking, i.e., sticking the carrot in the snowman. Included below in Melanie's quotes are Tami's quotes for context.

Figure 11. Carrot. "And stuck a carrot" (4:34 on Phase 1 video)

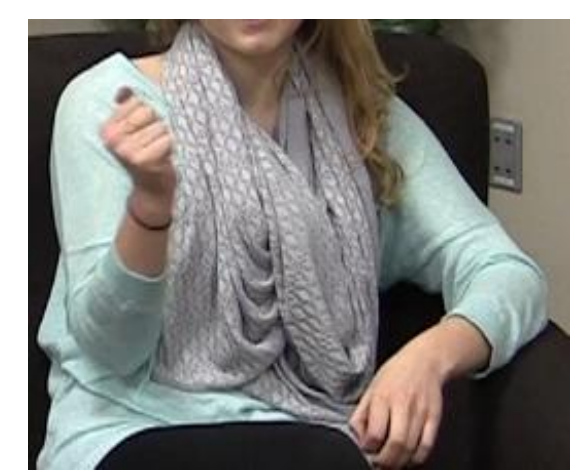

Caption 1. RH at shoulder.

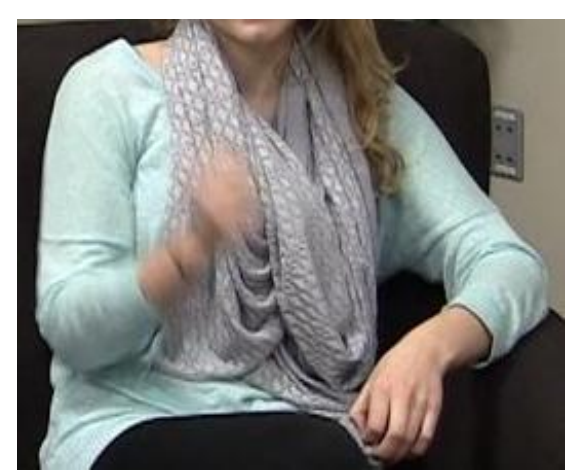

Caption 2. Wiggles and stabs down.

\section{"And stuck a carrot"}

[RH at shoulder, clenched, thumb up (Caption 1), wiggles and stabs down (Caption 2.]

(Melanie talking to Tami, from line 43, on Phase 1 video transcript)

Tami: And he [referring to her son] asked the people in the café if they have any carrots because he wants to make a snow man. And they came out with like the perfect carrot for a snow man. You know ... and it was so cute. He was so excited.

Melanie: Did you make a snow man?

Tami: Yeah, it was kind of hard though. None of the snow is sticking together. . Yeah it's more like we made a pile. (laughter)

Melanie: And stuck a carrot...

In the Phase 2 interview, Melanie's comments about mental imagery and awareness of the carrot-gesture were short and precise.

(From line 110, Phase 2 interview transcript)

... Sticking carrot in the snowman. . Yeah, maybe wiggle around a little bit. 
(From line 107, Phase 2 interview transcript)

I think I was trying to be like "stuck in it carrot" in it and then I'm just like.. revolves my hand down for some reason.

(From line 204, Phase 2 interview transcript)

Yeah, yeah, just - I mean I made a snowman in the past and it was something that I would, it's like the last thing you do is stick a carrot (laughter) into it, snowman. So.. there's something about it, I just like that image.

With respect to awareness of producing the carrot-gesture, Melanie didn't seem that she had been very aware of making the gesture because she talked about awareness using tentative phrases such as, "I think" and "for some reason." Melanie's self-reflective comment about having positive memories of making a snowman, and how she likes that mental image, suggests that there is an affective dimension to her carrot-gesture (Krauss et al., 1996; Poggi, 2001; Chafai et al., 2007) - as her last phrase "I just like that image" indicated. Melanie's comments about her carrot-gesture representing the sticking of a carrot in the snowman confirmed my initial analysis. Melanie's other comments (about a little bit of a wiggle, and the affective state of "liking" the image) resulted in an expanded subsequent analysis.

\section{Tami: Of Snow Patting, Sprung Up, Volunteers, and Pamphlets}

Gesture 12. Snow Patting. In the Phase 1 video, Tami talked to Melanie about the quality of snow she and her son used to make a snowman. As she told Melanie that the snow wasn't "sticking together," in synchrony Tami's open-fingered hands, held at chest height, moved toward each other in a patting motion. As I reviewed the Phase 1 video, I analyzed the snow-patting-gesture as an iconic and additive gesture, fueled by a 
motor mental image of the patting snow together to make it easier to work with. The snow-patting-gesture was additive because Tami didn't use any words about "patting" the snow together (LeBaron \& Streeck, 2000; Goldin-Meadow, 2003).

Figure 12. Snow Patting. "None of the snow is sticking together." (4:10 on Phase 1 video)

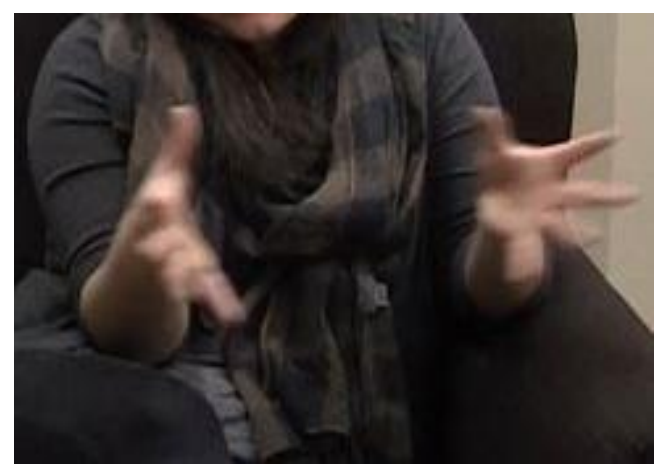

Caption 1. BH face each other.

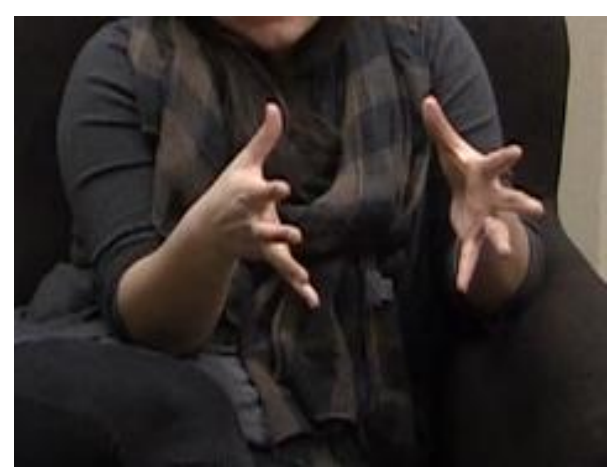

Caption 2. BH make small patting together movements.

"None of the snow is sticking together."

$[\mathrm{BH}$, fingers spread, palms facing in, thumbs up, chest height (Caption 1), series of small horizontal patting together movements (Caption 2).]

(Tami talking to Melanie, from line 16, Phase 1 video transcript)

Melanie: Did you make a snowman?

Tami: Yeah, it was kind of hard though. None of the snow is sticking together.

In the Phase 2 interview, Tami's comments confirmed my initial analysis of the snow-patting-gesture as iconic and additive. However, Tami described the mental imagery associated with the gesture, not in just motor terms, but as a mental simulation as well (Barsalou, 2008; Bach et al., 2010; Alibali \& Kita, 2010). She also talked about the mental simulation from a character viewpoint, i.e. the agent of the action (McNeill, 1992), as she saw herself trying to pat the snow together. 
(From line 36, Phase 2 interview transcript)

I saw the snow, I saw what it physically was like when we were out in the snow and so I was seeing myself trying to put it together, and it was falling apart, and then seeing the pile in my hands, what I was doing.

Tami's response to my interview question about whether she was aware of producing the snow-patting-gesture was a simple, "Uh-huh, yup." But she added a selfreflective comment that it wasn't as if she had been thinking about making the snowpatting-gesture to enhance the meaning of her words, but rather it was merely a natural flow of her conversation:

(From line 88, Phase 2 interview transcript)

I wasn't, I wasn't thinking in my head if I'm doing [patting of snow] gesture right now, she'll [a listener] understand a lot better, it was more just.. it was a natural flow of.. my conversation.

Taken together, Tami's comments confirmed my initial analysis that the gesture was iconic, motor based, and additive. Her comments expanded my subsequent analysis to include that the snow-patting-gesture was fueled by a mental simulation, with a C-VPT perspective, and was spontaneously produced as a natural flow.

Gesture 13. Sprung Up. In the Phase 1 video, Tami told Melanie how the gentrified area in Portland known as Hawthorne Street, which had been "dead" for many years, seemed to spring up out of nothing. As Tami said the linguistic metaphor, "Hawthorne sprung up," in synchrony her left hand starts out as fingers loosely closed, at her left, face height, and then springs open to a flat position, palm up. As I reviewed the Phase 1 video, I analyzed the gesture as iconic and direct, fueled by a mental motor image of something springing open. 
Figure 13. Sprung Up. "I think, like, Hawthorne sprung up" (10:01 on Phase 1 video)

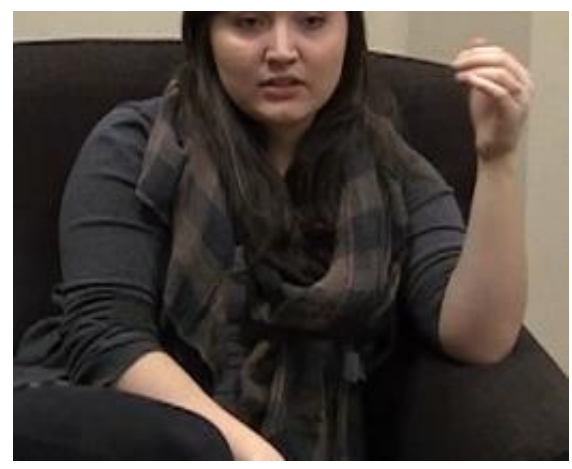

Caption 1. LH curled.

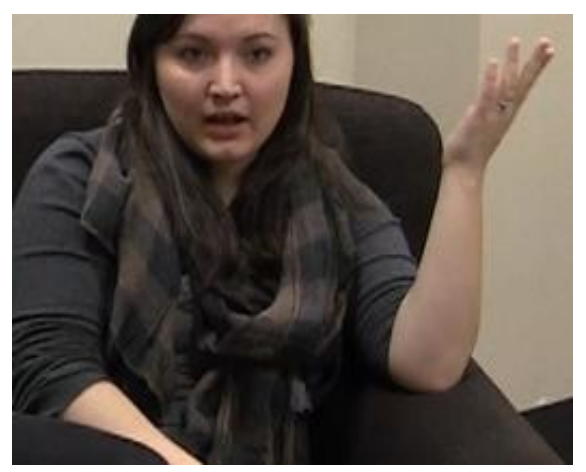

Caption 2. LH bursts open.

"I think like, Hawthorne like sprung up out of nothing."

[LH curled slightly at nose height (Caption 1), bursts open to flat (Caption 2).]

(Tami talking to Melanie, from line 176, Phase 1 video transcript)

I feel like Belmont was coming up, I think Division, I mean uhmm ... I think like Hawthorne like sprung up out of nothing.

In the Phase 2 interview, Tami explained that the sprung-up-gesture represented how the Hawthorne area, with its new restaurants, stores and shoppers, seemed to spring to life after being dead for many years. When I asked her about what her fingers and hands represented, she responded with other linguistic metaphors, talking about her gesture as "coming to life," "springing to life," and "a bud that's blooming."

(From lines 187-216, Phase 2 interview transcript)

Well in general.. there are a lot of places in Portland that have been sort of..dead and.. all the sudden, you know, a new restaurant coming in, new stores, have fun, young couples and to me it was sort of... a - Coming to life sort of?

Springing to life, coming out of it's... almost like a bud that's blooming or something maybe.

Yeah, like almost like waking up. Or coming to life. 
Unfortunately, I didn't ask her directly about the mental imagery of a bud blooming. But her comments tie to the theory that a speaker's thoughts, in the form of linguistic metaphors - can provide mental imagery that fuels the production of a representational gesture (Lakeoff \& Johnson, 1980; Barsalou, 2010; Cienki \& Mueller, 2010; Gibbs, 2006). When I asked Tami whether she was aware of producing the sprung-up-gesture, her response was a quick and simple "No" (line 200 Phase 2 interview transcript). But she added a self-reflective comment, that although is outside the scope of this study, is included here as evidence that participant comments can provide data for the study of other types of gestures as well. In the following quote, Tami says that she gestures while talking to add emphasis, as if to punctuate what she is saying, and that type of comment ties to McNeill's (1992) definition of a "beat" gesture.

(From line 207, Phase 2 interview transcript)

I think in general.. I think in general when I'm talking.. I'd like to have something accompanying it because I feel like if I were to say like, "Hey, Hawthorne really sprung up." Maybe gives a little more emphasis to it, so.. I think I was trying to give emphasis like, "It's like really sprung up"... I don't know - I.. It's like I'm punctuating the..

Tami's comments about her sprung-up-gesture confirmed my initial analysis that it was iconic and motor based. My subsequent analysis was expanded to include that she used linguistic metaphors to describe her sprung-up-gesture, and that it was used like a "beat gesture" is used for emphasis (McNeill, 1992).

Gesture 14. Volunteer. In the Phase 1 video, Tami told Melanie how her husband-to-be while living in Texas, had accepted a volunteer position in Cannon Beach, Oregon (the town she was living in at the time). He had accepted the position to be closer 
to her and to get to know her. As Tami said the words "volunteer position," in synchrony the fingers in her left hand, held at mid-torso, curled and squeezed. As I reviewed the Phase 1 video, I interpreted it as a representational gesture, possibly iconic, because it was produced in synchrony with the phrase volunteer position. But beyond that, I could not interpret, nor even speculate, what features she was mentally visualizing that would fuel the gesture. I included the findings here to show how Tami's comments about her volunteer-gesture during the Phase 2 interview were essential to my subsequent interpretation and analysis.

Figure 14. Volunteer. “. . . he got like a volunteer position” (20:11 on Phase 1 video)

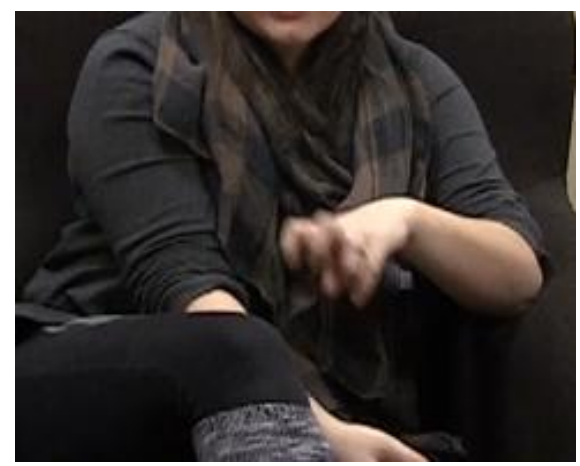

Caption 1. LH squeezes in place.

"So he flew out and got like a volunteer position. .."

[LH curled at waist height, and squeezes in place (Caption 1).]

(Tami talking to Melanie, from line 268, Phase 1 video transcript)

Can I take you out to dinner on like next Thursday? and I was like, you're in Texas. And he was like, Yeah ... so can I? and I was like, Uhmm sure. . . Seriously, just say yes and I'll be there to take you out next Thursday. And I'm finally like, sure. So he flew out and he got like a volunteer position at Cannon Beach so he'd stay for awhile because they gave them room and board. 
In the Phase 2 interview, I asked Tami about the volunteer-gesture because I was curious to find out about it, as I'd been unable to make an initial interpretation. Tami simply responded that she was "doing quotes." My quotes are included below for context.

(From line 273, Phase 2 interview transcript) Interviewer: Okay, this one, you were talking about your husband being a volunteer. That's when you said the word, "volunteer," you did something that I was..wanted to ask you about.

Tami: Hmm.. interesting.

Interviewer: Oh, let's start. Oh, let's just start over here. <plays video segment> So you said, "volun - "

Tami: Oh, wait, can you back? I just need to see what I just did.

Interviewer: Yeah. Oh, I know, it was just pretty subtle. <replays video segment>

Tami: Yeah, so.. I was doing quotes.

Interviewer: Oh, those are quotes? okay, (laughter) okay.

Tami: Yeah, I was just being lazy.

What I initially could not interpret from the Phase 1 video and felt worthy of exploring with Tami in the Phase 2 interview, was simply an "air-quote." McNeil and other scholars categorize an air-quote as an emblem. Emblems are standardized hand formations with a fixed meaning that is group or culturally shared. Lampert (2013) explains that an air-quote is a relative "newcomer" gesture in face-to-face communication and is used to indicate or "foreground" an upcoming verbal quote. A general definition of an "air-quote" is: "A gesture with raised pairs of fingers, when making a statement, to simulate quotation marks. It indicates that what is being said is ironic or otherwise not to be taken verbatim" (The Phrase Finder, 2013). 
I included this volunteer-gesture example and analysis to show how Tami's comments as data, proved essential to my subsequent analysis: Sometimes, a researcher's observations alone might not be enough to explain an observed gesture. What I initially interpreted (with speculation) as an iconic gesture, was actually an emblem. What had added to my confusion was that Tami produced the volunteer-gesture at waist level, and typically air-quote gestures are done with the hands held higher, at shoulder-width apart. Tami's comments as data, clarified my initial analysis that is was an emblem, not an iconic gesture - that she used the "lazy" air-quote gesture to mock the fact the her husband-to-be volunteered, not primarily for the work at Cannon Beach, but as a way to be near her, and for the room and board as well.

Gesture 15. Pamphlet. The last finding presented in this chapter is from a gesture Tami produced as she talked to Melanie about how she found a pamphlet about a study abroad program, and how finding that pamphlet changed her life for the better. Tami said that since the $2^{\text {nd }}$ grade she had been attending a strict French Catholic school and was not very happy there. One day she found a pamphlet about a study abroad program in Kenya and became excited about it. As Tami said "pamphlet," in synchrony both hands were closed at chest height, then opened up like the opening of a book. As I reviewed the Phase 1 video, I analyzed it as a straightforward, two-part, iconic, direct gesture fueled by a motor and visual mental imagery of holding and opening a pamphlet (McNeill, 1992; LeBaron \& Streeck, 2000; Goldin-Meadow, 2003).

I showed the pamphlet-gesture to Tami at the beginning of the Phase 2 interview only as a way for her to see an example of what I had analyzed as a simple iconic gesture 
from the Phase 1 video. I had not intended to use the pamphlet-gesture to stimulate comments from her about it during the Phase 2 interview. However, I included the pamphlet-gesture as a finding because it showed how Tami's comments provided essential data for a subsequent analysis.

Figure 15. Pamphlet. "I found a pamphlet" (21:35 on Phase 1 video)

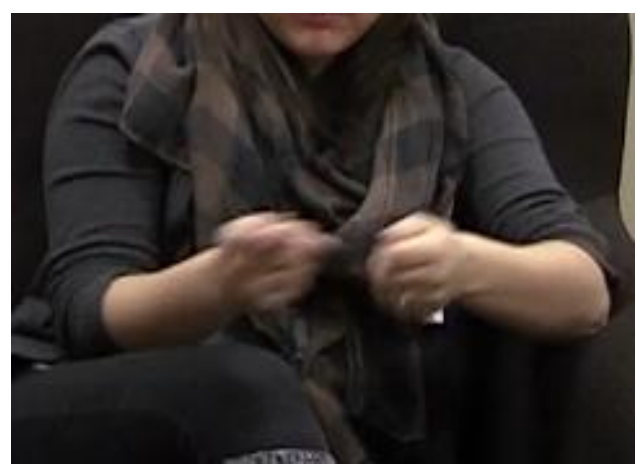

Caption 1. BH clenched.

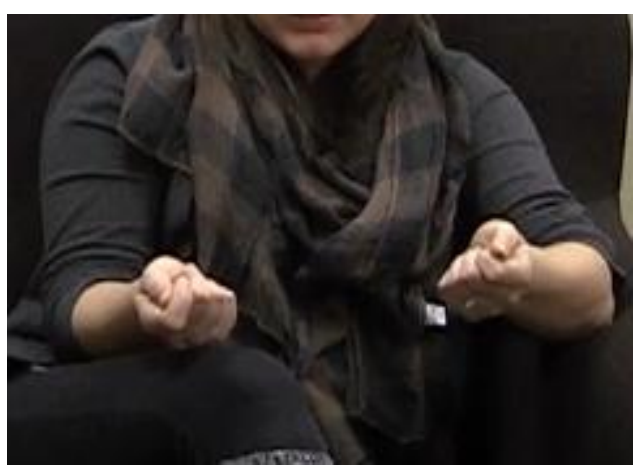

Caption 2. BH move apart.

"I found a pamphlet."

[BH clenched, palms in, at chest height, on "pam-" hands are close together (Caption 1), on "-phlet" BH clenched move apart and turn up (Caption 2).]

(Tami talking to Melanie, from line 101, Phase 1 video transcript)

And yeah, and in sixth grade I found this boarding school in Kenya. I found a pamphlet. It was a seven leaves pamphlet. And I was like, "This looks awesome!"

During the Phase 2 interview, Tami's comments became self-reflective in a story-

like manner as she talked in detail about her pamphlet-gesture. My quotes are included for context.

(From line 104, Phase 2 interview transcript)

Interviewer: Oh.. it was when you were talking about a pamphlet and this was more - I think you pretty much get it, but I always like to show a few just to.. to get people to understand what I'm looking at here. Um.. it was 21:35, so we'll start here, it's when you said the word, "pamphlet." <plays video segment> 
Interviewer: So, yup, pamphlet, (laughter) like this. Now, I mean that's a pretty straight forward gesture um.. but I guess I'm a little curious.. why, why do you think you might have gestured there as opposed to - or you know, another concrete word? I mean do you think.. do you think -

(From line 115, Phase 2 interview transcript)

Tami: Um.. that pamphlet to me.. was a, was an important turning point in my life actually. So whenever I talk about a transition I made to this boarding school, I kind of tend to tell the story about that pamphlet that I found because it was random that I just found this pamphlet and showed to my mom, and was like, "I wanted to go to this school," and then I ended up going. So I think it was more like.. it's such an insignificant thing that I'm trying to say this, actually pretty significant to me, really.

Tami's comments about her pamphlet-gesture confirmed my initial analysis that the gesture was fueled by a visual and motor mental image. Her comments reveal that the pamphlet-gesture is associated with an emotion about an important turning point in her life (Poggi, 2001; Chafai et al., 2007). Her comments confirmed my initial analysis that the pamphlet gesture is an iconic, direct, visual and motor-based gesture, and with Tami's comments, my subsequent analysis included that there was a strong emotion connected to her pamphlet-gesture.

All of the findings in this chapter will be discussed in broader terms in the following Discussion and Conclusion Chapter, along with implications, limitations, and considerations for future research. 


\section{Chapter 5: Discussion and Conclusion}

The overriding purpose of my study was to consider how participants' comments might be useful in research to enhance understanding of the mental imagery and gestural awareness associated with representational gestures produced in everyday talk. As the findings in the previous chapter indicated, with respect to my first research question, participants talked about the mental imagery and awareness of their representational gestures in ways that were descriptive, explanatory, and self-reflective. Their comments supported theoretical claims of mental imagery, embodied cognition, and gestural awareness; and added additional insights regarding mental imagery associated with a deictic gesture, and how their gestures were described in terms of linguistic metaphors, textural sensations, and affective states. With respect to my second research question, findings suggest that participant comments confirmed, clarified and/or expanded my initial analysis. This chapter begins with a summary of the findings across all of the participants' comments. It discusses implications of the findings and the study's limitations, offers suggestions for future research, and ends with concluding remarks.

\section{Summary of Findings}

To aid in the discussion of the findings, the 15 gestures analyzed in the previous chapter are shown here in two table formats. Table 3 illuminates the Phase 2 interview data in terms of categories and supporting details regarding the ways participants talked about mental imagery and gestural awareness. Table 4 shows the ways participant comments affected my initial and subsequent analysis of the representational gestures in question. 
Table 3

Findings: Participant Comments

\begin{tabular}{|c|c|c|c|c|c|c|c|}
\hline \multicolumn{6}{|c|}{ Participant comments - Mental imagery } & \multicolumn{2}{|c|}{$\begin{array}{l}\text { Participant comments - } \\
\text { Awareness }\end{array}$} \\
\hline $\begin{array}{l}\text { Identified } \\
\text { gesture }\end{array}$ & Visual & Motor & Textural & $\begin{array}{l}\text { Mental } \\
\text { simula- } \\
\text { tion }\end{array}$ & $\begin{array}{l}\text { Linguis- } \\
\text { tic meta- } \\
\text { phor }\end{array}$ & $\begin{array}{l}\text { Affective } \\
\text { state }\end{array}$ & Production \\
\hline \multicolumn{8}{|l|}{ Sam } \\
\hline $\begin{array}{l}\text { 1. Trombone } \\
\text { (metaphoric) }\end{array}$ & & $\begin{array}{l}\mathrm{x}- \\
\text { embod- } \\
\text { ied }\end{array}$ & & & & $\begin{array}{l}\text { Feels } \\
\text { stupid }\end{array}$ & $\begin{array}{l}\text { Automatic, } \\
\text { habitual } \\
\text { intrapersonal }\end{array}$ \\
\hline $\begin{array}{l}\text { 2. Derives } \\
\text { Stuff } \\
\text { (iconic, } \\
\text { direct) }\end{array}$ & $\mathrm{x}-$ mild & $\mathrm{x}$ & & & $\begin{array}{l}\mathrm{x}- \\
\text { adjective } \\
\mathrm{s}\end{array}$ & & $\begin{array}{l}\text { Associated } \\
\text { with } \\
\text { linguistic } \\
\text { metaphor } \\
\end{array}$ \\
\hline $\begin{array}{l}\text { 3. Brain } \\
\text { Refresh } \\
\text { (metaphoric) }\end{array}$ & $\mathrm{x}$ & $\mathrm{x}$ & & & $\mathrm{x}$ & & $\begin{array}{l}\text { Associated } \\
\text { with } \\
\text { linguistic } \\
\text { metaphor }\end{array}$ \\
\hline $\begin{array}{l}\text { 4. Timeline } \\
\text { (deictic*) }\end{array}$ & $\begin{array}{l}\mathrm{x}- \\
\text { visual } \\
\text { cue }\end{array}$ & & & & & & $\begin{array}{l}\text { Intrapersonal, } \\
\text { intentional, } \\
\text { spontaneous, } \\
\text { habitual }\end{array}$ \\
\hline \multicolumn{8}{|l|}{ Mary } \\
\hline $\begin{array}{l}\text { 5. Nitpicking } \\
\text { (iconic, } \\
\text { additive) }\end{array}$ & & $\mathrm{x}$ & $\mathrm{x}$ & $\begin{array}{l}\mathrm{x}- \\
\text { embod- } \\
\text { ied }\end{array}$ & $\mathrm{x}$ & $\begin{array}{l}\text { Frustra- } \\
\text { tion }\end{array}$ & $\begin{array}{l}\text { Fueled by } \\
\text { textural } \\
\text { sensation, } \\
\text { affective state }\end{array}$ \\
\hline $\begin{array}{l}\text { 6. Data } \\
\text { (iconic, } \\
\text { direct) }\end{array}$ & $\begin{array}{l}\mathrm{x} \text { - color, } \\
\text { shape }\end{array}$ & & $\begin{array}{l}\mathrm{x}-\text { feels } \\
\text { black } \\
\text { and } \\
\text { white, } \\
\text { lacks } \\
\text { depth }\end{array}$ & $\begin{array}{l}\mathrm{x}- \\
\text { embod- } \\
\text { ied }\end{array}$ & & & $\begin{array}{l}\text { Fueled by a } \\
\text { sense of } \\
\text { flatness }\end{array}$ \\
\hline $\begin{array}{l}\text { 7. Regrets } \\
\text { (metaphoric) }\end{array}$ & $\mathrm{x}-$ color & & $\mathrm{x}$ & $\begin{array}{l}\mathrm{x}- \\
\text { embod- } \\
\text { ied }\end{array}$ & & Tension & $\begin{array}{l}\text { Fueled by } \\
\text { textural } \\
\text { sensation, } \\
\text { affective state }\end{array}$ \\
\hline $\begin{array}{l}\text { 8. Money } \\
\text { (metaphoric) }\end{array}$ & $\mathrm{x}$ - color & $\mathrm{x}$ & $\mathrm{x}$ & $\begin{array}{l}\mathrm{x}- \\
\text { embod- } \\
\text { ied }\end{array}$ & $\mathrm{x}$ & $\begin{array}{l}\text { Negati- } \\
\text { vity }\end{array}$ & $\begin{array}{l}\text { Fueled by } \\
\text { multiple } \\
\text { textual } \\
\text { sensations }\end{array}$ \\
\hline \multicolumn{8}{|l|}{ Melanie } \\
\hline $\begin{array}{l}\text { 9. Skinny } \\
\text { Houses }\end{array}$ & $\begin{array}{l}\mathrm{x}-\text { not } \\
\text { specific }\end{array}$ & & & & & & $\begin{array}{l}\text { Easily } \\
\text { recalled }\end{array}$ \\
\hline
\end{tabular}




\begin{tabular}{|c|c|c|c|c|c|c|}
\hline $\begin{array}{l}\text { (iconic, } \\
\text { direct) }\end{array}$ & & & & & & strong image \\
\hline $\begin{array}{l}\text { 10. Snow } \\
\text { Pants } \\
\text { (iconic, } \\
\text { additive) }\end{array}$ & $\mathrm{x}$ & $\mathrm{x}$ & $\begin{array}{l}\mathrm{x}- \\
\mathrm{C} \text {-VPT, } \\
\mathrm{O} \text {-VPT }\end{array}$ & & & \\
\hline $\begin{array}{l}\text { 11. Carrot } \\
\text { (iconic, } \\
\text { additive) }\end{array}$ & $x$ & $\mathrm{x}$ & $x$ & & Fondness & $\begin{array}{l}\text { Tentative } \\
\text { awareness }\end{array}$ \\
\hline \multicolumn{7}{|l|}{ Tami } \\
\hline $\begin{array}{l}\text { 12. Snow } \\
\text { Patting } \\
\text { (iconic, } \\
\text { additive) }\end{array}$ & $\mathrm{x}$ & $\mathrm{x}$ & $\begin{array}{l}\mathrm{x}- \\
\mathrm{C}-\mathrm{VPT}\end{array}$ & & & $\begin{array}{l}\text { Spontaneous, } \\
\text { natural flow }\end{array}$ \\
\hline $\begin{array}{l}\text { 13. Sprung } \\
\text { Up } \\
\text { (iconic, } \\
\text { direct) }\end{array}$ & $\mathrm{x}$ & $\mathrm{x}$ & & $\mathrm{x}$ & & $\begin{array}{l}\text { No } \\
\text { awareness, } \\
\text { associated } \\
\text { with } \\
\text { linguistic } \\
\text { metaphor, } \\
\text { used to add } \\
\text { emphasis }\end{array}$ \\
\hline $\begin{array}{l}\text { 14. Volunteer } \\
\text { (emblem**) }\end{array}$ & & & & & $\begin{array}{l}\mathrm{x}- \\
\text { mocking }\end{array}$ & $\begin{array}{l}\text { Awareness } \\
\text { that it was a } \\
\text { lazy air-quote }\end{array}$ \\
\hline $\begin{array}{l}\text { 15. Pamphlet } \\
\text { (iconic, } \\
\text { direct) }\end{array}$ & $\mathrm{x}$ & $\mathrm{x}$ & & & $\begin{array}{l}\mathrm{X}- \\
\text { Strong, } \\
\text { positive, } \\
\text { story-like }\end{array}$ & $\begin{array}{l}\text { Automatic, } \\
\text { habitual }\end{array}$ \\
\hline
\end{tabular}

* Timeline-gesture included as a findings to show that a deictic gesture can have associated mental imagery.

** Volunteer-gesture included as a finding to show how a participant's comment was pertinent to analysis.

Findings in Table 3 show that of the 13 representational gestures, five were analyzed as iconic and direct (\#s 6, 9, 13, and 15); four were iconic and additive (\#s 5, 10,11 , and 12); and four were metaphoric (\#s 1, 3, 7, 8). The deictic and emblem gestures, although not representational, are included as findings because the participants' comments about them related to my research questions about mental imagery, awareness, and to the effect participant comments have on analysis. The finding for the timeline deictic gesture (\#4) was included because the participant commented on it in terms of a 
visual mental image of a line in front of him, and because he was aware of it as a visual cue that he often uses. The volunteer emblem gesture (\#14) was included in my findings to show how the participant's comments were essential to my subsequent analysis.

Further, the findings in Table 3 show that participants talked about visual mental imagery only, in four of the gestures; and motor mental imagery only, in two of the gestures. Eight of the gestures included both motor and visual mental imagery comments. Seven comments included mental simulations, five comments included linguistic metaphors, and six comments included affective states. All of the comments (except Gesture \#14) provided data that resulted in an expanded subsequent analysis of the representational gesture's mental imagery and gestural awareness.

Findings in Table 4 below show the effect participant comments had on my initial analysis of gesture type and mental imagery made from the Phase 1 video, and my subsequent analysis as a result of incorporating participant comments. Table 4 shows instances where my initial analysis of the type of gesture (iconic or metaphoric) was "confirmed" by participant comments in 14 of the 15 analyzed gestures. Table 4 also indicates that participant comments clarified and/or expanded my initial analysis of all 15 gestures.

\section{Table 4}

Participant Comments Effects on Analysis

\begin{tabular}{|l|l|l|l|}
\hline Identified gesture & $\begin{array}{l}\text { Initial Analysis } \\
\text { (Gesture type/mental } \\
\text { imagery) }\end{array}$ & $\begin{array}{l}\text { Subsequent Analysis } \\
\text { (as a result of } \\
\text { participant comments) }\end{array}$ & $\begin{array}{l}\text { Effect on Initial and } \\
\text { Subsequent Analysis: } \\
\text { Confirmed, clarified, } \\
\text { expanded }\end{array}$ \\
\hline Sam 1. Trombone & $\begin{array}{l}\text { Metaphoric, "happy } \\
\text { dance" hand }\end{array}$ & $\begin{array}{l}\text { Metaphoric, trombone } \\
\text { playing }\end{array}$ & $\begin{array}{l}\text { Confirmed, clarified, } \\
\text { expanded }\end{array}$ \\
\hline
\end{tabular}




\begin{tabular}{|c|c|c|c|}
\hline & movements & & \\
\hline 2. Derives Stuff & Iconic, pulling & $\begin{array}{l}\text { Iconic, pulling, } \\
\text { associated with } \\
\text { linguistic metaphor }\end{array}$ & Confirmed, expanded \\
\hline 3. Brain Refresh & Metaphoric, washing & $\begin{array}{l}\text { Metaphoric, stirring, } \\
\text { with mental images of a } \\
\text { refresh button, and } \\
\text { linguistic metaphor } \\
\text { influence }\end{array}$ & $\begin{array}{l}\text { Confirmed, clarified, } \\
\text { expanded }\end{array}$ \\
\hline 4. Timeline & $\begin{array}{l}\text { Deictic, no mental } \\
\text { image }\end{array}$ & $\begin{array}{l}\text { Deictic, associated } \\
\text { mental imagery, } \\
\text { spontaneous, habitual }\end{array}$ & Confirmed, expanded \\
\hline \multicolumn{4}{|l|}{ Mary } \\
\hline 5. Nitpicking & $\begin{array}{l}\text { Iconic, pulling a book } \\
\text { apart, holding its edges }\end{array}$ & $\begin{array}{l}\text { Iconic, fueled by } \\
\text { texture, linguistic } \\
\text { metaphor, affective } \\
\text { state }\end{array}$ & $\begin{array}{l}\text { Confirmed, clarified, } \\
\text { expanded }\end{array}$ \\
\hline 6. Data & Iconic, flat paper & $\begin{array}{l}\text { Iconic, black and white } \\
\text { as flat }\end{array}$ & Confirmed, expanded \\
\hline 7. Regrets & $\begin{array}{l}\text { Iconic, small (regrets) } \\
\text { and not able to discern } \\
\text { motion }\end{array}$ & $\begin{array}{l}\text { Iconic, fueled by } \\
\text { texture, linguistic } \\
\text { metaphor, affective } \\
\text { state }\end{array}$ & $\begin{array}{l}\text { Confirmed, clarified, } \\
\text { expanded }\end{array}$ \\
\hline 8. Money & $\begin{array}{l}\text { Metaphoric, pushing } \\
\text { money away }\end{array}$ & $\begin{array}{l}\text { Metaphoric, associated } \\
\text { with color and textural } \\
\text { sensations }\end{array}$ & $\begin{array}{l}\text { Confirmed, clarified, } \\
\text { expanded }\end{array}$ \\
\hline \multicolumn{4}{|l|}{ Melanie } \\
\hline 9. Skinny Houses & $\begin{array}{l}\text { Iconic, tall, skinny } \\
\text { house }\end{array}$ & Iconic, vague image & Confirmed, expanded \\
\hline 10. Snow Pants & $\begin{array}{l}\text { Iconic, holding snow } \\
\text { pants }\end{array}$ & $\begin{array}{l}\text { Iconic, putting on snow } \\
\text { pants, mental } \\
\text { simulation, } \\
\text { C-VPT, O-VPT }\end{array}$ & $\begin{array}{l}\text { Confirmed, clarified, } \\
\text { expanded }\end{array}$ \\
\hline 11. Carrot & $\begin{array}{l}\text { Iconic, sticking a carrot } \\
\text { in }\end{array}$ & $\begin{array}{l}\text { Iconic, sticking a carrot } \\
\text { in with a little wiggle }\end{array}$ & Confirmed, expanded \\
\hline \multicolumn{4}{|l|}{ Tami } \\
\hline 12. Snow Patting & Iconic, patting snow & $\begin{array}{l}\text { Iconic, mental } \\
\text { simulation, C-VPT }\end{array}$ & Confirmed, expanded \\
\hline 13. Sprung Up & Iconic, springing open & $\begin{array}{l}\text { Iconic, associated with } \\
\text { linguistic metaphor }\end{array}$ & Confirmed, expanded \\
\hline 14. Volunteer & Not able to discern & Air-quotes & Clarified \\
\hline 15. Pamphlet & $\begin{array}{l}\text { Iconic, holding and } \\
\text { opening a pamphlet }\end{array}$ & Iconic, affective state & Confirmed, expanded \\
\hline
\end{tabular}

Given that the purpose of my study was to gain a better understanding of

representational gestures used in everyday talk, these findings demonstrate the potential benefit for using participant comments as data for analysis. Participants could talk about 
mental imagery and gestural awareness, and did so in descriptive, explanatory, and selfreflective ways. Findings derived from participant comments support theoretical claims that visual and motor mental imagery, and mental simulations fuel representational gesture production, as espoused by such scholars as Hostetter and Alibali (2008), Alibali and Kita (2010), Bach et al. (2010), and LeBaron \& Streeck (2000). Findings also support claims of embodied cognition as participants talked about mental imagery and gestural awareness in terms of textural sensations and affective states as, espoused by such scholars as Barsalou (1999, 2008), Gibbs (2006), Hostetter \& Alibali (2008), Poggi (2001), and Chafai et al. (2007). Finally, findings suggest that participant comments confirmed and/or clarified my initial analyses, which resulted in expanded subsequent analyses.

\section{Implications}

Participant comments expand analysis. Because participants were able to recall and talk about their mental imagery and gestural awareness, one of the implications of my study is that soliciting participant comments about their own gestures could be considered as a possible method of credible data collection to confirm, clarify and/or expand a researcher's analysis. Participant comments supported theoretical claims of mental imagery and gesture production, as they described their mental imagery in terms of visual, motor, and mental simulations. In addition, participants' use of linguistic metaphors to describe their mental imagery, such as Sam's "knowledge cloud" and Mary's "money down the drain" metaphors (Gestures \#2 and \#8, respectively) invites the consideration of a possible connection between linguistic thinking, mental imagery, and 
gesture production. Findings imply that mental imagery can be associated with nonrepresentational gestures. such as Sam's deictic timeline-gesture (Gesture \# 4); and that what fuels a gesture isn't limited to visual or motor imagery - because participant comments indicated that textural sensations and affective states such as Mary's nitpicking- and regrets gestures (\#5 and \#7) can also be considered as fueling representational gestures.

Embodied cognition. Findings imply that embodied cognition is a useful theoretical framework in the study of representational gestures, as other scholars have argued previously (Hostetter \& Alibali, 2008; Barsalou, 1999, 2008). This theoretical framework includes mental imagery and mental simulations that are based upon perceptions, actions, sensations, and affective states acquired from real-world experiences (Barsalou, 2008; Poggi, 2001; Bach et al., 2010). Barsalou (2008) uses the term "grounded cognition" and argues that cognition is acquired and grounded in multiple ways, including perceptions, actions, and bodily states. Stored in memory as mental simulations, they are "the reenactment of perceptual, motor, and introspective states acquired during experience with world, body, and mind" (p. 618). These simulations are later reactivated (Barsalou, 2008) for use during speech planning and can become the fuel for representational gesture production (Hostetter \& Alibali, 2008). For example, analysis of Mary's comments about her nitpicking-, data-, regrets-, and money-gestures (Gestures \#5 through \#8), which include motor and visual mental imagery, textural sensations, and affective states, support claims of embodied cognition. 
Practical application. As a student and researcher of representational gestures, I can no longer not notice people's gestures co-expressed with speech. I see representational gestures as "information rich movements" - hand shapes and movements full of meaning, beyond the speaker's synchronized word or phrase (Beattie, Webster, \& Ross, 2010). As Cassell and McNeill (1991) state:

If language is a window into the mind, we find that it is not the only one; gesture is a second window or, better, a second eye, and gesture and language together provide something like binocular vision and a new dimension of seeing." (p. 377)

If representational gestures are information rich, an implication of my findings for practical application is that learning to be aware of a speaker's representational gestures could add communicative information for a listener to act upon. For example, in a study about communication between medical practitioners and patients, Rowbotham, Lloyd, Holler, and Wearden $(2012,2015)$ observed how patients gestured as they talked about their physical pain and found that at times there was a mismatch between a patient's description of his pain and his co-occurring representational gesture, as when a patient described her pain as sharp while producing a throbbing-gesture with her hands. In this case the medical practitioner could probe the patient for further clarification. Other times the researchers noted that a representational gesture added information as when a patient said, "It's a really bad headache," while producing a hammer-pounding-gesture (2015, p.75). Rowbotham et al. (2015) suggest that with gesture observation training, communication between medical practitioners and patients about pain could be promoted if the medical practitioner could learn to observe a patient's representational gestures for 
discrepancies and for additional information that patients provide while talking about their pain.

Expressions of individuality. One other implication is that each participant offered comments about his or her mental imagery and gestural awareness in personally distinguishing ways, appearing to offer a glimpse at who they are as thinking and reflective individuals. For example, I learned that Sam feels "stupid" producing the trombone-gesture (Gesture \#1), and that his trombone- and timeline- gestures (Gestures $\# 1$ and \#4) are habitually produced. Sam also appears to think in linguistic metaphors, as when he described his derives-stuff- and brain-refresh-gestures (Gestures \#2 and \#3). Mary appears to have the most embodied way of describing mental imagery as she talks about it in terms of abstract shapes, colors, textural sensations, and affective states (Gestures \#5-8). Finally, Melanie and Tami also appear to be individuals who reflect on affective states as they describe the mental simulations associated with their snow-pants-, carrot-, and pamphlet-gestures (Gestures \#10,\#11, and \#15) in terms of positive emotions.

\section{Limitations}

A primary limitation to consider with respect to my study is my lack of experience as a researcher. Lacking experience in research design, implementing processes for data collection and analysis, operating video and audio equipment, and conducting interviews, needs to be taken into account as the findings in my study are reviewed. In addition, the small sample size and the use of participant comments as data makes my study at most to be considered as "exploratory research" (Patton, 2002, p. 
193). As I delved into the literature and into this line of inquiry and methodology of exploring mental imagery using participant comments as data, I found that it is a seldomused approach and method for studying the mental imagery and gestural awareness of representational gestures. It may be because using participant comments as data raises questions of validity of data and resulting findings, which are discussed next.

Validity of participant comments as data. A key question is this: Can my study that uses participant comments as data for analysis make credible and valid research claims? As mentioned earlier, there is an ongoing discussion between CA scholars about the limitations to validity of a study's findings and analytical claims that are based on participant comments. CA scholars assert a range of arguments about using participant comments as data, from credible and complementary, to irrelevant and disconnected from the aims of the research (Pomerantz, 2012; Anataki, 2012; Ford, 2012; Waring et al., 2012). They debate about the connection between what a researcher observes and analyzes, to what a participant recalls and self-reports. When using participant comments as data, Pomerantz (2012) argues that it is the analytic aims of the research that determine whether participant comments are relevant and useful for analysis. If there is a questionable analytical connection between the research questions and data collected from participant comments, there is risk to the validity of the findings, and at minimum, a potentially unfocused analysis. Key discussion points between CA scholars in the debate about the validity of participant comments include issues regarding: 1) participant memory and recall; and 2) the social nature of an interview and how that affects participant comments. 
Memory and recall. Because gesture scholars generally agree that representational gestures are unplanned and unwittingly produced during real-time speaking, speakers engaged in everyday talk may not be necessarily aware they had produced a representational gesture, or that they were consciously thinking about the mental imagery associated with it at that moment (Ekman \& Friesen, 1969; McNeill, 1992). Bavelas (1994) states, “. . . each gesture is typically made, decoded, acted upon, and forgotten in a matter of seconds, usually without ever entering long-term memory or metalinguistic awareness" (p. 202).

My study relied on Phase 1video recordings taken at an earlier time to stimulate participant comments during the Phase 2 interviews that were conducted at a later time. Participants had to draw on memory to recall and make comments on their mental imagery and gestural awareness. And recall that while Sam and Tami were able to return for their Phase 2 interviews the same day, due to scheduling conflicts Melanie's and Mary's Phase 2 interviews had to be conducted two and 10 days later, respectively. CA scholar Anataki (2012) argues that memory and recall itself can be an unsatisfactory source of evidence. At risk is that a researcher may be too trusting that a participant's video stimulated comments represent what actually transpired (p. 493). Another consideration is as Pomerantz (2005) states: participant comments can simply be "artifacts of watching the videotape" (p.101), in other words, a participant's comments may be created in response to the interview questions.

For example, in my study during the Phase 2 interviews some participants used words and phrases that could seem to suggest issues of recall. When I asked them 
questions about their mental imagery and gestural awareness, they used phrases, such as "I think...I guess ... I feel like it was ..." A specific example of recall and the possibility of creating a response is when Melanie said, "Maybe it was..." or "Yeah, I think I was trying to like..." Another example of recall and creating a response was when Mary said, "So I would have never been thinking of this when I was doing it, but watching myself do it, it seems really obvious that ..."

The social setting of an interview. Another limitation is the effect of the social nature of an interview. Scholars argue that because an interview can be considered as a social activity, it could be that participant comments are a reflection of the social nature between the researcher and the participant - that is, the interaction between the interviewer and the interviewee, where a participant's responses or comments can be motivated by social motives resulting in data that has no relationship to the research question (Mills, 1940; Ford, 2012). Regarding this consideration, CA scholar Ford (2012) asks and concludes:

So what is to be made of participants' self-reports of their interactional practices? And what of their perceptions and experiences as they view video records of their actions? In terms of CA's goals, such moments are new opportunities to inspect the joint construction of social activity; they are interactions between an interviewer and an interviewee, and results can be studied as interactions in their own right to help us understand practices for doing interviews. (p. 511)

Transferability. Lastly, a limitation of my study concerns the transferability of the findings to other research (Lincoln \& Guba, 1985). Gesture scholars label and define representational gestures in different ways. My study employed the McNeill typology and definitions of representational, iconic and metaphoric gestures - while other scholars use 
different typologies and definitions for their studies, some even considered to be problematic, and of questionable utility and reliability (McNeill, 1992, 2000; Krauss et al., 2000; de Ruiter, 2000; Becvar et al., 2008). For example, there are myriad terms I found in the literature to define hands that physically depict visual and motor features of speech referents, and attributed to scholars, such as "symbolic" (Wundt, 1922); "physiographic" and "ideographic" (Efron, 1941); "illustrators" (Ekman \& Friesen, 1969); "topic" (Bavelas, 1994); "lexical" (Krauss et al., 2000); and "imagistic (Beattie \& Shovelton, 2002). Even definitions about the distinction between iconic and metaphoric gestures can be "somewhat problematic" according to Becvar et al. (2008, p. 121). Thus, in order for the methods and findings of my study to be applicable and transferable to another study, definitions of gestures used in my study would have to be translated to an accommodating typology.

\section{Future Research}

My study has opened a line of inquiry into the study of representational gestures, mental imagery, and gestural awareness that uses participant comments as data for analysis. Future research could continue to explore ways participants talk about mental imagery and gestural awareness; to test the credibility of comments as data; and to extend theories regarding the nature of visual, motor, and simulated mental imagery (e.g., Alibali \& Kita, 2010; Hostetter \& Alibali, 2008; Gibbs, 2006; Barsalou, 1999). Using participant comments as data, future research could explore aspects of gestural awareness such as levels of awareness, and the intrapersonal or interpersonal communicative intentions and 
goals of representational gesture use (e.g., Ekman \& Friesen, 1969; McNeill, 1985, 1992;

Bavelas, 1994; Krauss et al., 2000; Goldin-Meadow, 2003; Hostetter \& Alibali, 2008).

Research could continue to use embodied cognition as the primary theoretical framework to more fully explore how senses like hearing, smell, and taste might influence representational gesture production. Other research could explore the effects that linguistic metaphors have on the production of representational gestures, or could explore the association between non-representational gestures, such as deictic gestures (as seemed to be evident from Sam's comments), and mental imagery. Finally, research could be conducted on participants with brain conditions such as synesthesia (as participant Mary has), to explore how different ways of thinking affect representational gesture production.

All of my study's Phase 1video recordings, Phase 2 interview audio recordings, and transcriptions are available and could be used in the future as primary data for any number of observational studies. For example, a researcher could review the Phase 1video recordings to study such characteristics as gaze, facial expressions, posture, and other intra- or interpersonal communicative dynamics. Or a review of the audio recorded Phase 2 interviews could reveal additional data for analysis pertaining not only to mental imagery and gestural awareness, but to the other types of comments that participants provided that were outside the scope of my study. The topics of observational studies using the video and audio recordings and transcripts are seemingly endless. 


\section{Conclusion}

My study explores mental imagery and gestural awareness through the eyes of the participants. As participants talked, listening to their comments was like seeing through a "window into their minds" (Cassell \& McNeill, 1991). While their descriptive, explanatory, and self-reflective comments have the potential to offer information and insights about their mental imagery and gestural awareness, the analytical complexities of using participant comments as data must be considered. Bavelas (1994) understood the complexities of studying gesture when she asserted that doing so was not simply about the researcher's observations and classifications of the movements of a speaker's hands, but that the study of gesture involves "an inference about its meaning and function" (p. 201). To help gain access to this inference, I obtained participant comments. From their comments, I was able to discover ways participants talked about their mental imagery and gestural awareness, and how their comments affected my analysis. To that end, my study addressed its research questions, and offers a contribution to research to suggest that using participant comments about their mental imagery and gestural awareness might enhance our understanding of representational gestures used in everyday talk.

Finally, a personal note about conducting this study is that I came to realize that as a speaker's representational gestures express speech content, they can also reveal things about the speaker's unique life experiences, perceptions, actions, and more - only if we can learn to see representational gestures in that way. 


\section{References}

Adams, J. K. (1957). Laboratory studies of behavior without awareness. Psychological Bulletin, 54(5), 383.

Alibali, M. (2005). Gesture in spatial cognition: Expressing, communicating, and thinking about spatial information. Spatial Cognition and Computation, 5(4), 307331.

Alibali, M. W., \& Kita, S. (2010). Gesture highlights perceptually present information for speakers. Gesture, 10(1), 3-28.

Anataki, C. (2012). What actions mean, to whom, and when. Discourse Studies, 14(4), 493-498.

Bach, P., Griffiths, D., Weigelt, M., \& Tipper, S.P. (2010). Gesturing meaning: Nonaction words activate the motor system. Frontiers in Human Neuroscience, 4 , article 214.

Baker L. (2006). Observation: A complex research method. Library Trends, 55(1), 171-189.

Barsalou, L. W. (1999). Perceptual symbol systems. Behavioral \& Brain Sciences, 22, $577-660$.

Barsalou, L. W. (2008). Grounded cognition. Annual Review of Psychology, 59, 617-645

Bavelas, J. (1994). Gestures as part of speech: Methodological implications. Research on Language and Social Interaction, 27(3), 201-221.

Baumeister, R. F. \& Masicampo, E. J. (2010). Conscious thought is for facilitating social and cultural interactions: How mental simulations serve the animal - culture interface. Psychological Review, 117, 945-971.

Beattie, G., \& Shovelton, H (1999). Mapping the range of information contained in the iconic hand gestures that accompany spontaneous speech. Journal of Language and Social Psychology, 18(4), 438-462. 
Beattie, G., \& Shovelton, H. (2002). What properties of talk are associated with generation of spontaneous iconic hand gestures? British Journal of Social Psychology, 41, 403-417.

Beattie, G., Webster, K., \& Ross, J. (2010). The fixation and processing of the iconic gestures that accompany talk. Journal of Language and Social Psychology. Published online 8 March 2010 at http://jls.sagepub.com/content/early/2010/02/15/0261927X09359589

Becvar, A., Hollan, J., \& Hutchins, E. (2008). Representational gestures as cognitive artifacts for developing theories in a scientific laboratory. Resources, CoEvolution and Artifacts, 117-143.

Boroditsky, L., \& Ramscar, M. (2002). The roles of body and mind in abstract thought. Psychological Science, 13(2), 185-189.

Casasanto, D., \& Boroditsky, L. (2008). Time in the mind: Using space to think about time. Cognition, 106, 579-593.

Cassell, J., \& McNeill, D. (1991). Gesture and the poetics of prose. Poetics Today, 12(3), 375-404.

Cassell, J. (1998). A framework for gesture generation and interpretation. Computer Vision in Human-Machine Interaction, 191-215, Cipolla, R., \& Pentland, A., (Eds.). Cambridge: Cambridge University Press.

Chafai, N.E., Pelachaud, C., \& Pelé, D. (Dec., 2007). A case study of gesture expressivity breaks. Language Resources and Evaluation, 41(3/4), 341-365.

Cienki, A., \& Müller, C. (2010). Metaphor, gesture, and thought. In Gibbs, R. W. (Ed.), The Cambridge Handbook of Metaphor and Thought, 483-501. Cambridge University Press.

Cole, J., Gallagher, S., \& McNeill, D. (2002). Gesture following deafferentation: A phenomenologically informed experimental study. Phenomenology and the Cognitive Sciences, 1(1), 49-67. 
Cytowic, Richard E. (2002). Synesthesia: A union of the senses (2nd Edition). Cambridge, MA, USA: MIT Press, ProQuest ebrary. Web. 15 November 2014.

De Ruiter, J. P. (2000). The production of language and speech. In McNeill, D. (Ed.), Language and Gesture. Cambridge University Press.

Efron, D. (1941). Gesture and environment: A tentative study of some of the spatiotemporal and linguistic aspects of the gestural behavior of eastern Jews and southern Italians in New York City, living under similar as well as different environmental conditions. King's Crown Press.

Ekman, P., \& Friesen, W.V. (1969). The repertoire of nonverbal behavior: Categories, origins, usage, and coding. Semiotica, 1(1), 49-98.

Ekman, P. (2004). Emotional and conversational nonverbal signals. In Larrazabal, J. M., Pérez Miranda, L.A. (Eds.). Language, Knowledge and Representation. Kluwer Academic Publishers: Netherlands.

Erickson, F. (2011). Uses of video in social research: A brief history. International Journal of Social Research Methodology, 14(3), 179-189.

Feyereisen, P., \& Havard, I. (1999). Mental imagery and production of hand gestures while speaking in younger and older adults. Journal of Nonverbal Behavior, 23, 153-171.

Ford, C. E. (2012). Clarity in applied and interdisciplinary conversation analysis. Discourse Studies, 14(4) 507-513

Frick-Horbury, D. (2002). The effects of hand gestures on verbal recall as a function of high- and low-verbal-skill levels. The Journal of General Psychology, 129(2), 137-147.

Friedlander, J. Abstract, concrete, general, and specific terms. Retrieved June 16, 2012 from http://grammar.ccc.commnet.edu/grammar/composition/abstract.htm

Gentner, D., Imai, M., \& Boroditsky, L. (2002). As time goes by: Evidence for two systems in processing space $\rightarrow$ time metaphors. Language and Cognitive Processes, 17(5), 537-565. 
Gibbs, R. W., Jr. (1999). Intentions in the experience of meaning. New York \& Cambridge, UK: Cambridge University Press.

Gibbs, R. W. (2006), Metaphor interpretation as embodied simulation. Mind \& Language, 21: 434-458. doi: 10.1111/j.1468-0017.2006.00285.x

Goldin-Meadow, S. (2003). Hearing gesture: How our hands help us think. The Belknap Press of Harvard University Press: Cambridge, Mass.

Goldin -Meadow, S., \& Beilock, S.L. (2010). Action's influence on thought: The case of gesture. Perspectives on Psychological Science (1745-6916), (5)6, 664-674.

Guest, G., Namey, E.E., \& Mitchell, M. L. (2012). Collecting Qualitative Data: A Field Manual for Applied Research. Sage.

Hadar, U., \& Pinchas-Zamir, L. (2004). The semantic specificity of gesture: Implications for gesture classification and function. Journal of Language and Social Psychology, 23(2), 204-214. (0261-927X), 23(2), 204.

Holler, J., \& Beattie, G. (2002). A micro-analytic investigation of how iconic gestures and speech represent the core semantic feature in talk. Semiotica, 142:1/4, 31-69.

Hostetter, A. B., \& Alibali, M. W. (2008). Visible embodiment: Gestures as simulated action. Psychonomic Bulletin \& Review 15(3), 495-513.

Kendon, A. (1980). Gesticulation and speech: Two aspects of the process of utterance. The Relationship of Verbal and Nonverbal Communication, 25, 207227.

Kendon, A. (1982). The study of gesture: Some remarks on its history. Recherches Semiotiques/Semiotic Inquiry, 2, 45-62.

Kendon, A. (2000). Unity or duality? In McNeill, D. (Ed.), Language and Gesture, 4763. Cambridge: Cambridge University Press.

Kendon, A. (2004). Gesture: Visible action visual action of utterance. Cambridge: Cambridge University Press. 
Kita, S., \& Özyürek, A. (2003). What does cross-linguistic variation in semantic coordination of speech and gesture reveal?: Evidence for an interface representation of spatial thinking and speaking. Journal of Memory and Language, 48 (1), 16-32.

Krauss, R. M., Chen, Y., \& Chawla, P. (1996). Nonverbal behavior and nonverbal communication: What do conversational hand gestures tell us? Advances in Experimental Social Psychology, 28, 389-450.

Krauss, R.M. (1998). Why do we gesture when we speak? Current Directions in Psychological Science, 7(2), 54-60.

Krauss R. M., Chen, Y., Gottesman, R. F. (2000). Lexical gestures and lexical access: A process model. In McNiell, D. (Ed.), Language and Gesture, 261-283. Cambridge; New York: Cambridge University Press.

Lakoff, G., \& Johnson, M. (1980). Metaphors we live by. Chicago, IL: University of Chicago Press.

Lampert, M. (2013). Say, be like, quote (unquote), and the air-quotes: interactive quotatives and their multimodal implications. English Today, 29(04), 45-56.

Latvala, E., Vuokila-Oikkonen, P. and Janhonen, S. (2000).Videotaped recording as a method of participant observation in psychiatric nursing research. Journal of Advanced Nursing, 31: 1252-1257. doi: 10.1046/j.1365-2648.2000.01383.x

LeBaron, C., \& Streeck, J. (2000). Gestures, knowledge, and the world. In D. McNeill (Ed). Language and Gesture, 118-138. Cambridge: Cambridge University Press.

Lincoln, Y.S., \& Guba, E.G. (1985). Naturalistic inquiry. Newbury Park: Sage.

Lopez, M. M. (2007) Interview techniques. Encyclopedia of Epidemiology. Sage. Retrieved Oct. 21, 2013 from. http://www.sage ereference.com/view/epidemiology/n241.xml.

Lutfey, K., \& Maynard, D. W. (1998). Bad news in oncology: How physician and patient talk about death and dying without using those words. Social Psychology Quarterly, 61, 321-341. 
Major, M. (2007). Artist identity and the role of criticism. Unpublished manuscript. Department of Communication, Portland State University, Portland, OR.

McClave, E. (1998). Pitch and manual gestures. Journal of Psycholinguistic Research, 27(1), 69-89.

McNeill, D. (1985). So you think gestures are nonverbal? Psychological Review, 92(3), 350-371.

McNeill, D. (1992). Hand and mind: What gestures reveal about thought. Chicago: University of Chicago Press.

McNeill, D. (2000). Language and gesture. Cambridge: Cambridge University Press.

McNeill, D. (2005). Gesture and thought. University of Chicago Press.

McNeill, D. (2005) Essay on gesture and thought. Retrieved Sept. 15, 2012 from http://mcneilllab.uchicago.edu.proxy.lib.pdx.edu/pdfs/gesture.thought.fundamenta ls.pdf

McNeill Lab. Retrieved June 12, 2012 from

http://mcneilllab.uchicago.edu/writing/growth_points.html

Miles, M., \& Huberman A. (1984). Qualitative data analysis. Thousand Oaks: Sage.

Mills, C.W. (1940). Situated actions and vocabularies of motive. American Sociological Review, 5(6), 904-913.

Müller C. (1998). Redebegleitende Gesten. Kulturgeschichte - Theorie Sprachvergleich. Berlin Verlag Arno Spitz: Berlin.

Parrill, F., Bullen, J., \& Hoburg, H. (2010). Effect of input modality on speech-gesture integration. Journal of Pragmatics, 42, 3130-3137.

Patton, M. Q. (2002). Qualitative Research \& Evaluation Methods, $3^{\text {rd }}$ Edition. Sage. Poggi, I. (2001). From a typology of gestures to a procedure for gesture production. In Gesture Workshop, 158-168. Springer Verlag. 
Pomerantz, A. (2005). Using participants' video stimulated comments to complement analyses of interactional practices. Conversation and cognition, 93-113.

Pomerantz, A. (2012). Do participants' reports enhance conversation analytic claims? Explanations of one sort or another. Discourse Studies, 14(4), 499-505. Sage.

Quam, KF (1990). Evaluation of patient comfort during a videotaped office visit. Evaluation and program planning (0149-7189), 13 (4), 395-398.

Ritchie, L. D., \& Negrea-Busuioc, E. (2014). Now everyone knows I'm a serial killer: Spontaneous intentionality in conversational metaphor and story-telling. Metaphor and the Social World, 4(2), 174-198.

Rowbotham, S., Lloyd, D.M., Holler, J., \& Wearden, A. (2012). How do we communicate about pain? A systematic analysis of the semantic contribution of co-speech gestures in pain-focused conversations. Journal of Nonverbal Behavior, $36,1-21$.

Rowbotham, S., Lloyd, D.M., Holler, J., \& Wearden, A. (2015). Externalizing the private experience of pain: A role for co-speech gestures in pain communication? Health Communication, 30(1), 70-80, DOI:10.1080/10410236.2013.836070

Schooler, J., \& Smallwood, J. (2007). Meta-awareness. In R. Baumeister, \& K. Vohs (Eds.), Encyclopedia of Social Psychology, 563-565. Thousand Oaks, CA: SAGE Publications, Inc.

Sheperis, C. J., Young, J. S., \& Daniels, M. H. (2010). Counseling research: Quantitative, qualitative, and mixed methods. Pearson Education Inc.

SIL International. What is a referent? Retrieved June 12, 2014 from http://www.sil.org/linguistics/GlossaryOfLinguisticTerms/WhatIsAReferent.htm.

The Phrase Finder. The meaning and origin of the expression: Air quotes. Retrieved December, 3, 2013 from http://www.phrases.org.uk/meanings/air-quotes.html.

Streeck, J. (1993). Gesture as communication: Its coordination with gaze and speech. Communication Monographs, 60(4), 275-299. 
Streeck, J., Grothues, J., \& Villanueva, J. (2009). Gesturecraft: The manu-facture of meaning. John Benjamins Publishing Company.

Tracy, K., \& Naughton, J. (1994). The identity work of questioning in intellectual discussion. Communication Monographs, 61, 281-302.

Waring, H.Z., Creider S., Tarpey T., and Black, R. (2012) A search for specificity in understanding CA and context. Discourse Studies, 14(4), 477-92.

Wiemann, J. M. (1981). Effects of laboratory videotaping procedures on selected conversation behaviors. Human Communication Research, 7, 302-311.

Woodzicka, J. A. (2008). Sex differences in self-awareness of smiling during a mock job interview. Journal of Nonverbal Behavior, 32(2), 109-121. 


\section{Appendix A: Initial Contact Letter}

Dear Communication student,

I am a Communication graduate student here at Portland State University looking for participants for my thesis research which focuses on everyday conversation between two people. The study is being conducted in partial fulfillment of the requirements for a master's degree in Communication Studies, and is under the supervision of Dr. David Ritchie, faculty member in the PSU Department of Communication. What would be required is about a total of an hour-and-a-half of your and a friend's time. The time would be split and involve video recording a casual, everyday conversation between the two of you for about 20 minutes, and following that, coming back later for an audio recording of a separate interview with each of you for about 30 minutes each.

Nothing high pressure, as during the "everyday conversation" you can talk about anything you want. And during the subsequent interview, there are no right or wrong responses. Extra credit can be arranged with your Communication course professor for your participation as well.

If this is something you and a friend are interested in doing together, please email your response to me at suemwendel@gmail.com_and provide your name, email address and phone number. I will get back to you to set up a time, and give you more information about the study. Or, feel free to call about dates and times that we could meet, or if you have any questions $-503-313-4552$.

Looking forward to hearing from you.

Sincerely,

Sue Wendel

Graduate Student

Department of Communication 


\section{Appendix B: Confirmation Letter}

Dear

Thank you for your interest and for signing up for my study. To confirm, the designated time for you and your friend is [day , date time , place ]. I will send you an email reminder closer to the date as well. If you need to reach me before then you can email or call me, suemwendel@gmail.com, 503-313-4552.

As mentioned when you signed up, I am a Communication Studies graduate student here at Portland State University and my study will focus on everyday conversation between two people. It is being conducted in partial fulfillment of the requirements for a master's degree in Communication Studies, and is under the supervision of Dr. David Ritchie, faculty member in the PSU Department of Communication.

What will be required is about a total of an hour-and-a-half of your and a friend's time. The time would be split and involve video recording a casual, everyday conversation between the two of you for about 20 minutes, and following that, coming back later for an audio recording of a separate interview with each of you for about 30 minutes each.

Nothing high pressure, as during the "everyday conversation" you can talk about anything you want. And during the subsequent interview, there are no right or wrong responses. Extra credit can be arranged with your Communication course professor for your participation as well.

In the meantime, I've attached the Consent Form for you to look over that explains details about the research and about informed consent. When we meet for the study, I will provide you with hard copy for you to sign and a copy for you to keep.

Thank you again for your interest and participation.

Sue Wendel

Graduate Student

Department of Communication

Portland State University 


\section{Appendix C: Informed Consent Form}

- You have read and understand all of the preceding information.

- You are willing to participate in the study's video recorded conversation with a friend, and the subsequent one-on-one audio recorded interview with the researcher.

- You understand the participation is voluntary and that you can back out at any time.

- You understand and agree that video and/or audio recordings, and digital images of me, may be provided by Portland State University for a fee to other researchers or research groups for research purposes.

Participant Signature

Date

Print name

To the best of my ability, I have explained and discussed the full contents of the study, including all of the information contained in this consent form. All questions of the research participant have been accurately answered.

Researcher Signature

Date

\section{What is Informed Consent?}

Informed consent is a process that lets participants know their rights and provides information that helps participants to decide whether they wish to volunteer for a research study. It helps you as a participant understand what the study is about and what will happen during the course of the study.

After all your questions about the study have been answered, you will be asked to sign the Informed Consent Form. The main researcher, Sue Wendel, will also sign it. You will be given a copy to keep. If you have questions at any time during the research study, you should feel free to ask them and should expect to be given answers that you completely understand.

\section{Why is this study being done?}

You are invited to participate in a research study conducted by graduate student Sue Wendel from Portland State University, Department of Communication. The researcher hopes to learn about interpersonal communication. The study is being conducted in partial fulfillment of the requirements for a master's degree in Communication Studies, and is under the supervision of Dr. David Ritchie, primary investigator and faculty member in the PSU Department of Communication. 


\section{What are the requirements for participation?}

Participants have shown an interest in participating, are an adult (i.e., at least 18 years old), and are a native English speaker.

\section{What will I be asked to do if I take part in this research study?}

If you decide to participate, you will be asked to engage in an everyday conversation with a friend and then a subsequent one-on-one interview with the researcher. The conversation will be video recorded and the interview will be audio recorded in the Communication Research Collaboratory at PSU in the Department of Communication. The conversation can be about anything you want to talk about and will last about 20 minutes. During the subsequent interview, the researcher will play back segments of the video recorded conversation and ask you some questions about them. This will take about 30 minutes.

\section{What are any risks or benefits?}

While participating in this study, it is possible that you may experience mild discomfort at being video or audio recorded, but after a few minutes, research shows that this diminishes quickly, and people become acclimated and comfortable. As a benefit you will a small monetary token of $\$ 10$, and knowing that this study may help to increase the knowledge of what we know about inter/intra communication.

\section{How will information about me be kept private or confidential?}

Any information that is obtained in connection with this study and that can be linked to you or identify you will be kept confidential. This information will be kept confidential by creating code names for each participant during transcription, so that neither your name nor any identifying information will appear in the final research document. Further, the transcript and video recording will be protected by being stored on a password protected computer and an online data storage system.

The Department of Communication plans to license potentially edited versions of the data - including video recordings and transcripts of conversations, which may include explanatory notes made by the researcher - and make it available, for a fee, to other researchers for research purposes. Licensed data will be edited such that, on both video recordings and transcripts, the following personally identifying information will be omitted such as: Participants' full name, national identification number, IP address(es), vehicle registration plate number, driver's license number, credit card number(s), and digital identities and passwords. Portland State University will oversee this licensing process, including legal and safeguarding processes.

\section{What are my rights if I decide to take part in this research study?}

You have the right to ask questions about any part of the study at any time. You should not sign the informed consent form unless you have had a chance to ask questions and have been given answers to all of your questions.

\section{What will happen if I do not wish to take part in the study after all, or if I later decide not to stay in the study?}

If you do choose to take part in the study, it is voluntary. You may choose not to take part in the study, or pull out of the study at any time during the study. After your participation is complete, you may contact the main researcher and request to review your data. After review, you may elect to have your data erased. If you do not participate, pull out of the study during the study, or subsequently review your data and decide to have it erased, your relationship with the 
study researcher will not change, and you may do so without penalty and without loss of benefits to which you are otherwise entitled.

\section{Who can you call if you have any questions?}

If you have any questions or concerns about your participation in this study you can contact researcher Sue Wendel at suemwendel@gmail.com or 503-313-4552; or Dr. David Ritchie, primary investigator and faculty in the Department of Communication at 503-725-5384, or cgrd@pdx.edu. If you have concerns about your rights as a research subject, you can contact Research and Strategic Partnerships, Market Center Building $6^{\text {th }}$ floor, Portland State University, (503) $725-4288$. 
Appendix D: Phase 1 Video Representational Gesture Identification Form Speaker:

Date:

\begin{tabular}{|l|l|l|}
\hline $\begin{array}{l}\text { Time of } \\
\text { observed } \\
\text { gesture/type }\end{array}$ & Associated word/phrase & $\begin{array}{l}\text { Researcher's initial analysis of } \\
\text { gesture type and mental imagery }\end{array}$ \\
\hline 1. & & \\
\hline 2. & & \\
\hline 3. & & \\
\hline 4. & & \\
\hline 5. & & \\
\hline 6. & & \\
\hline 7. & & \\
\hline 8. & & \\
\hline 9. & & \\
\hline 10. & & \\
\hline
\end{tabular}




\section{Appendix E: Micro Analysis Form}

Speaker Gesture

Time stamp:

1. Word or phrase, and description: Example: "If teachers would only cooperate."

[BH, palms in, thumbs up, fingers interlaced.]

2. __ Iconic or __ Metaphoric

2a. If iconic, what concrete feature(s) are depicted?

$2 \mathrm{~b}$. If iconic, are they visual, motor, or a simulation?

2a. If iconic, is the gesture direct or additive?

2.c If metaphoric, what is the iconic concrete association?

Visual, motor, or a simulation?

3. Hand form

3a. L, R, or BH

3b. Palm \& finger orientation

3c. Shape

3d. Gesture space (location of gesture in space)

4. Hand motion

4a. Shape of trajectory

4b. Place in space

4c. Direction 


\section{Appendix F: Phase 2 Guiding Interview Questions}

1. Tell me about the various shapes and movements of your hands and fingers.

2. What do you think they depict?

3. Tell me about the mental imagery.

4. Talk about awareness of producing the gesture. 